\title{
Metal-Free Difluoromethylselenolation of Arylamines Under Visible-light Photocatalysis
}

Kui Lu, ${ }^{\dagger}, *$ Quan Li, ${ }^{\dagger}$ Xiaolan Xi, ${ }^{\dagger}$ Ting Zhou ${ }^{\dagger}$ and Xia Zhao ${ }^{\ddagger}, *$

$\dagger$ China International Science and Technology Cooperation Base of Food Nutrition/Safety and Medicinal Chemistry, College of Biotechnology, Tianjin University of Science \& Technology, Tianjin, China, 300457

* College of Chemistry, Tianjin Key Laboratory of Structure and Performance for Functional Molecules, Key laboratory of Inorganic-organic Hybrid Functional Material Chemistry, Ministry of Education, Tianjin Normal University, Tianjin, China, 300387

lukui@,tust.edu,cn

hxxyzhx@mail.tjnu.edu.cn

Contents

Page

1) Mechanistic study for reagent 1 under white LED (5 W)

S2-S2

2) Mechanistic study for ${ }^{19}$ F NMR monitoring

S3-S5

3) Mechanistic study for trapping experiments

S6-S7

4) NMR spectra

S8-S49 


\section{1) Mechanistic study for reagent 1 under white LED (5 W)}

$$
\mathrm{TsSeCF}_{2} \mathrm{H} \underset{\text { DMSO }}{\stackrel{\text { White LED }(5 \mathrm{~W})}{\longrightarrow}} \quad \mathrm{HF}_{2} \mathrm{CSe}-\mathrm{SeCF}_{2} \mathrm{H}
$$

To a sealed tube was added 1 (0.375 mmol 1.5 equiv.) and dry DMSO (1.0 mL). The mixture was irradiated with white light LED $(5 \mathrm{~W})$ at room temperature and monitored by ${ }^{19} \mathrm{~F}$ NMR spectroscopies with $\operatorname{PhCF}_{3}(\delta=-63.2 \mathrm{ppm})$ as the internal standard and GC-MS.
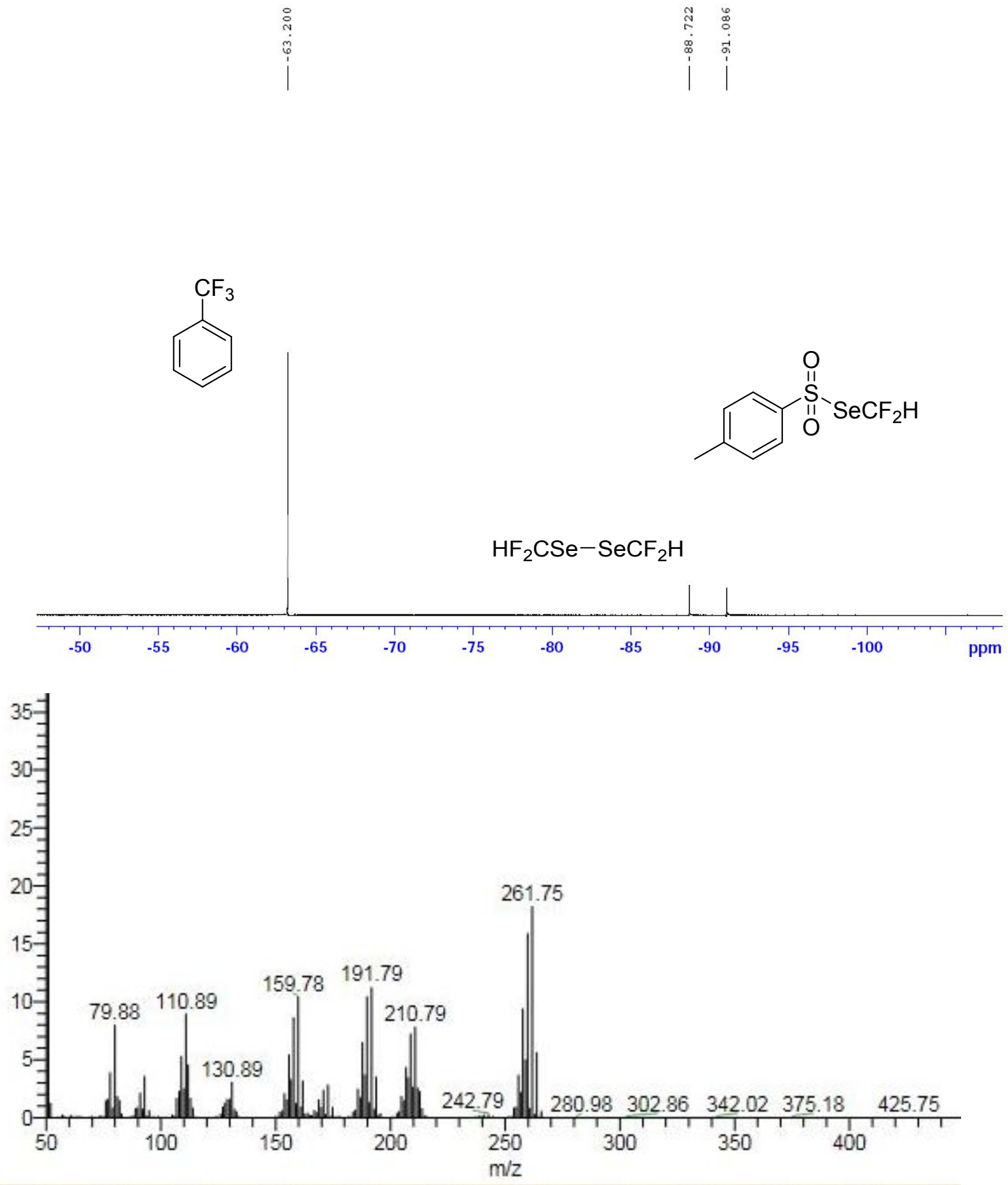


\section{2) Mechanistic study for ${ }^{19}$ F NMR monitoring}

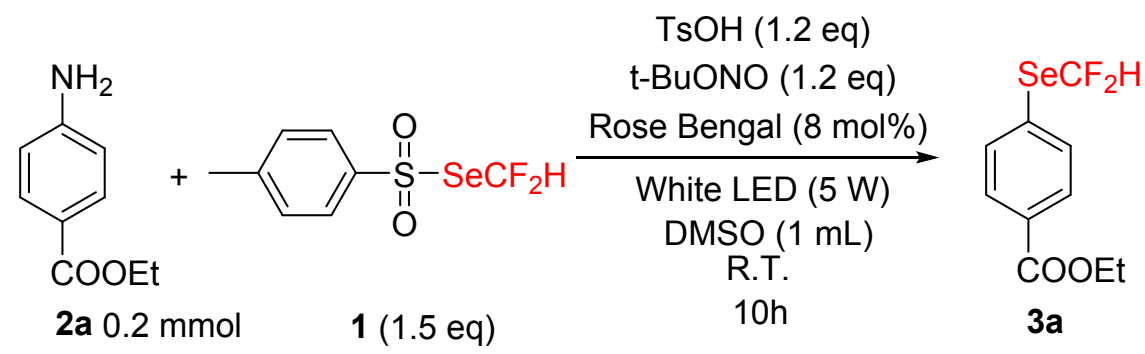

To a sealed tube was added $\mathbf{2 a}(0.25 \mathrm{mmol}, 1.0$ equiv.), $p$-TsOH (0.30 mmol, 1.2 equiv.) and Rose Bengale (0.02 mmol, 0.08 equiv.) and dry DMSO (1.0 mL). The reaction mixture was stirred for 5 minutes, then $t$-BuONO $(0.30 \mathrm{mmol}, 1.2$ equiv. $)$ and $1(0.375$ mmol 1.5 equiv.) was added in turn, and the mixture was irradiated with white light LED $(5 \mathrm{~W})$ at room temperature and monitored by ${ }^{19} \mathrm{~F}$ NMR spectroscopies with $\mathrm{PhCF}_{3}(\delta=-63.2 \mathrm{ppm})$ as the internal standard.

\section{$15 \mathrm{~min}$}
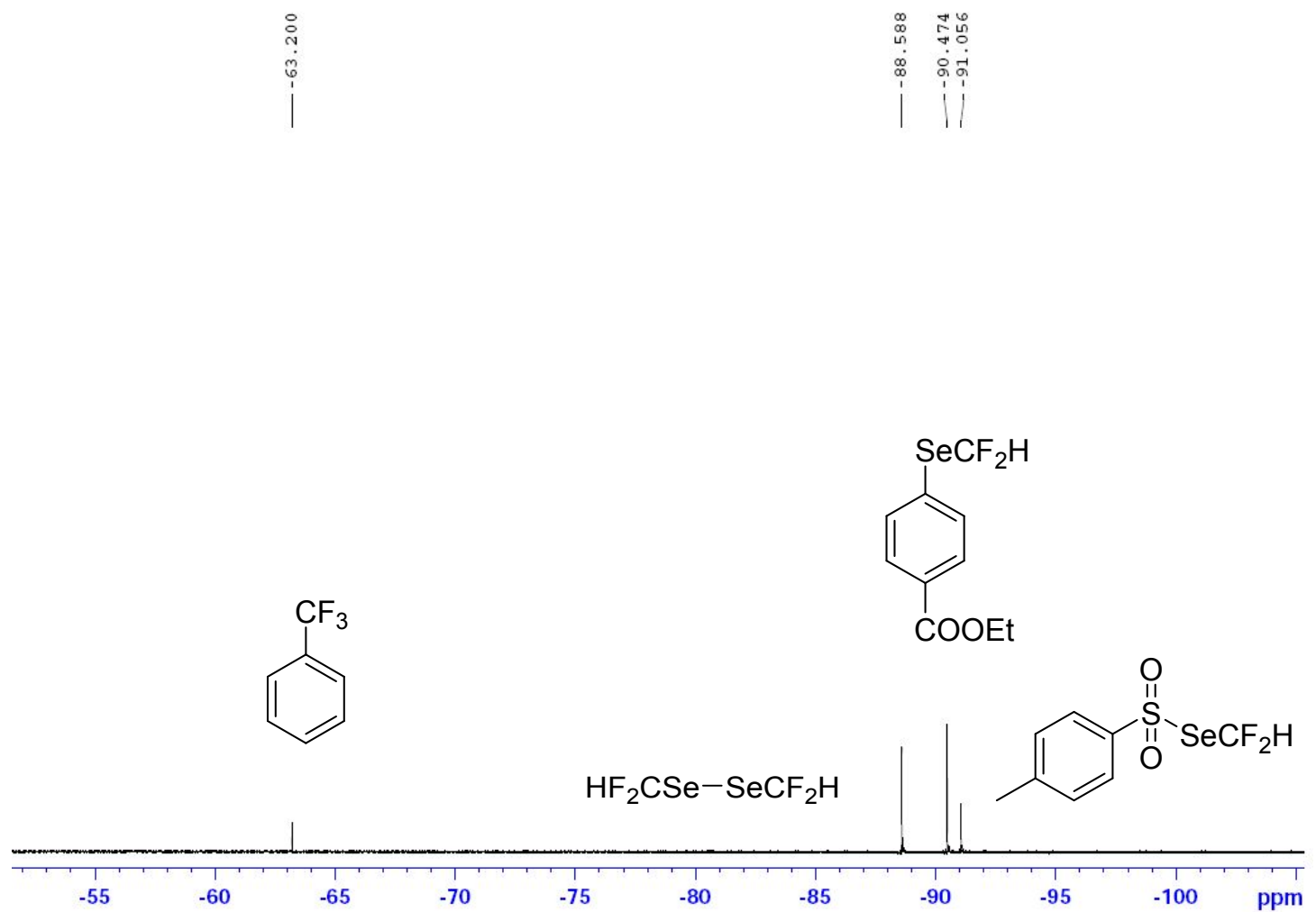

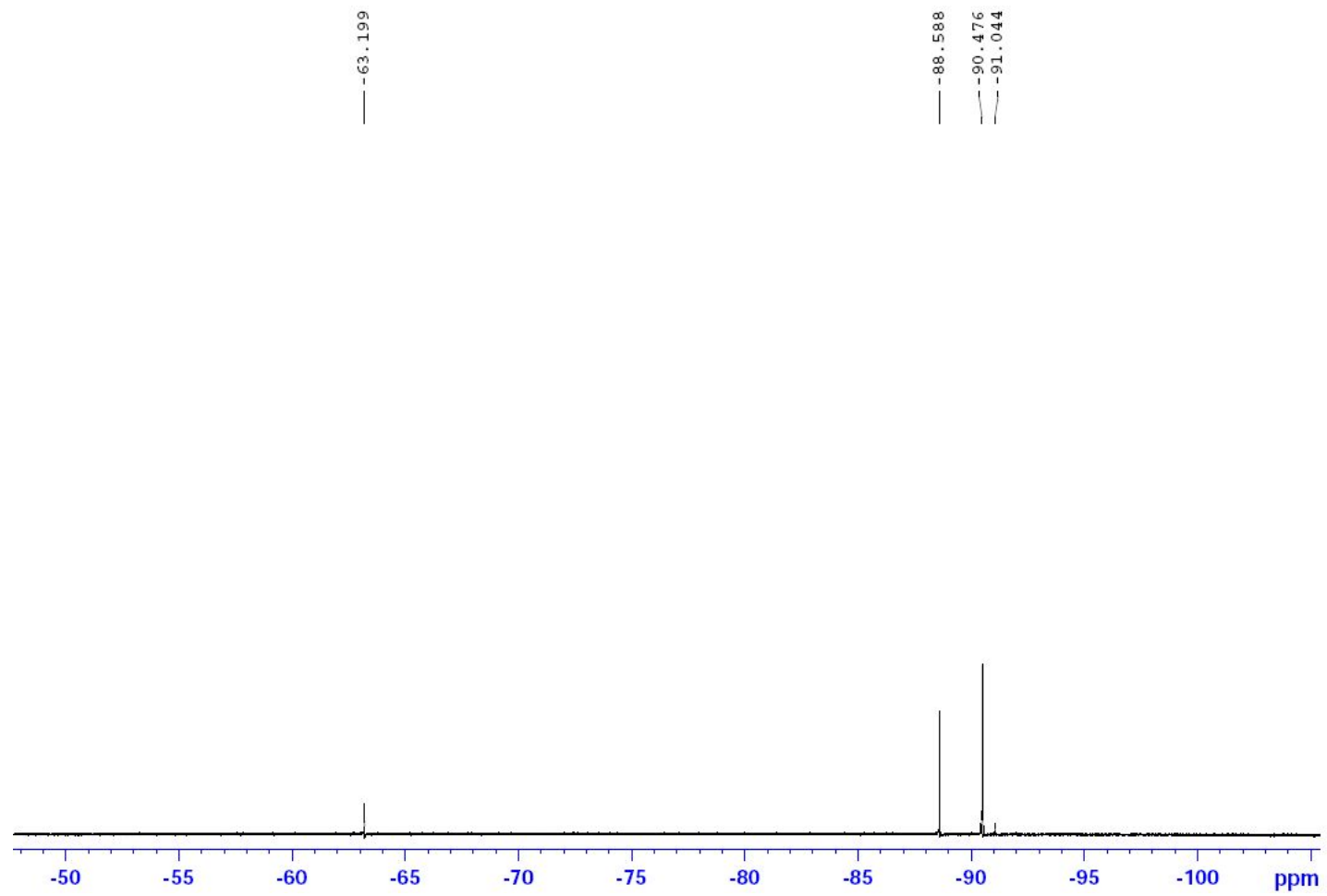

$1 h$
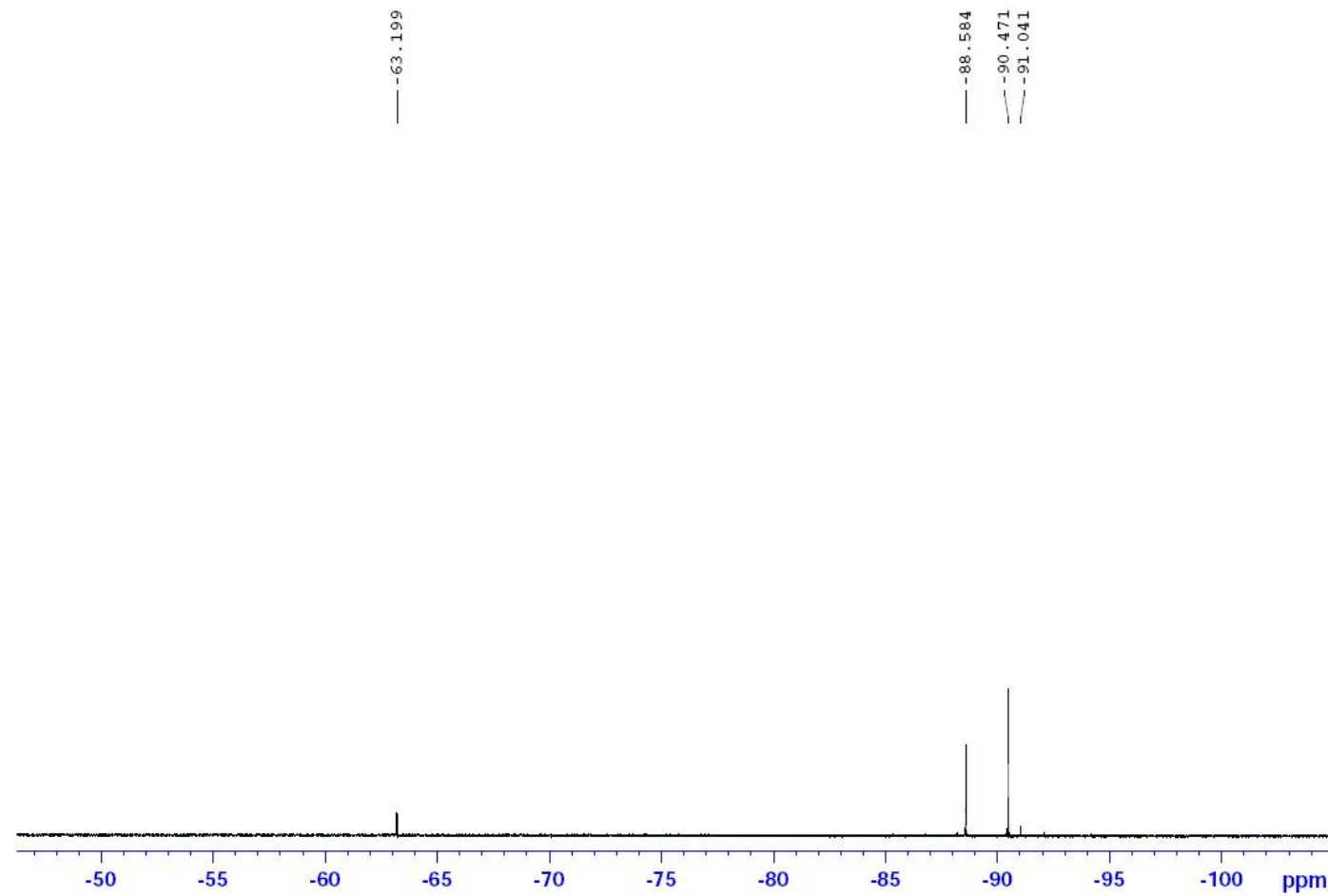

$2 h$ 
|⿱亠䒑十⿻

$\mid$

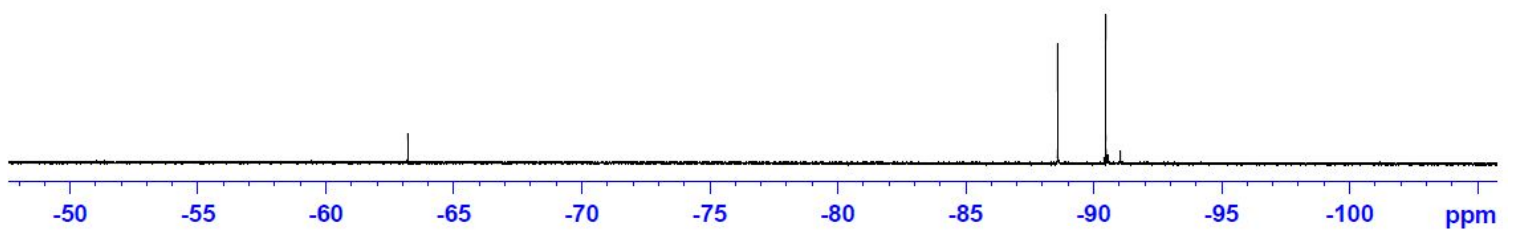

4h
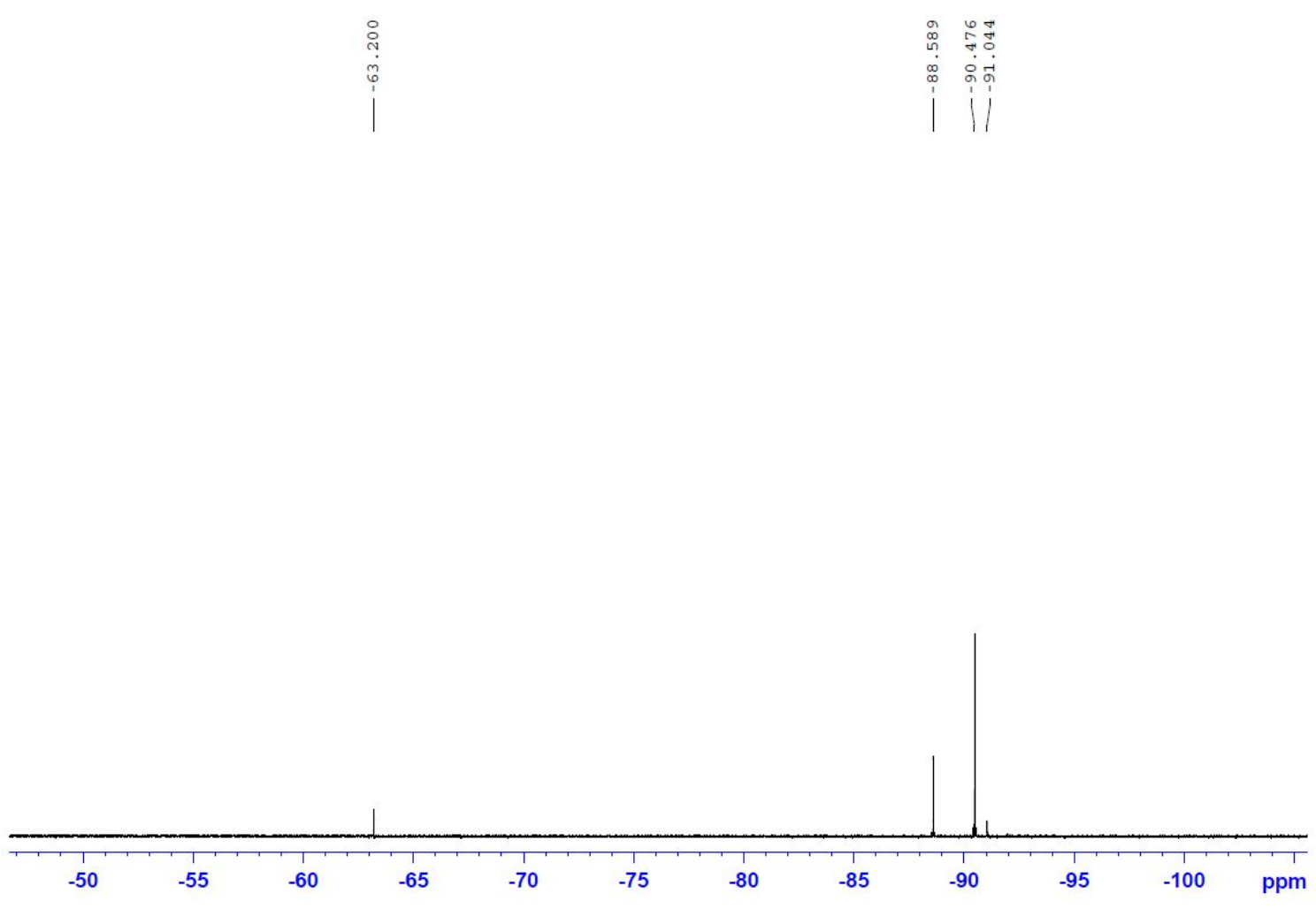

S5 


\section{3) Mechanistic study for trapping experiments}<smiles>CCOC(=O)c1ccc(N)cc1</smiles>

$2 a$

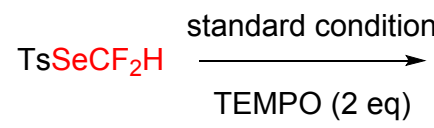

1<smiles>CCOC(=O)c1ccc(S(=O)(F)(F)F)cc1</smiles>

3a $10 \%$<smiles>CCOC(=O)c1ccc(ON2C(C)(C)CCCC2(C)C)cc1</smiles>

detected by HRMS (ESI)

4a

To a sealed tube was added $2 \mathbf{2 a}(0.25 \mathrm{mmol}, 1.0$ equiv. $), p$-TsOH $(0.30 \mathrm{mmol}, 1.2$ equiv.) and Rose Bengale (0.02 mmol, 0.08 equiv.) and dry DMSO (1.0 mL). The reaction mixture was stirred for 5 minutes, then $t$-BuONO ( $0.30 \mathrm{mmol}, 1.2$ equiv. $), 1$ (0.375 mmol 1.5 equiv.) and TEMPO ( 0.5 mmol, 2.0 equiv.) was added in turn, and the mixture was irradiated with white light LED $(5 \mathrm{~W})$ at room temperature and post-processing was carried out according to general procedures to give $\mathbf{3 a}$ (10 \%), In addition, 4a can be detected by HRMS-ESI. HRMS-ESI (m/z) calcd. for $\mathrm{C}_{18} \mathrm{H}_{27} \mathrm{O}_{3} \mathrm{~N}$ $[\mathrm{M}+\mathrm{Na}]^{+}, 328.1883$; found, 328.1861.

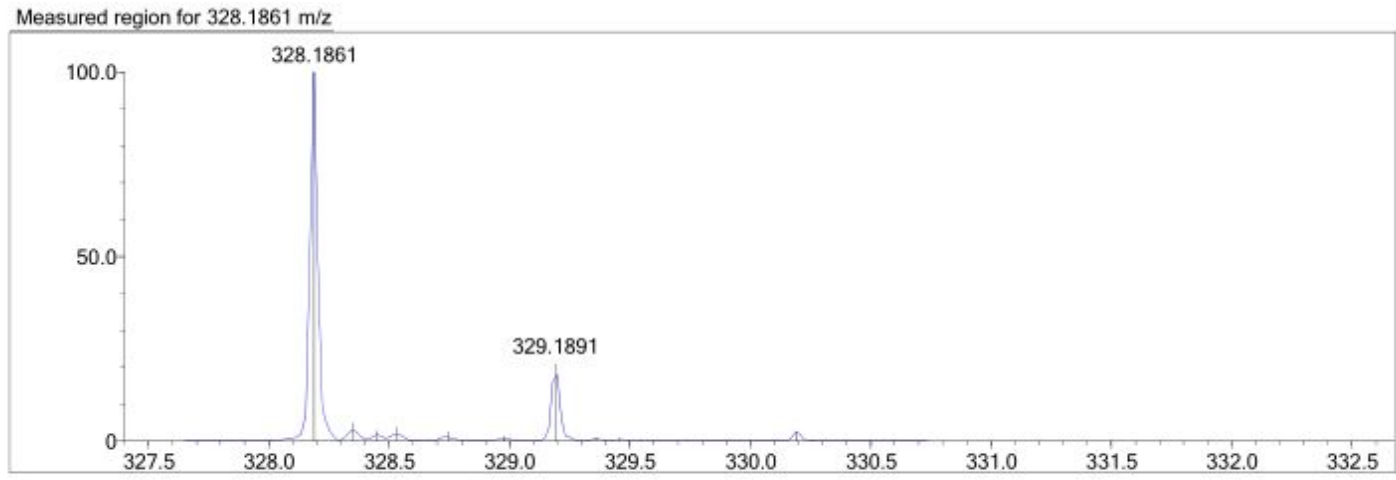

C18 H27 N O3 [M+Na]+ : Predicted region for $328.1883 \mathrm{~m} / \mathrm{z}$

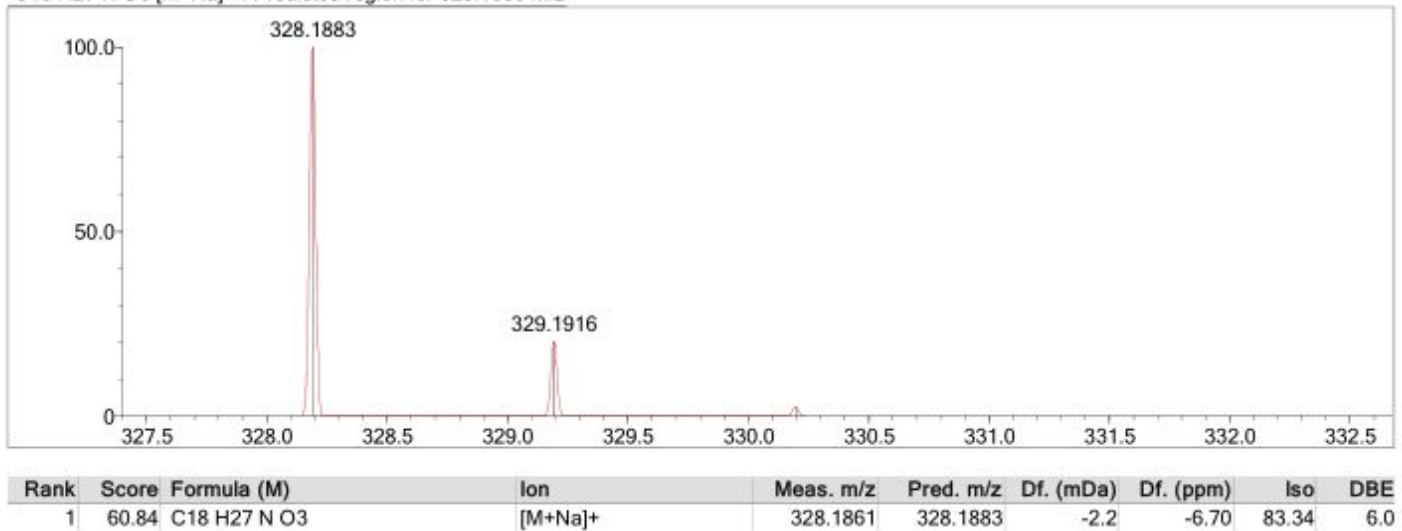


<smiles>CCOC(=O)c1ccc(N)cc1</smiles>

2a

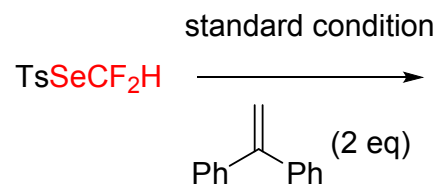

1<smiles>CCOC(=O)c1ccc(OCC)cc1</smiles>

$3 a 42 \%$<smiles>CCOC(=O)c1ccc(C=C(c2ccccc2)c2ccccc2)cc1</smiles>

detected by HRMS (ESI)

$5 a$

To a sealed tube was added $\mathbf{2 a}(0.25 \mathrm{mmol}, 1.0$ equiv. $), p$-TsOH $(0.30 \mathrm{mmol}, 1.2$ equiv.) and Rose Bengale (0.02 mmol, 0.08 equiv.) and dry DMSO (1.0 mL). The reaction mixture was stirred for 5 minutes, then $t$-BuONO ( $0.30 \mathrm{mmol}, 1.2$ equiv. $), 1$ (0.375 mmol 1.5 equiv.) and 1,1-diphenylethylene ( $0.5 \mathrm{mmol}, 2.0$ equiv.) was added in turn, and the mixture was irradiated with white light LED $(5 \mathrm{~W})$ at room temperature and post-processing was carried out according to general procedures to give 3a (42\%), In addition, 5a can be detected by HRMS-ESI. HRMS-ESI (m/z) calcd. for $\mathrm{C}_{23} \mathrm{H}_{20} \mathrm{O}_{2}[\mathrm{M}+\mathrm{Na}]^{+}, 351.1356$; found, 351.1339 .

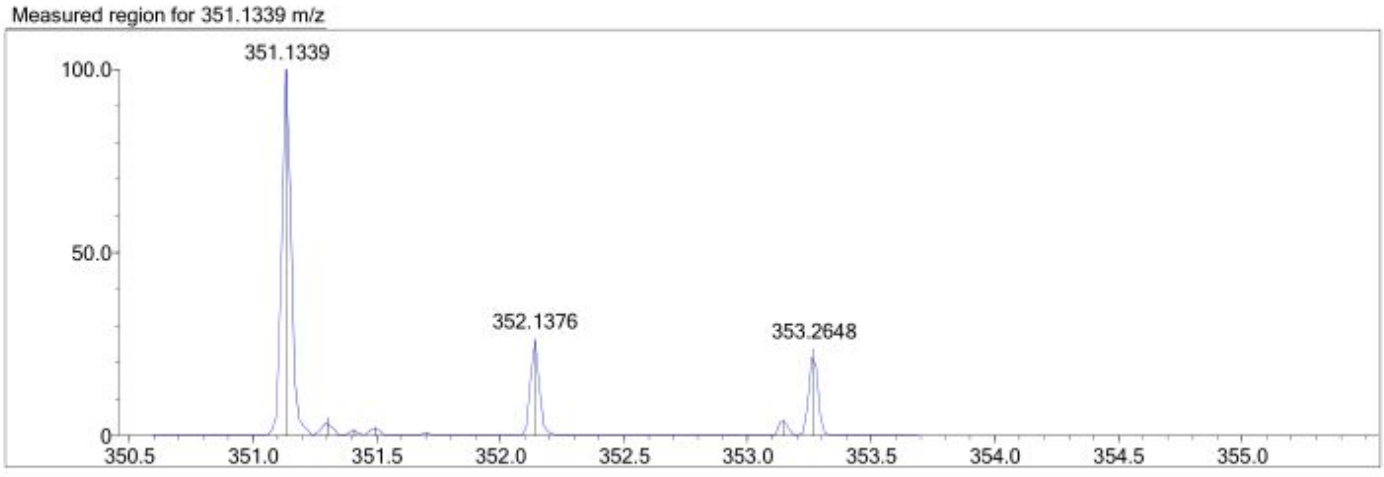

$\mathrm{C} 23 \mathrm{H} 20 \mathrm{O} 2$ [M+Na]+ : Predicted region for $351.1356 \mathrm{~m} / \mathrm{z}$

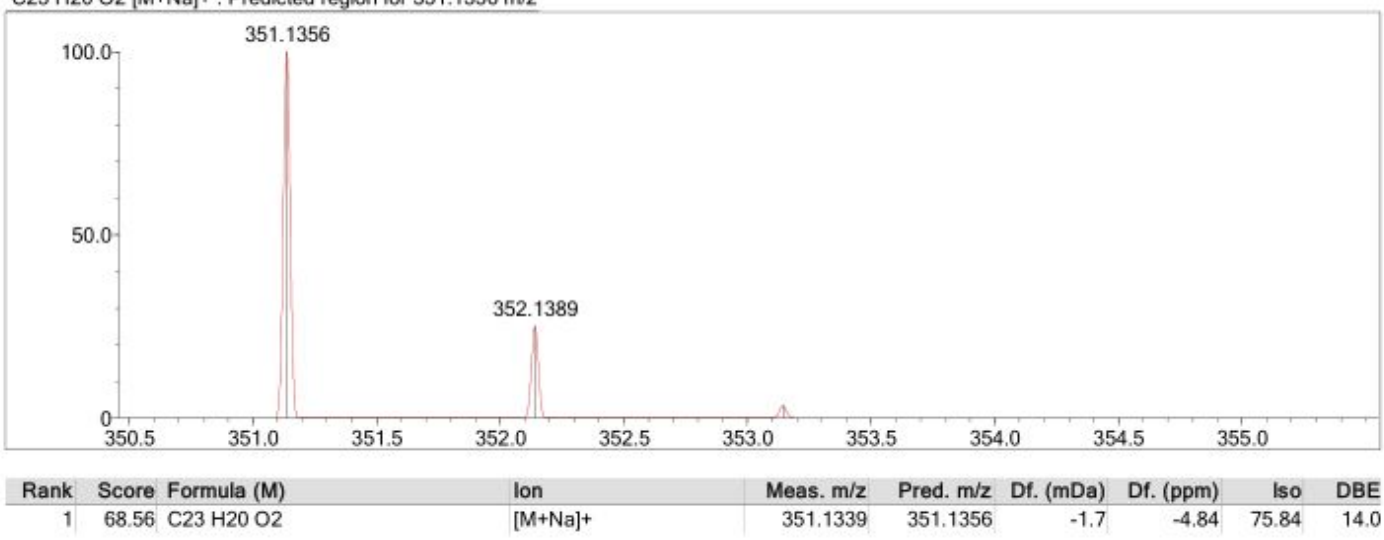


4) NMR and HRMS spectra

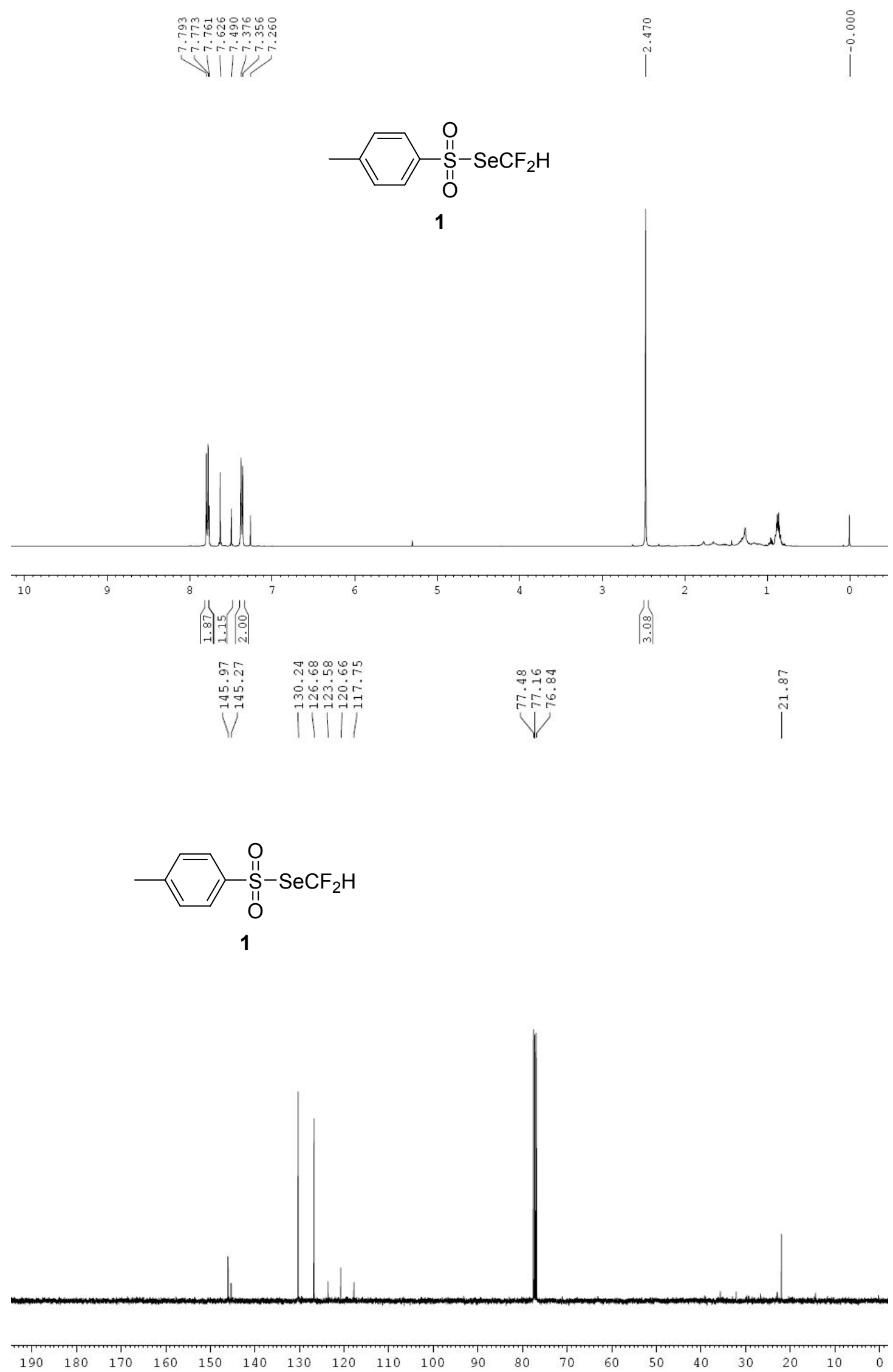



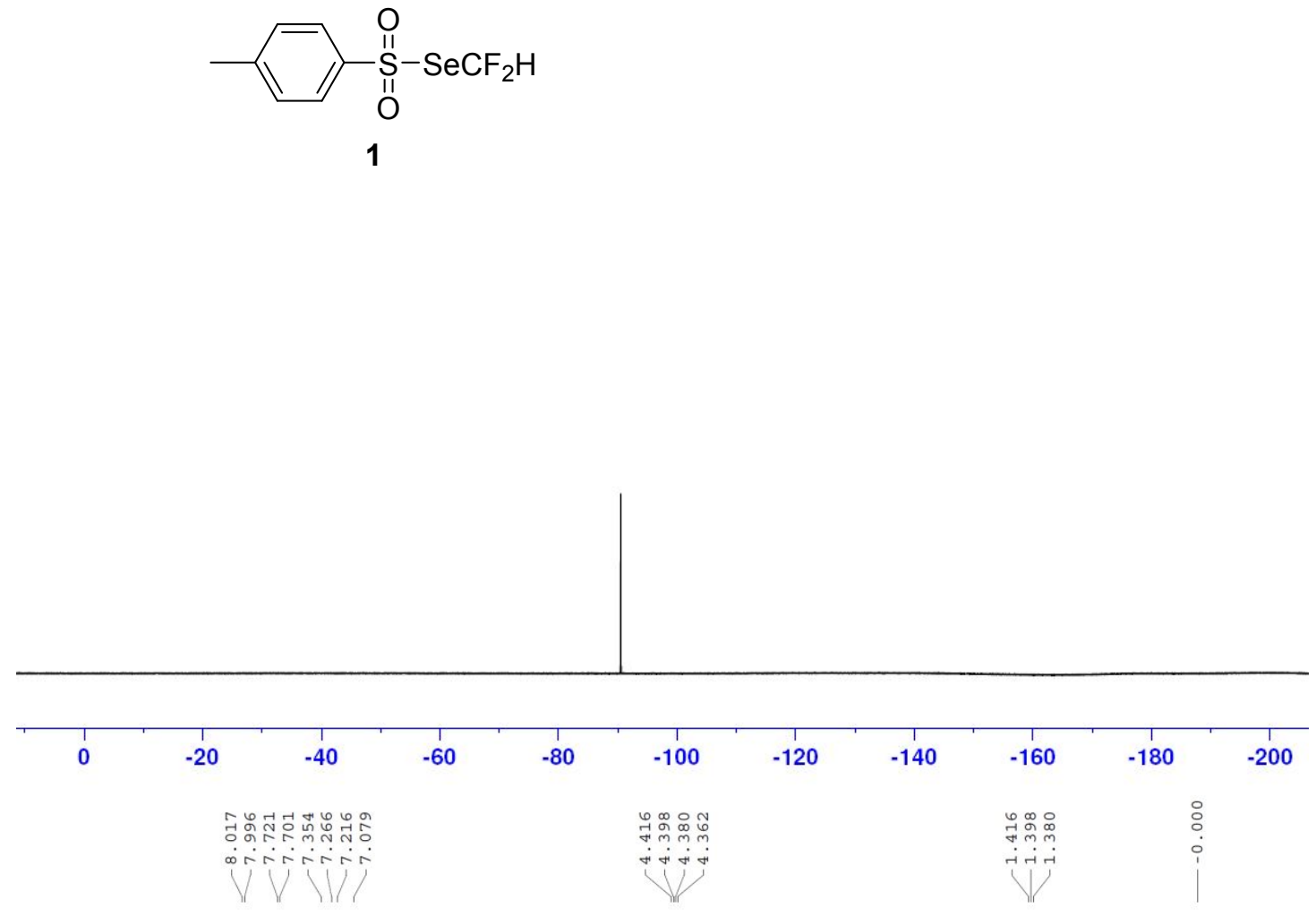

$\mathrm{SeCF}_{2} \mathrm{H}$

$3 a$

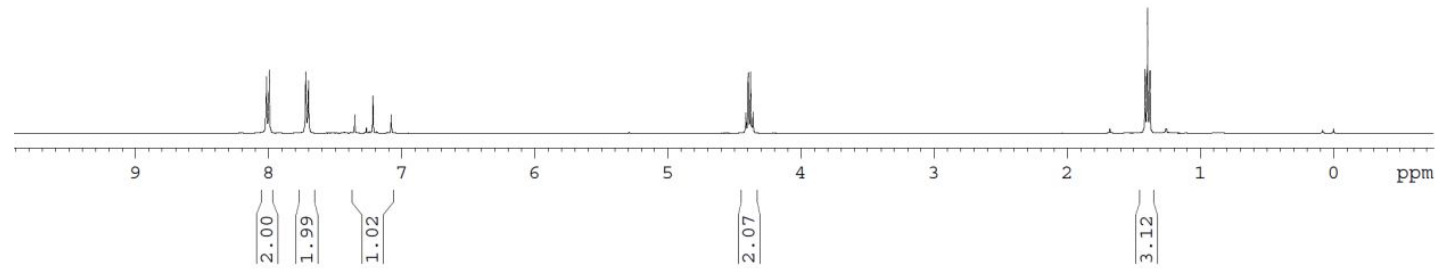




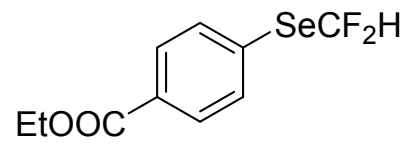

$3 a$
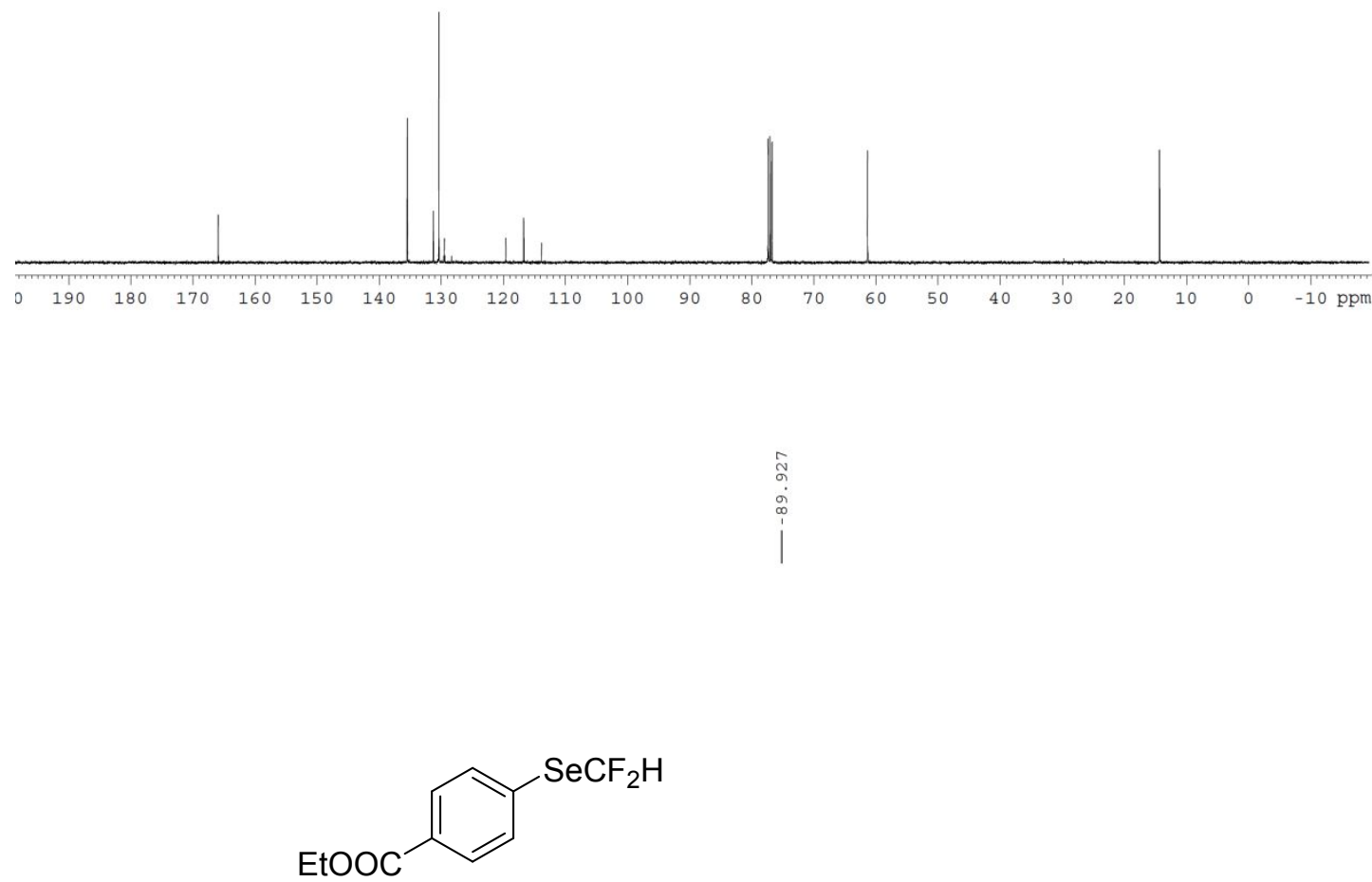

$3 a$

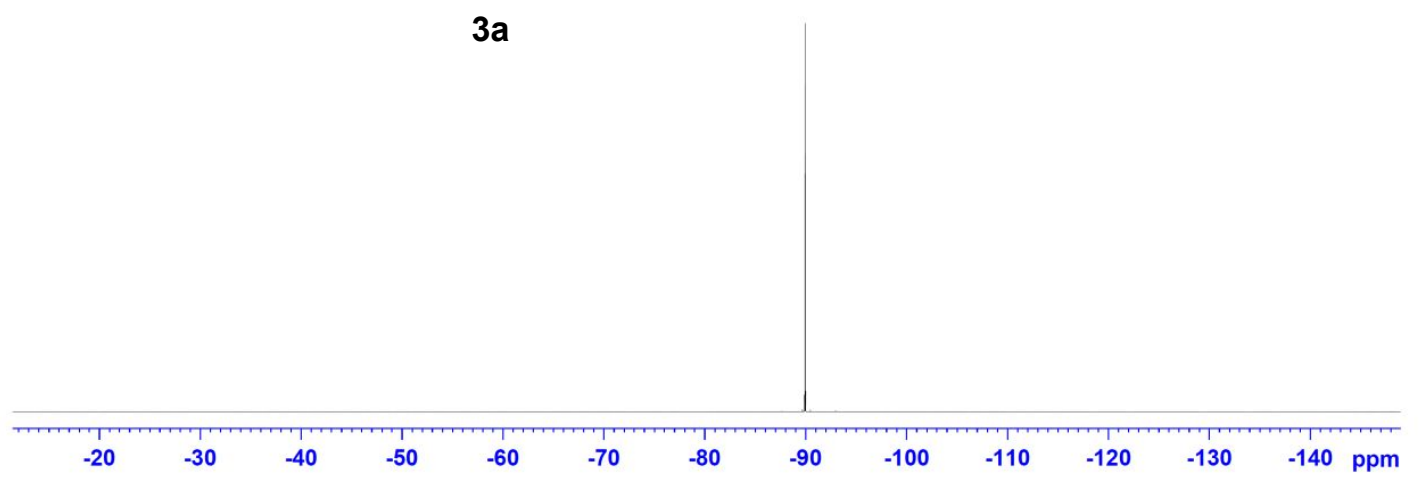




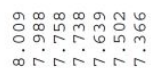

递

$\mathrm{SeCF}_{2} \mathrm{H}$

3b
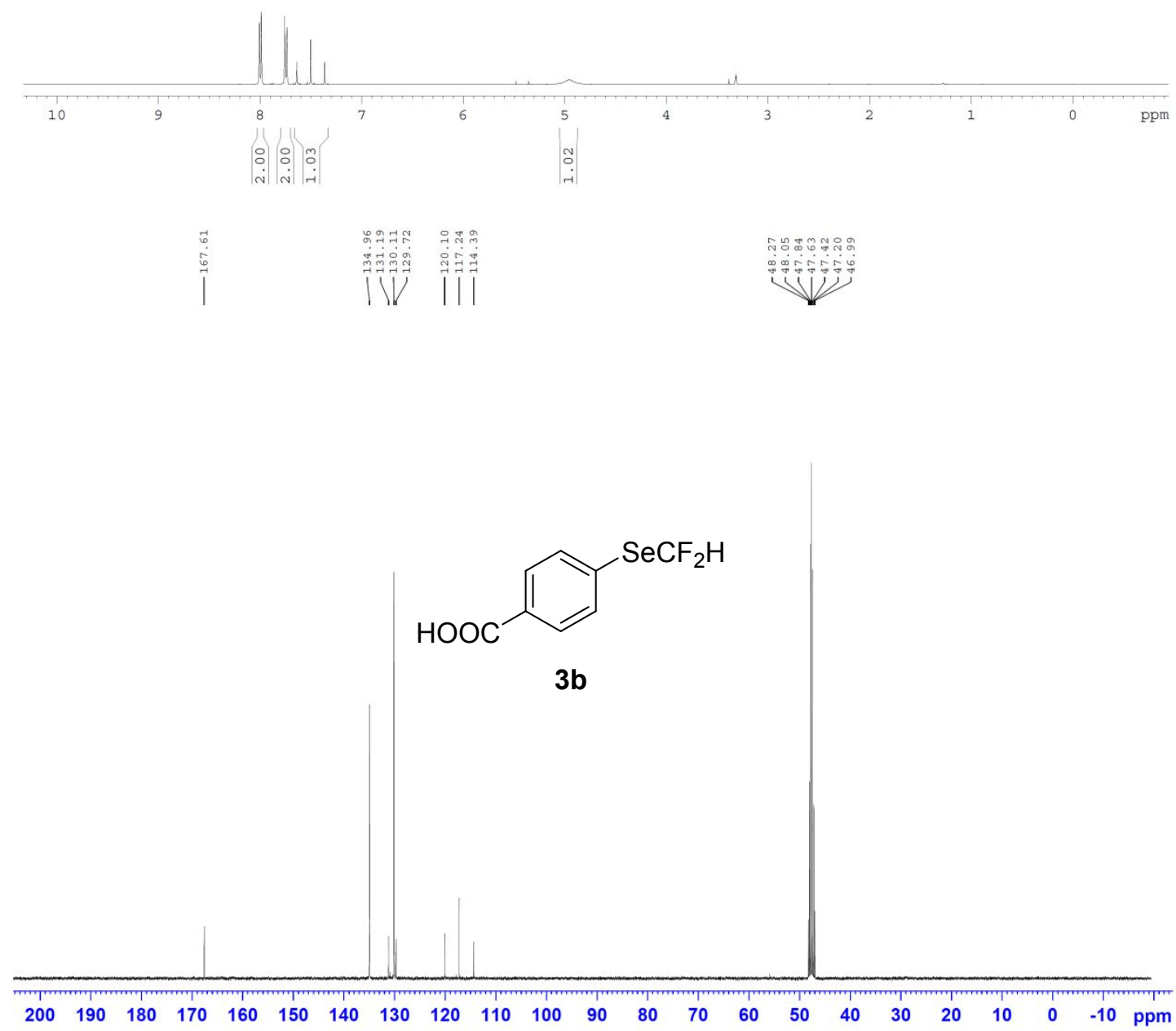


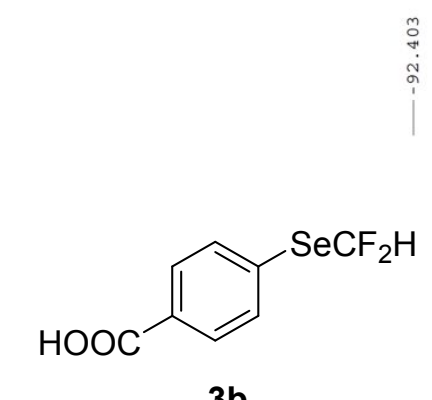

$3 b$

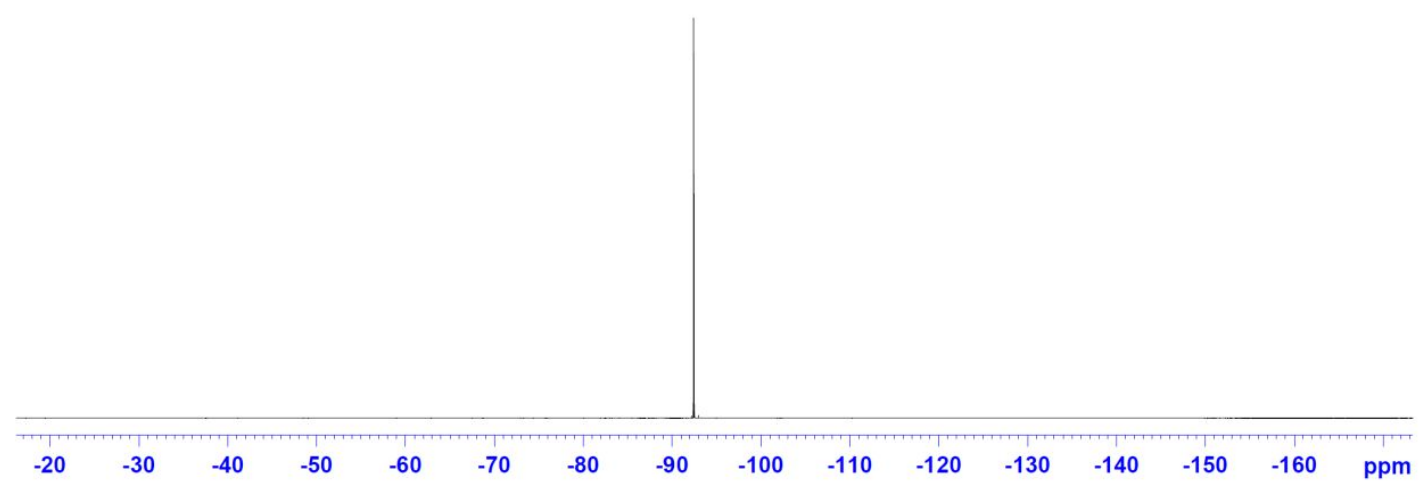

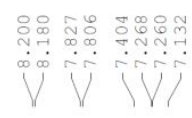

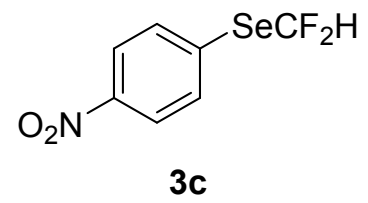

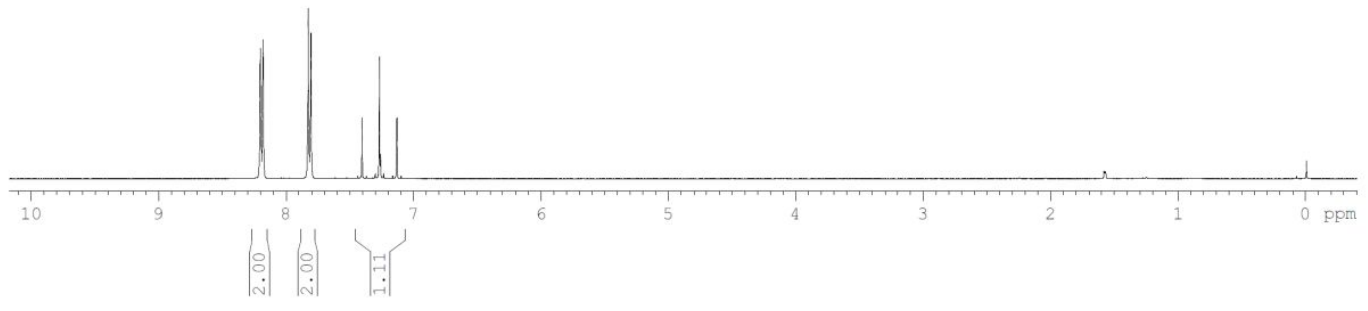




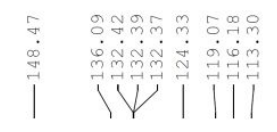

V|
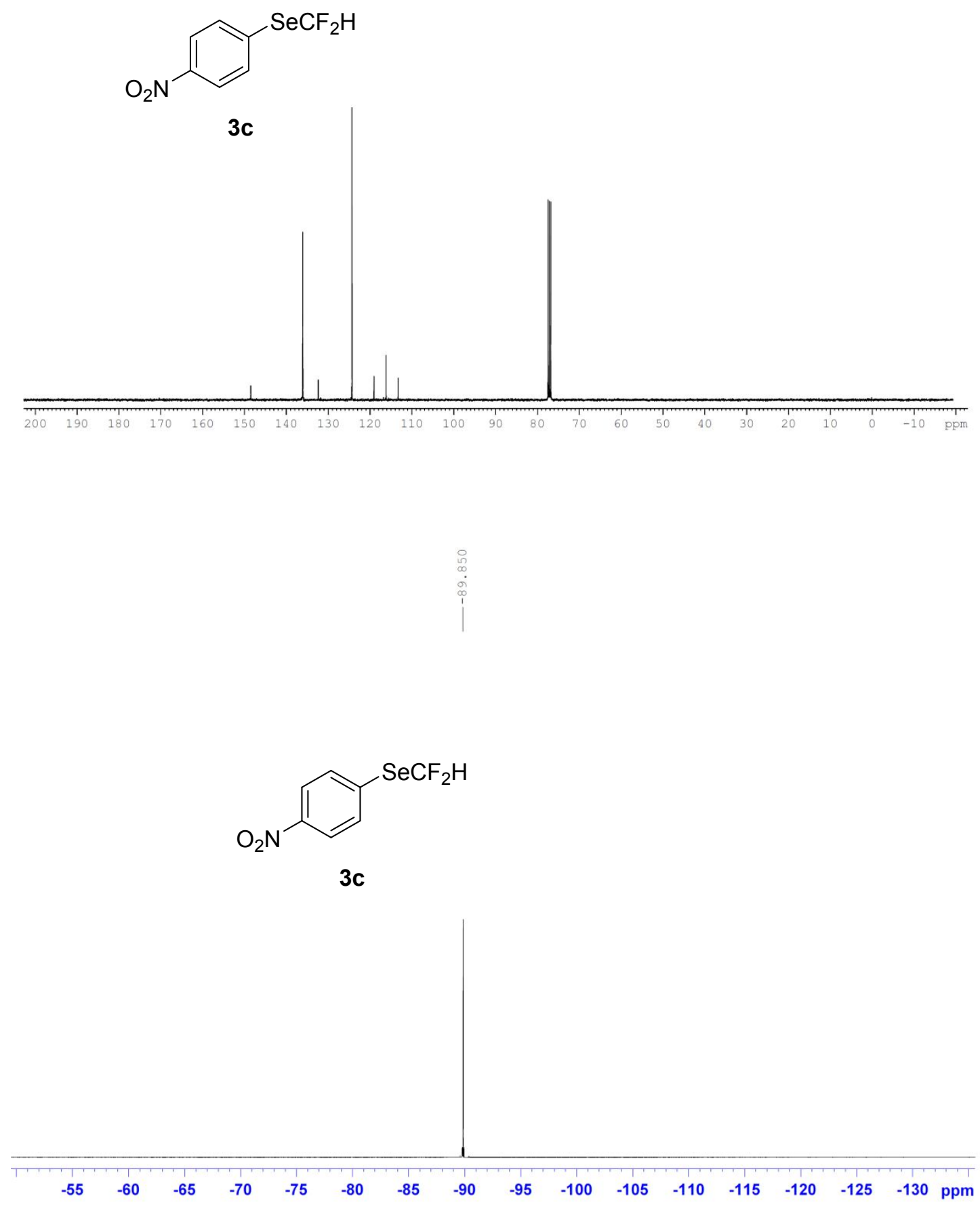


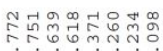

WIII

$\mathrm{SeCF}_{2} \mathrm{H}$

$3 d$

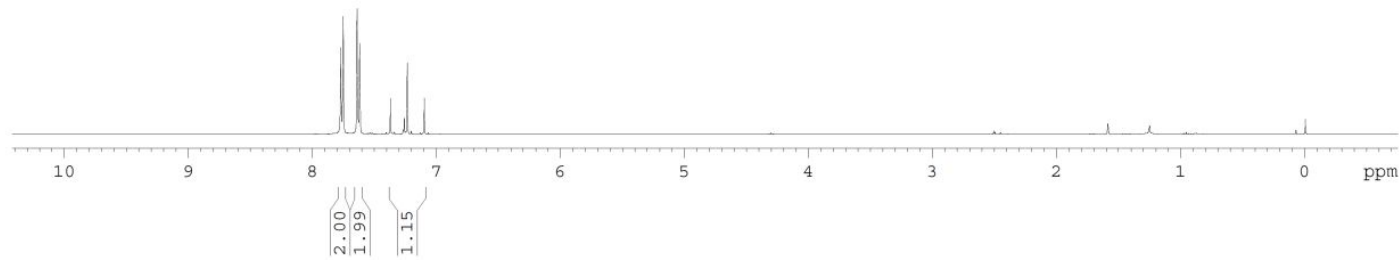

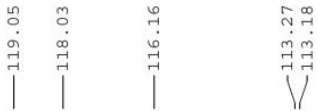
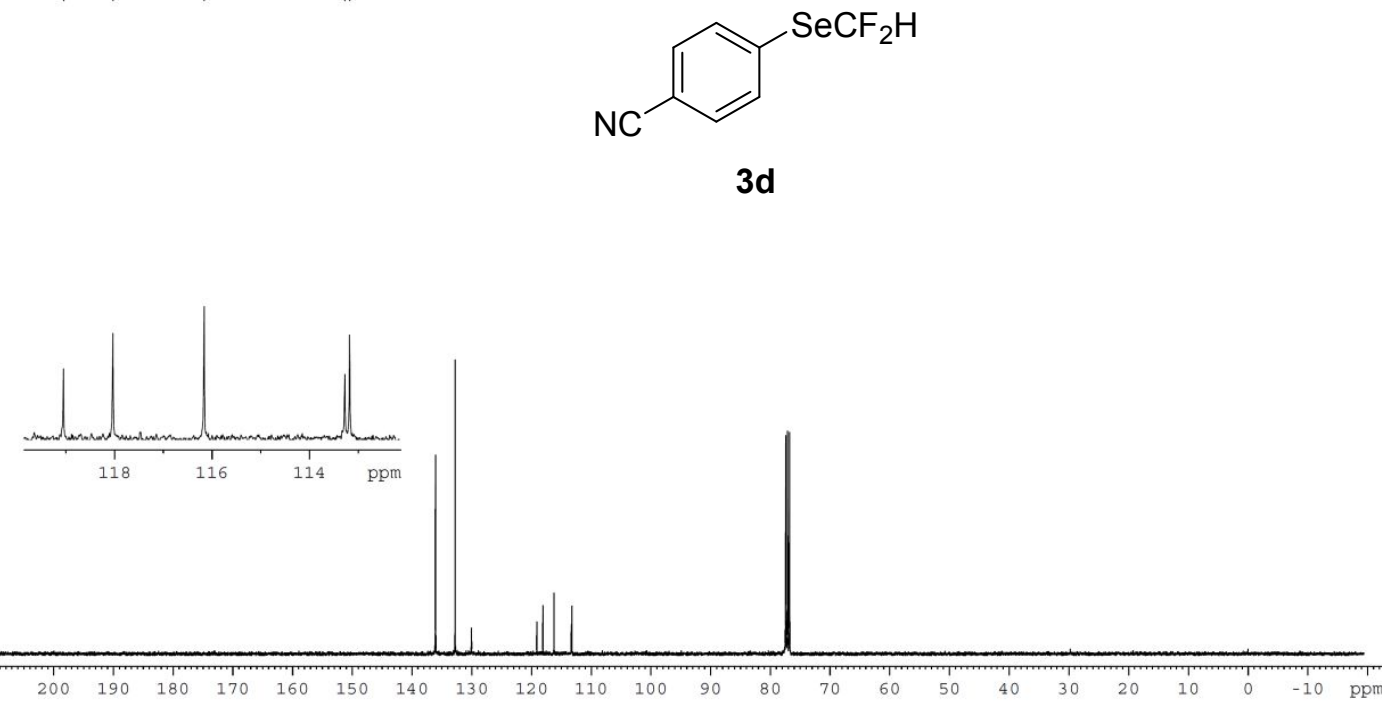

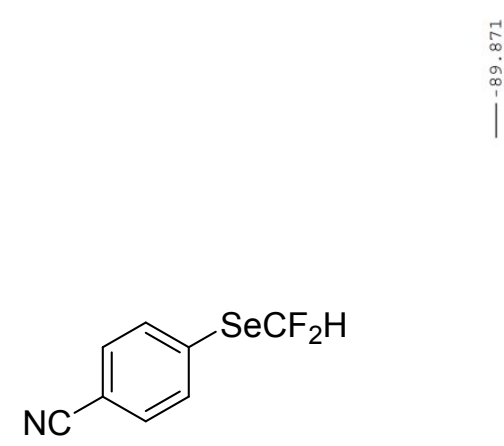

3d

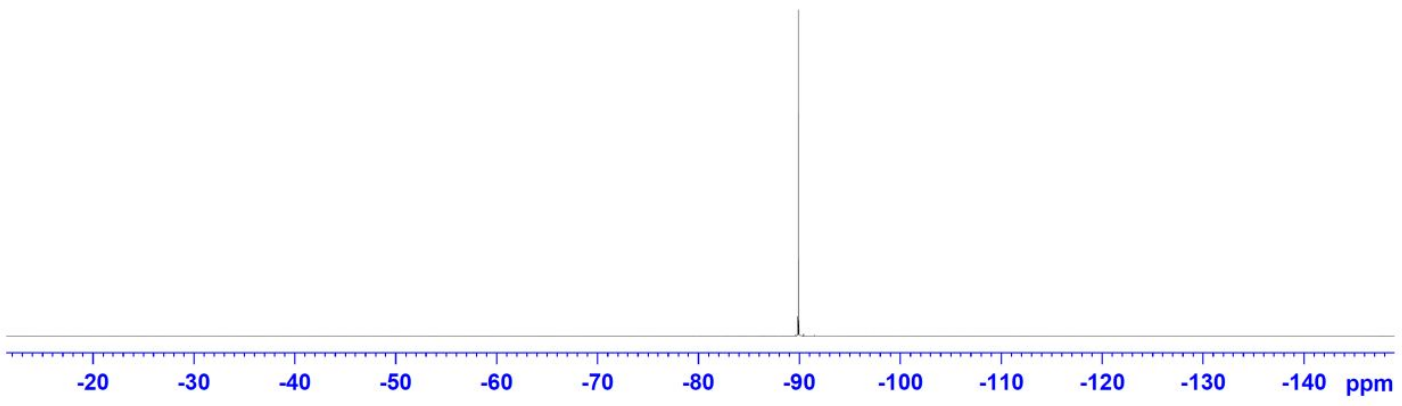

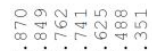

risiri

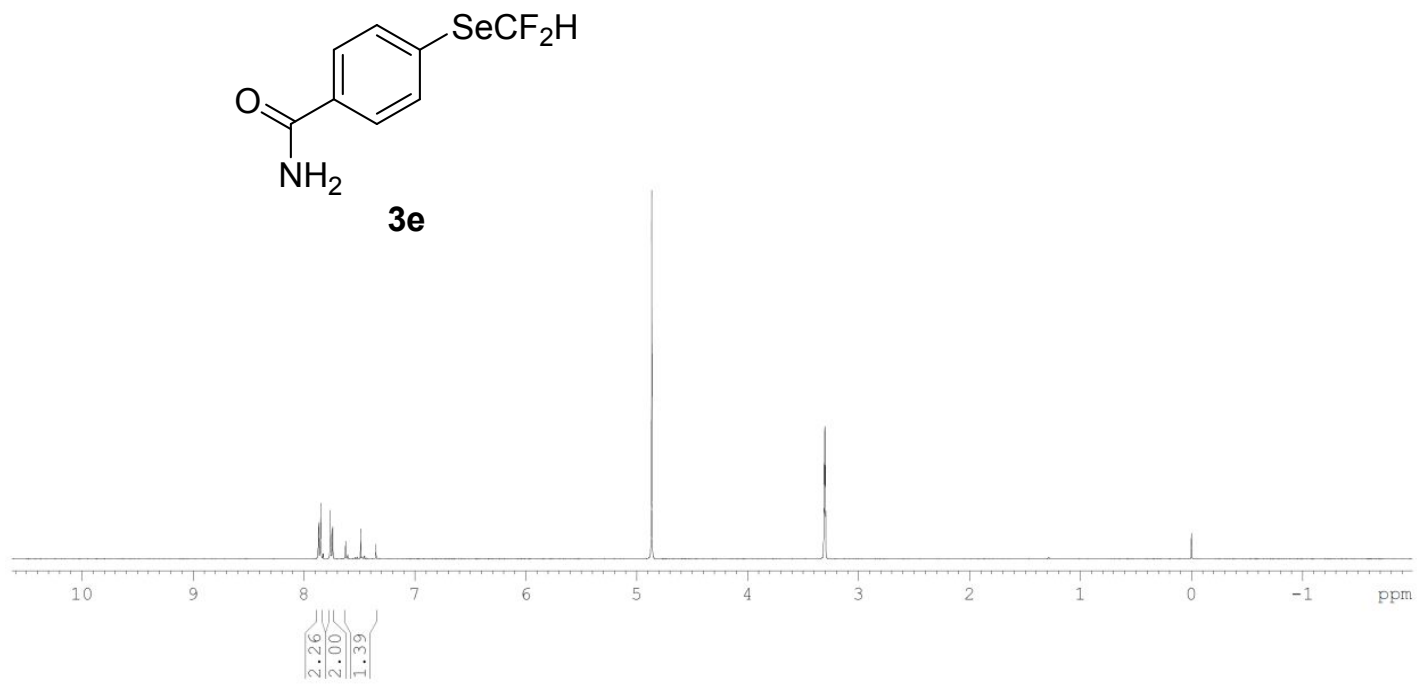



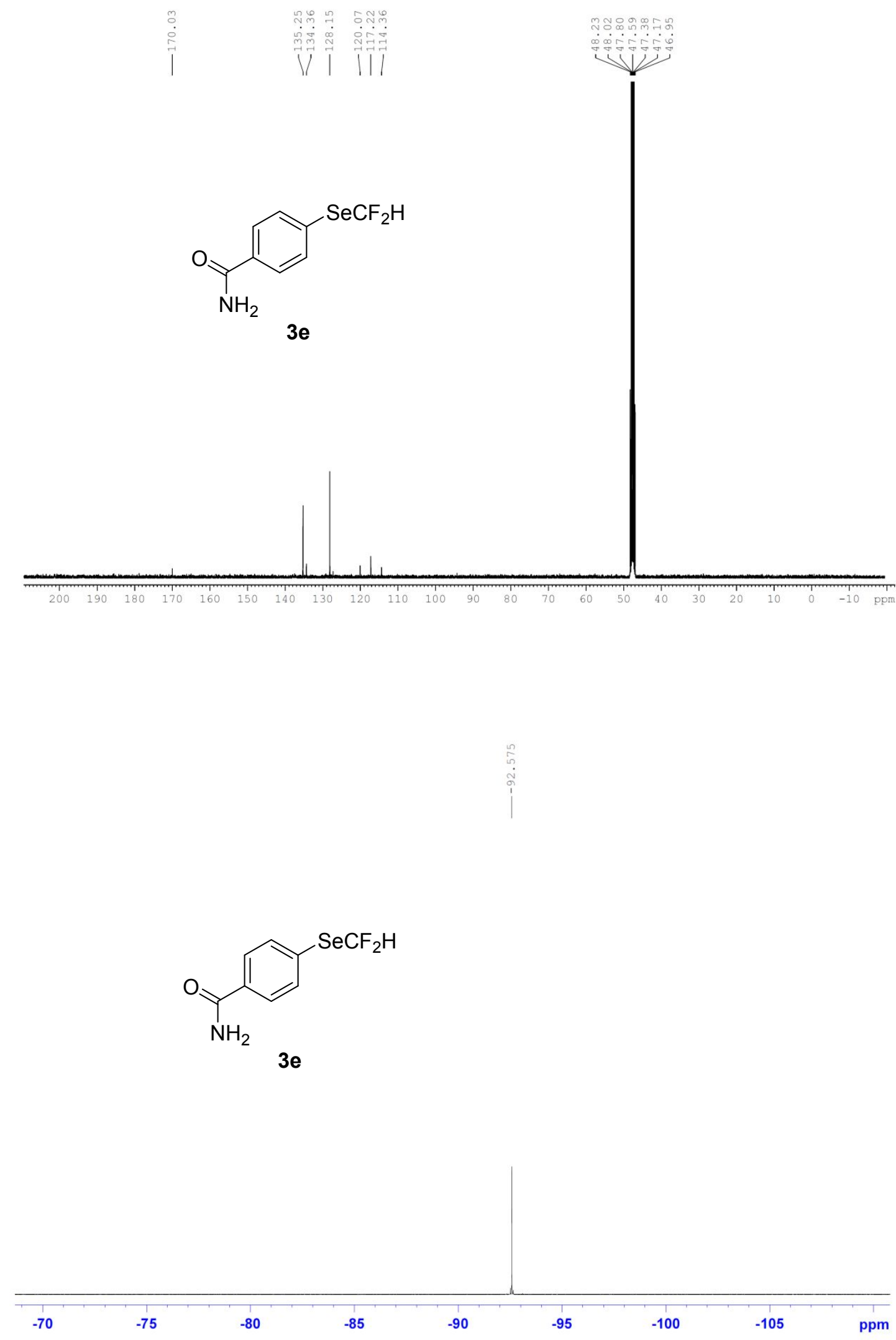


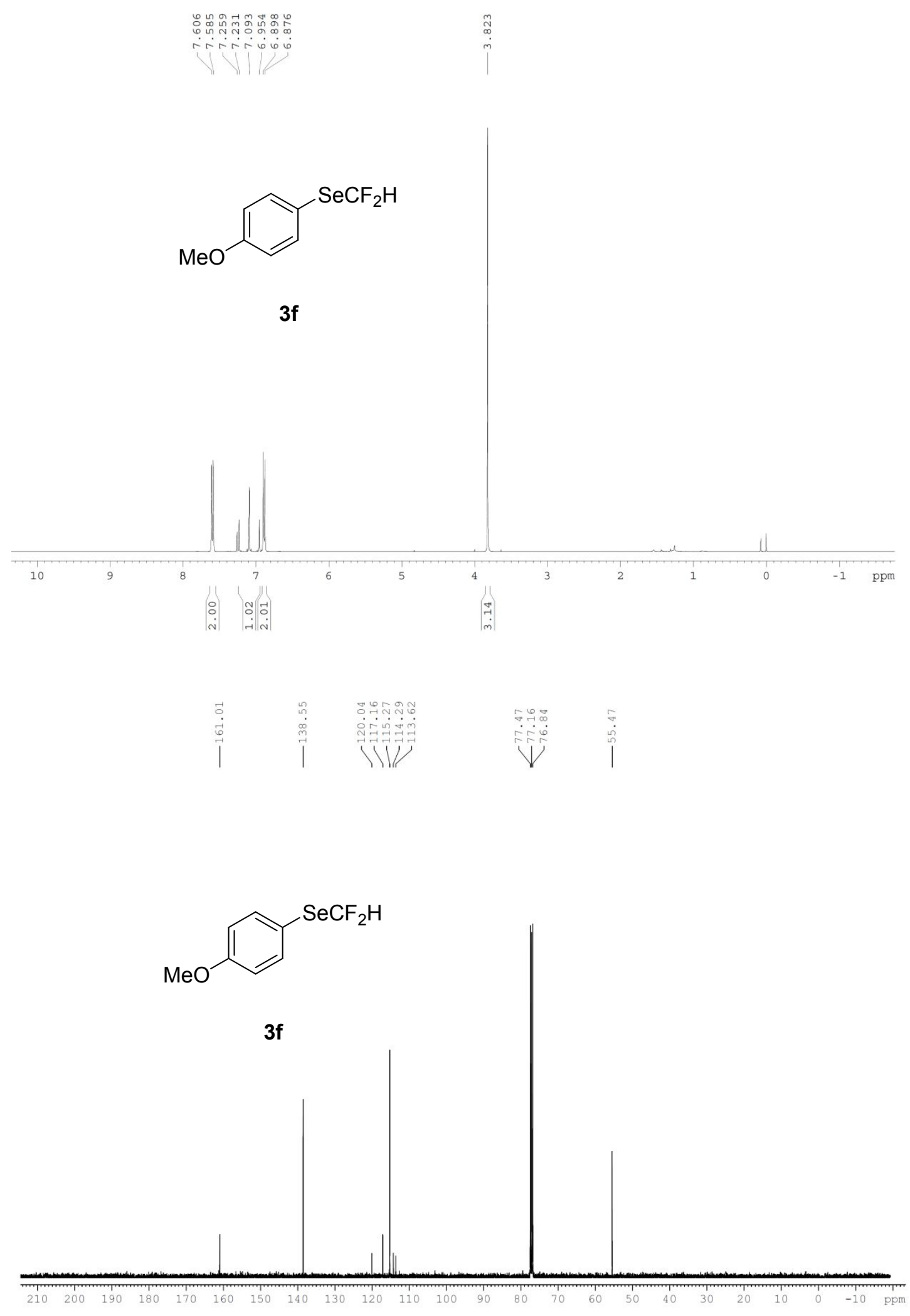




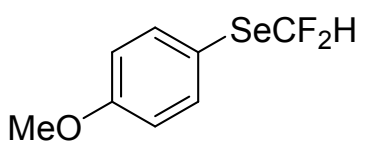

$3 f$

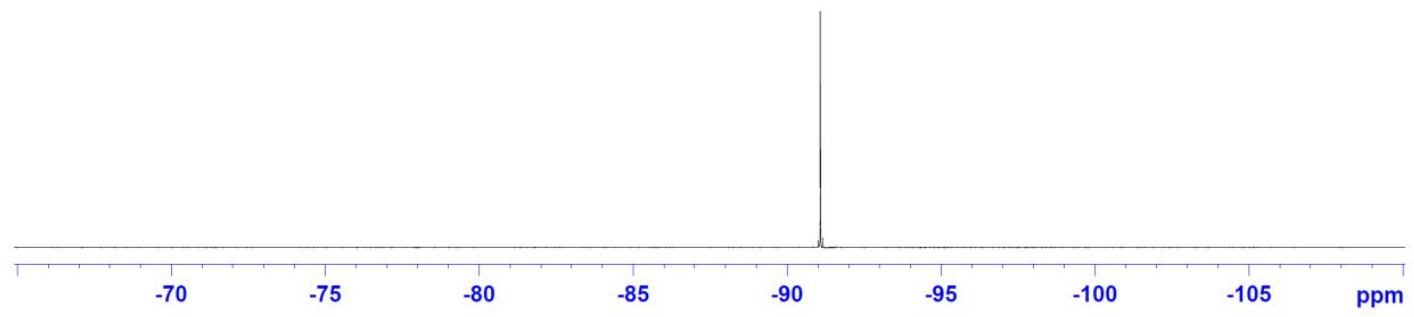

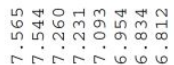

v Vill

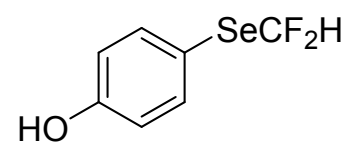

$3 g$

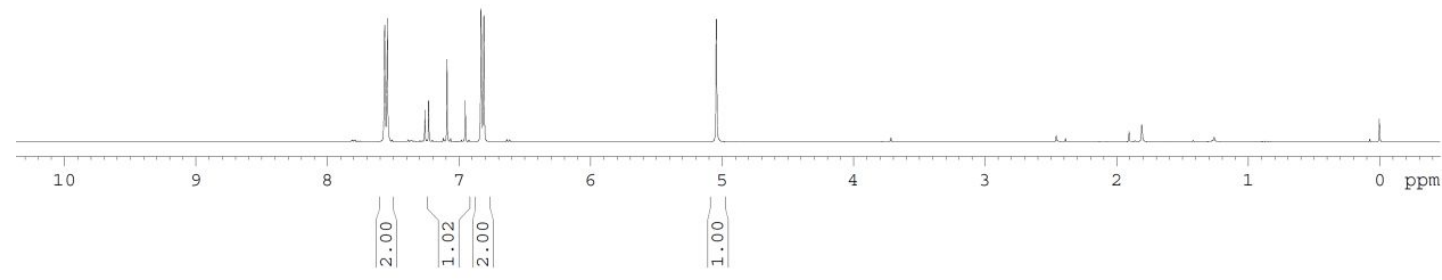




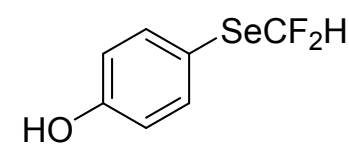

$3 g$

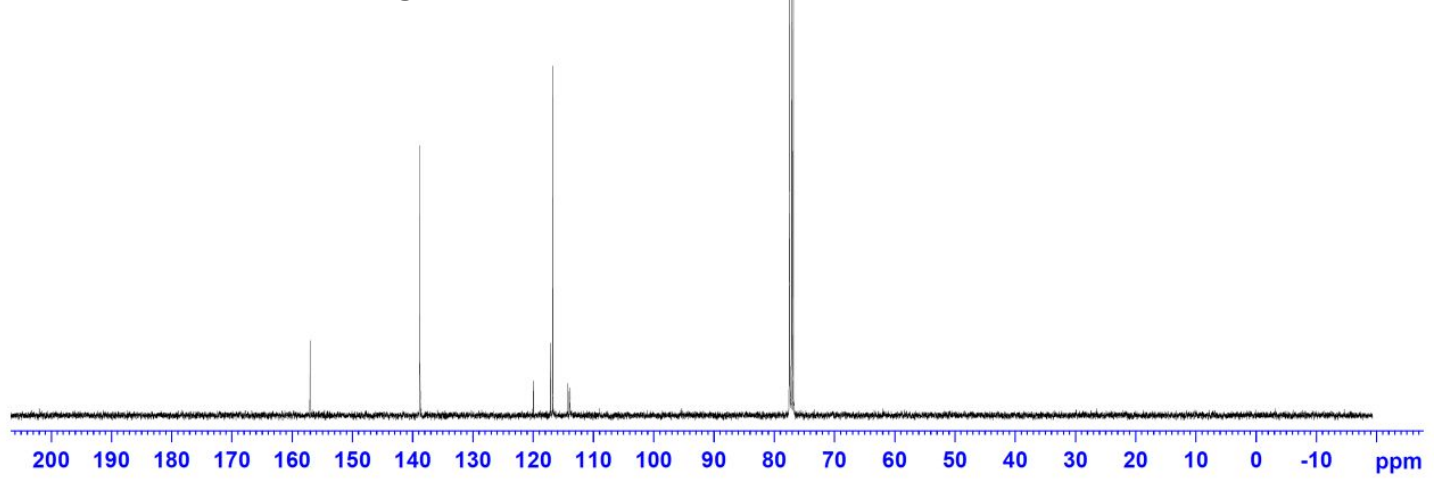

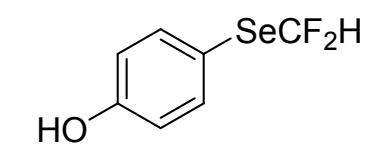

$3 g$

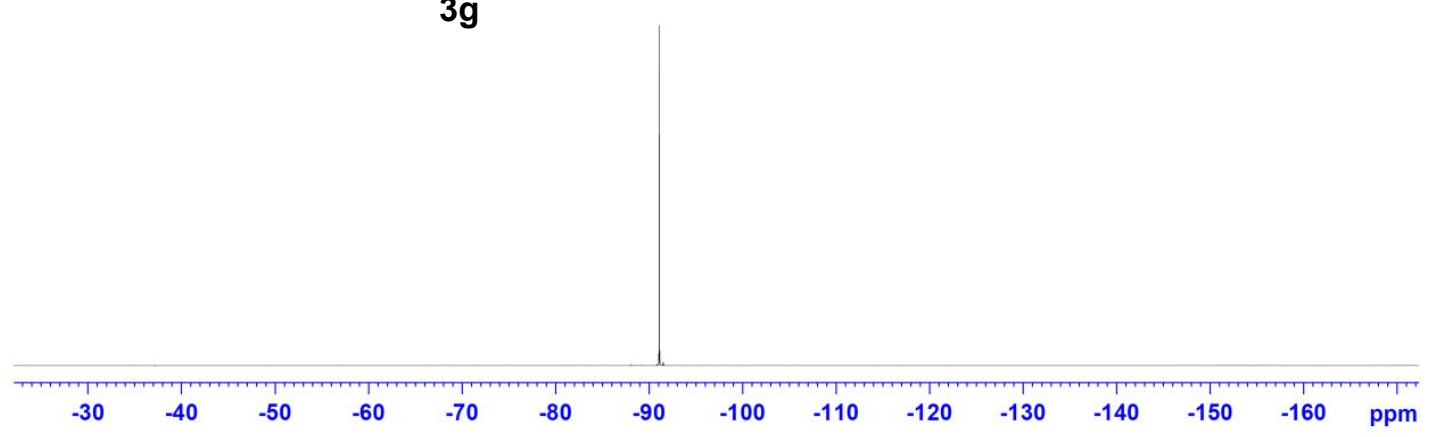




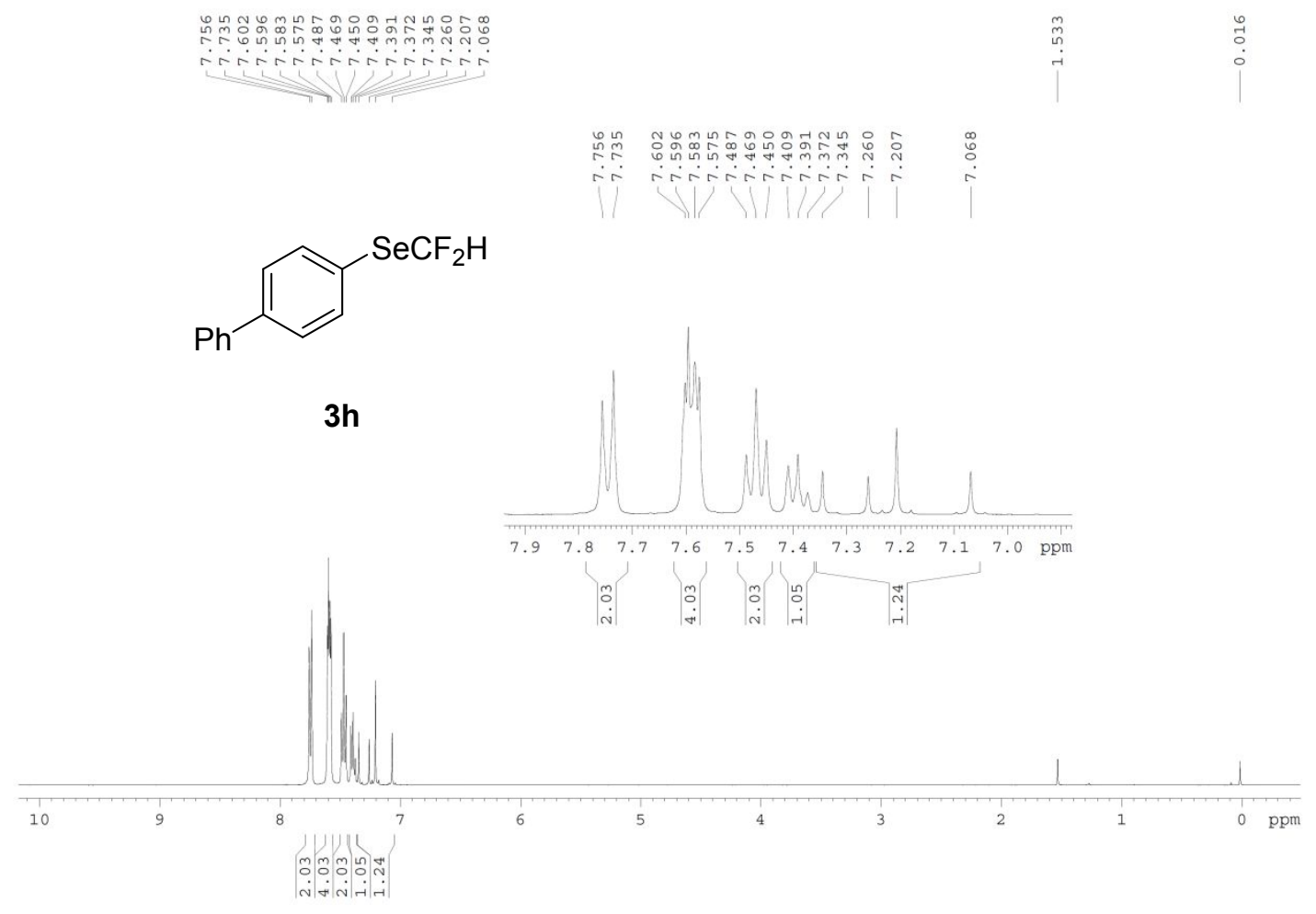

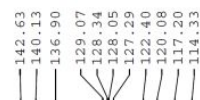
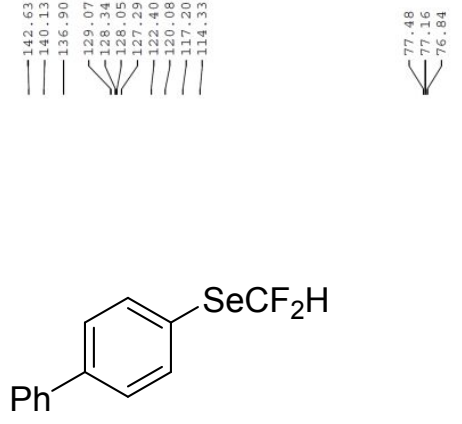

$3 h$

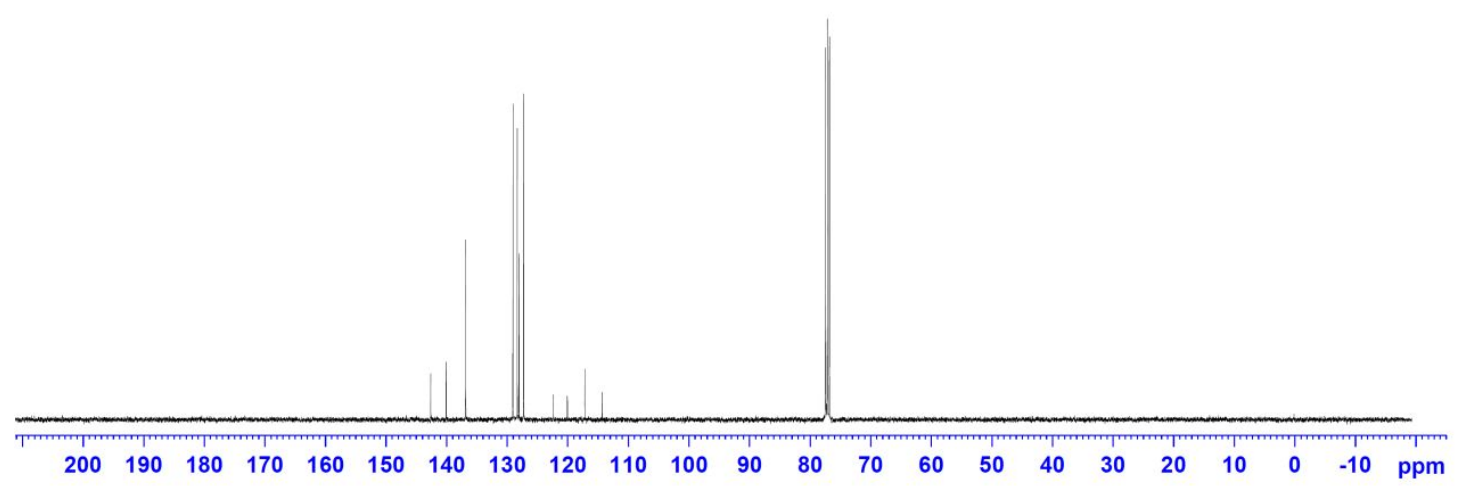




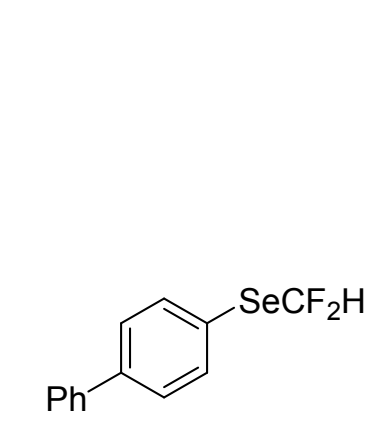

$3 h$
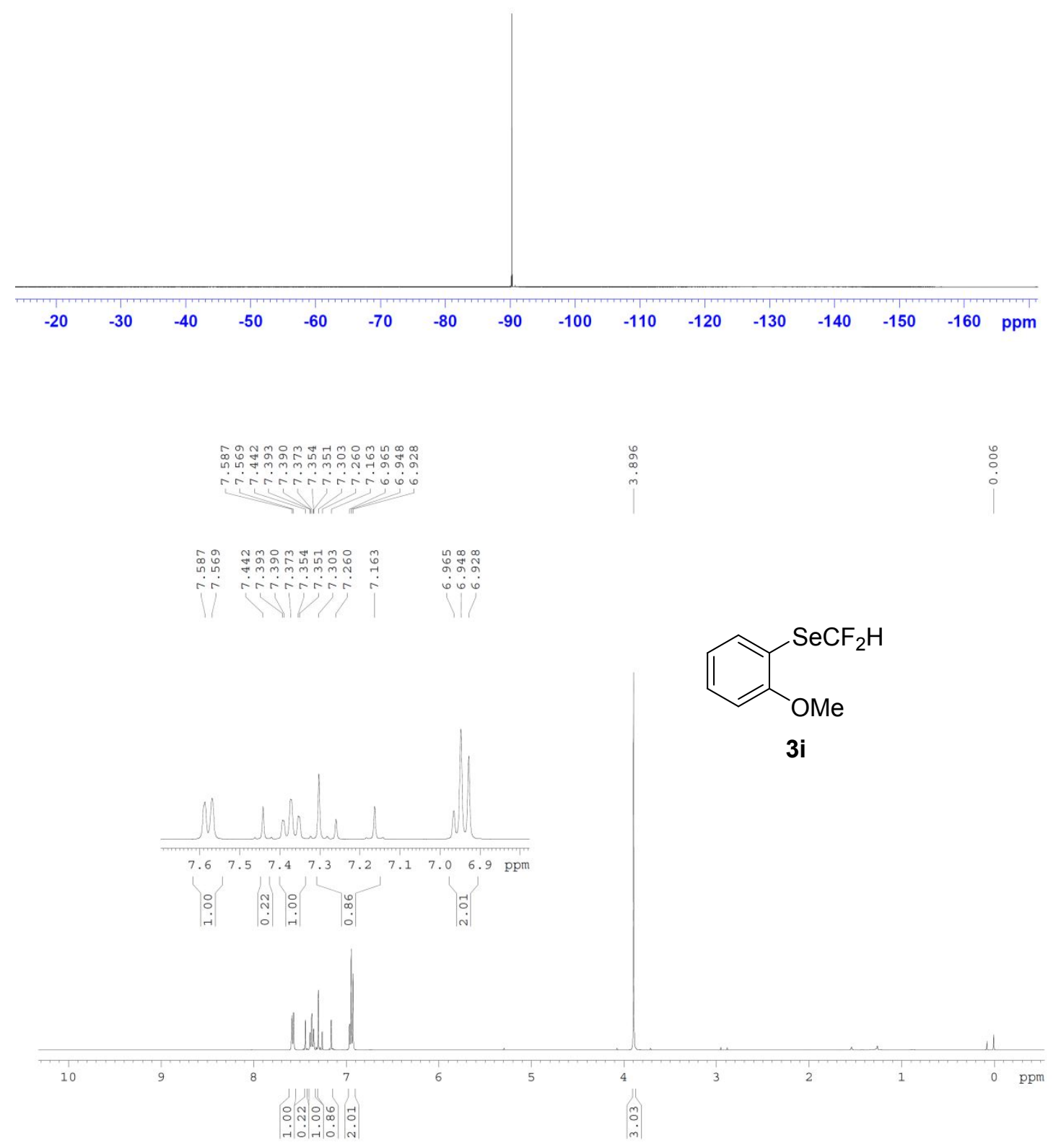

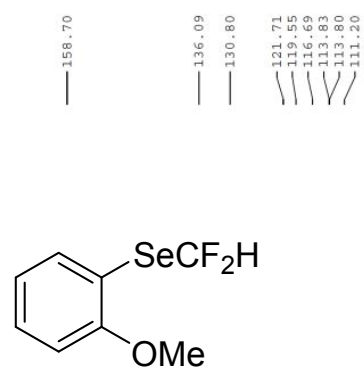

$3 \mathbf{i}$

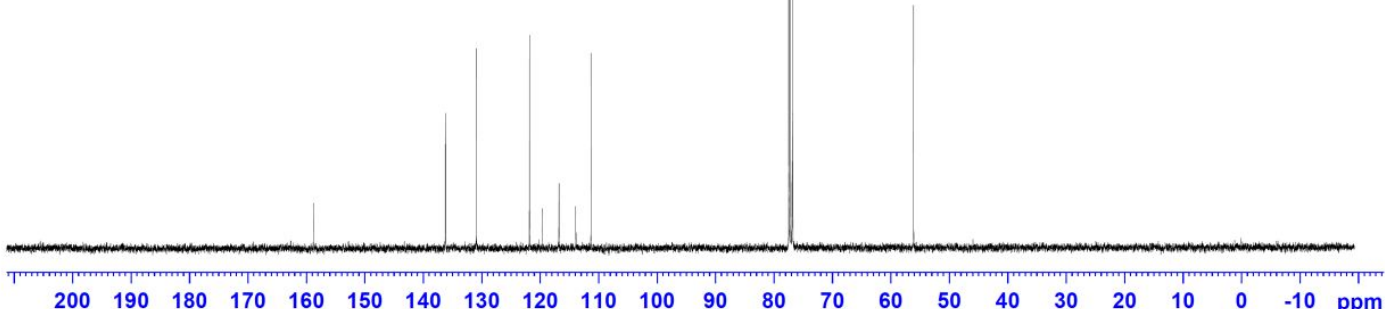<smiles>COc1ccccc1[Se]C(F)(F)F</smiles>

$3 \mathbf{i}$

\begin{tabular}{|c|c|c|c|c|c|c|c|c|c|c|c|c|}
\hline-20 & -30 & -40 & -50 & -60 & -70 & -80 & -90 & -100 & -110 & -120 & -130 & $-140 \mathrm{ppm}$ \\
\hline
\end{tabular}



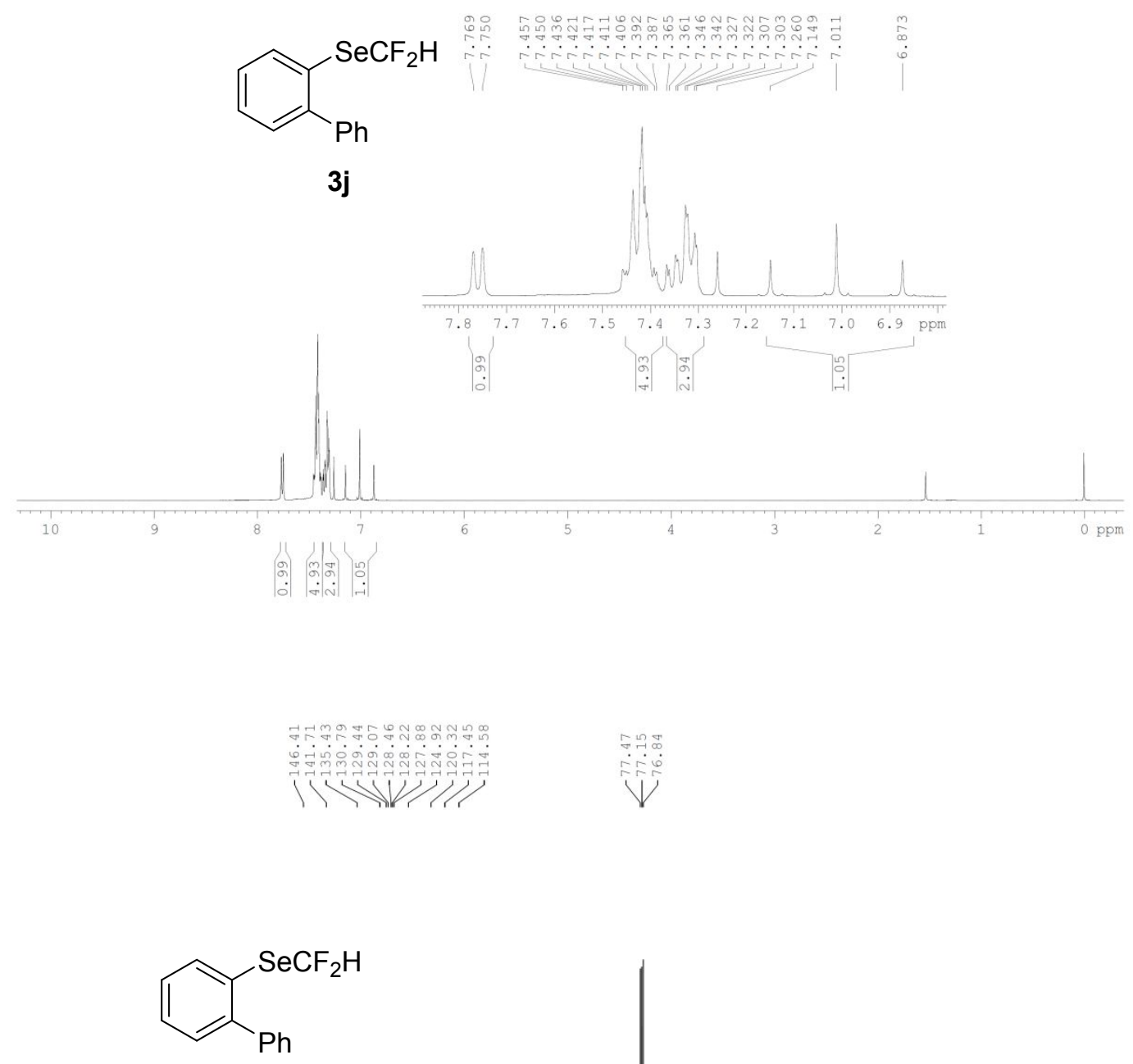

3j

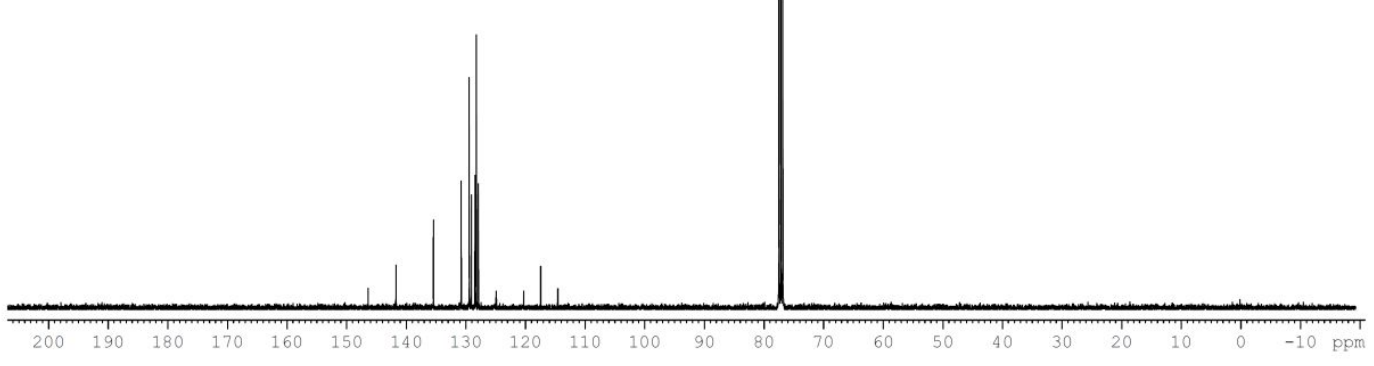




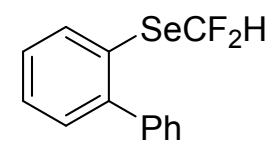

3j

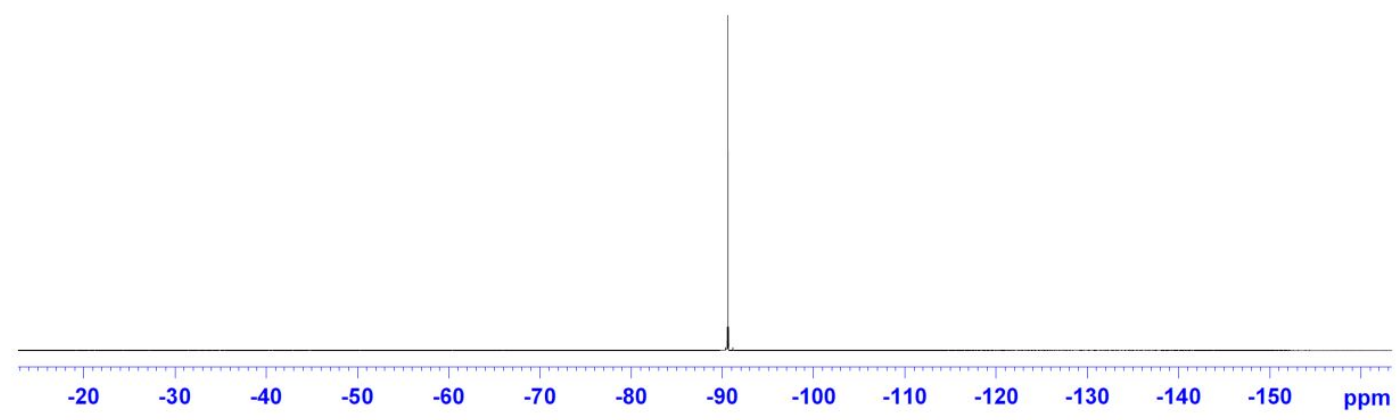

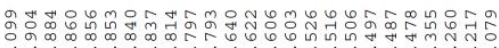

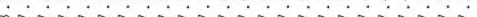

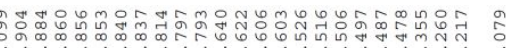

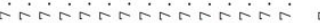

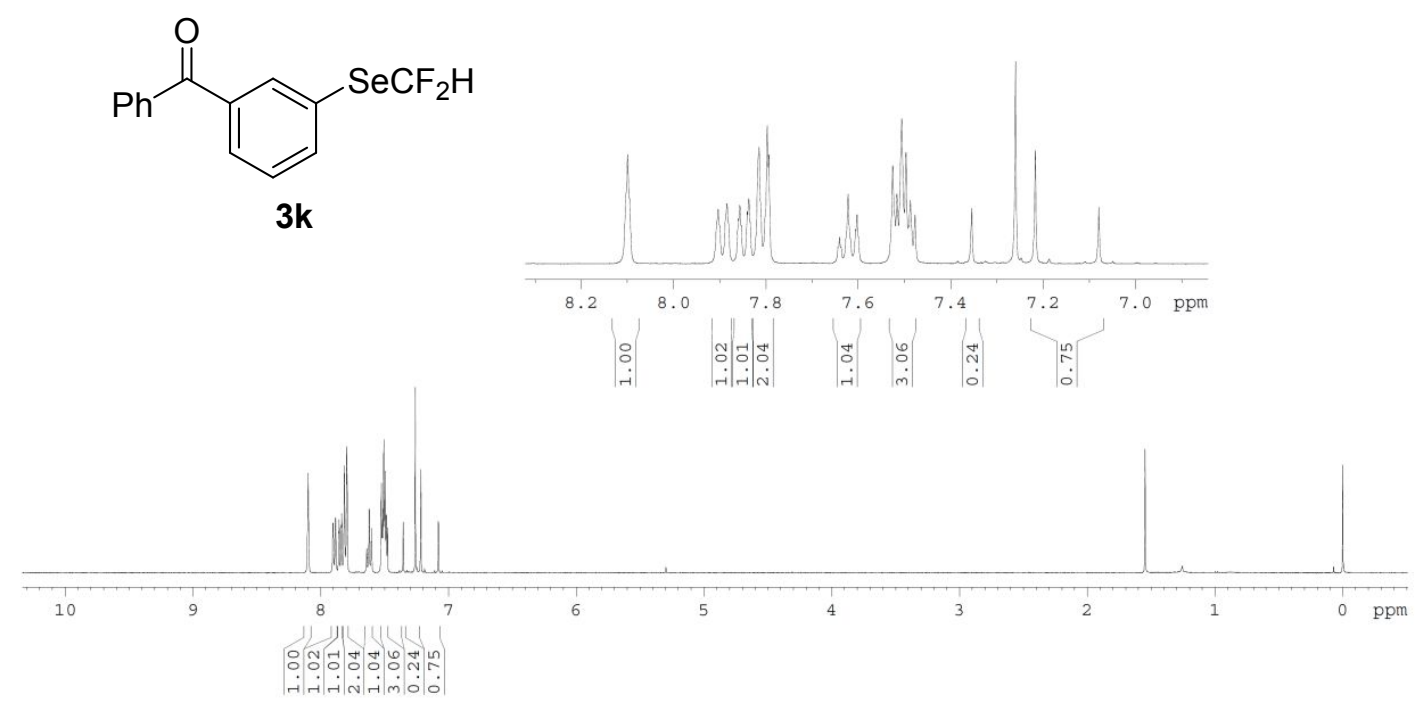


<smiles>O=C(c1ccccc1)c1cccc([Se]C(F)(F)F)c1</smiles>

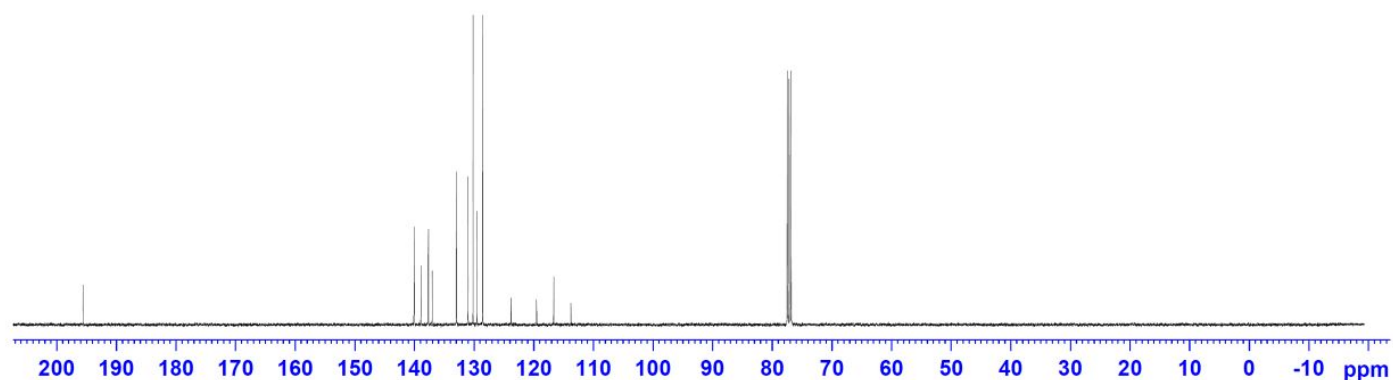<smiles>CCCOc1cccc(C(=O)c2ccccc2)c1</smiles>

$3 k$

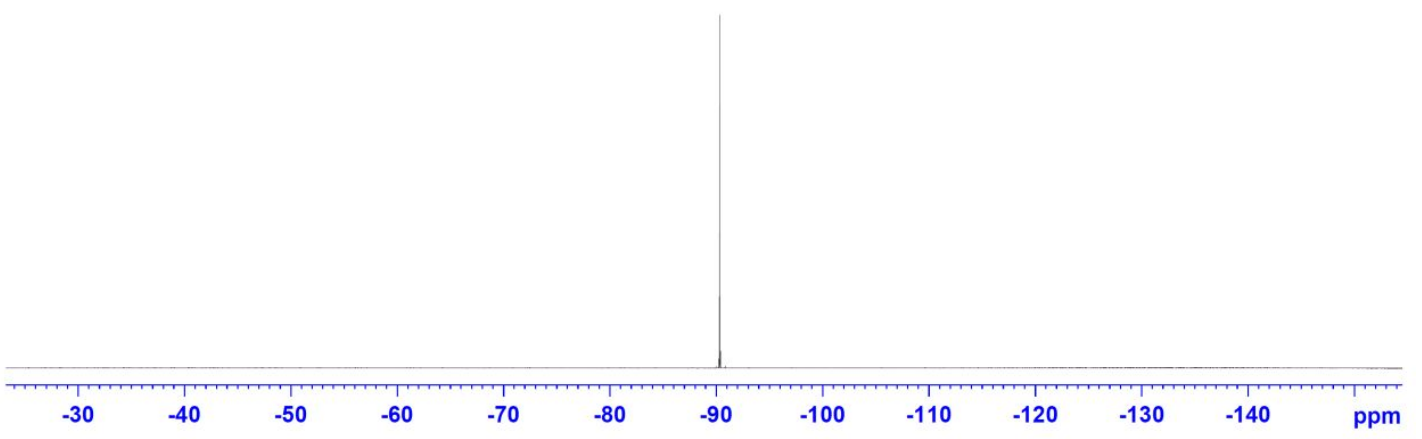




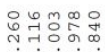

움웜

นับ

\section{뭄ํ.}

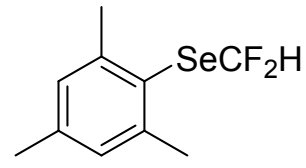

3I

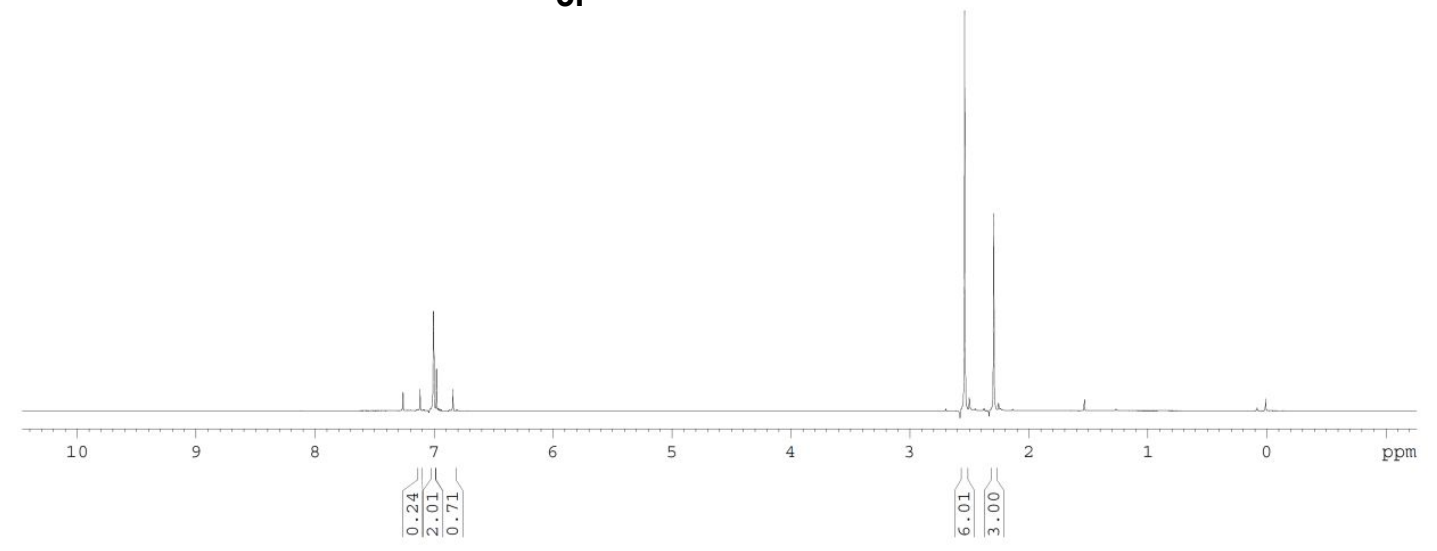

$\left.\right|^{\infty}$
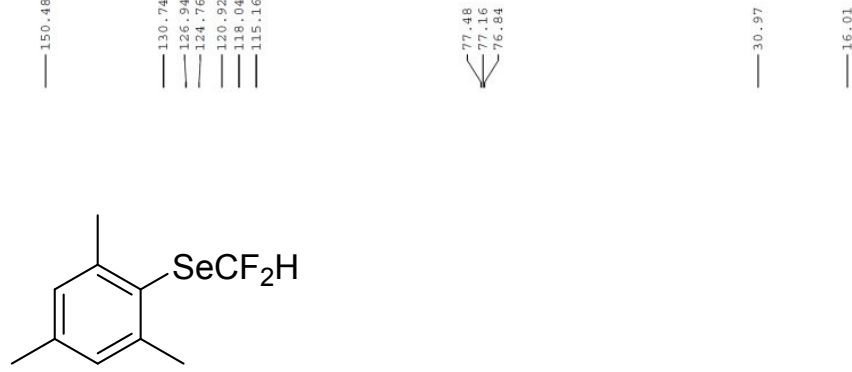

3I

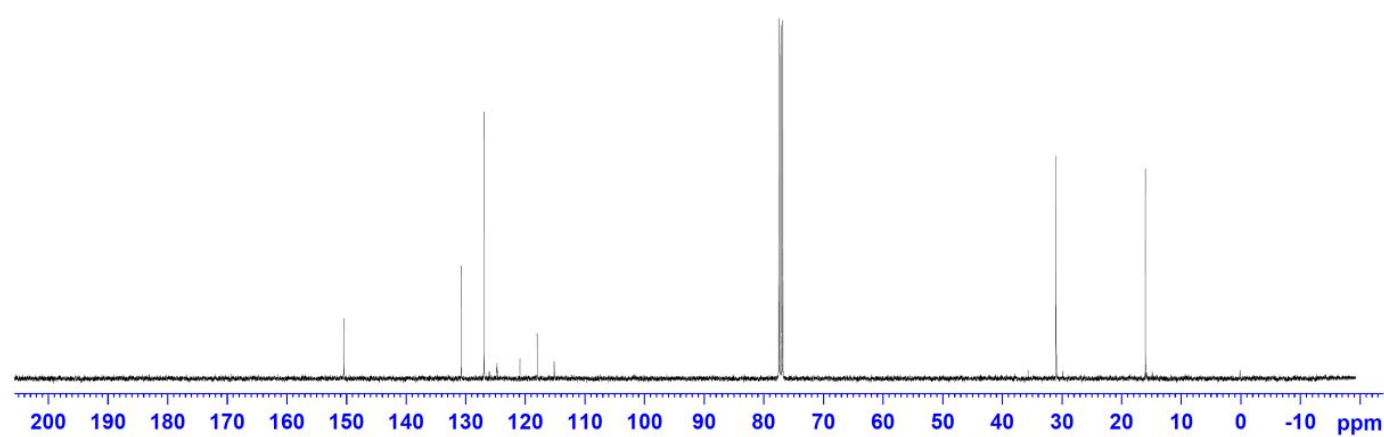




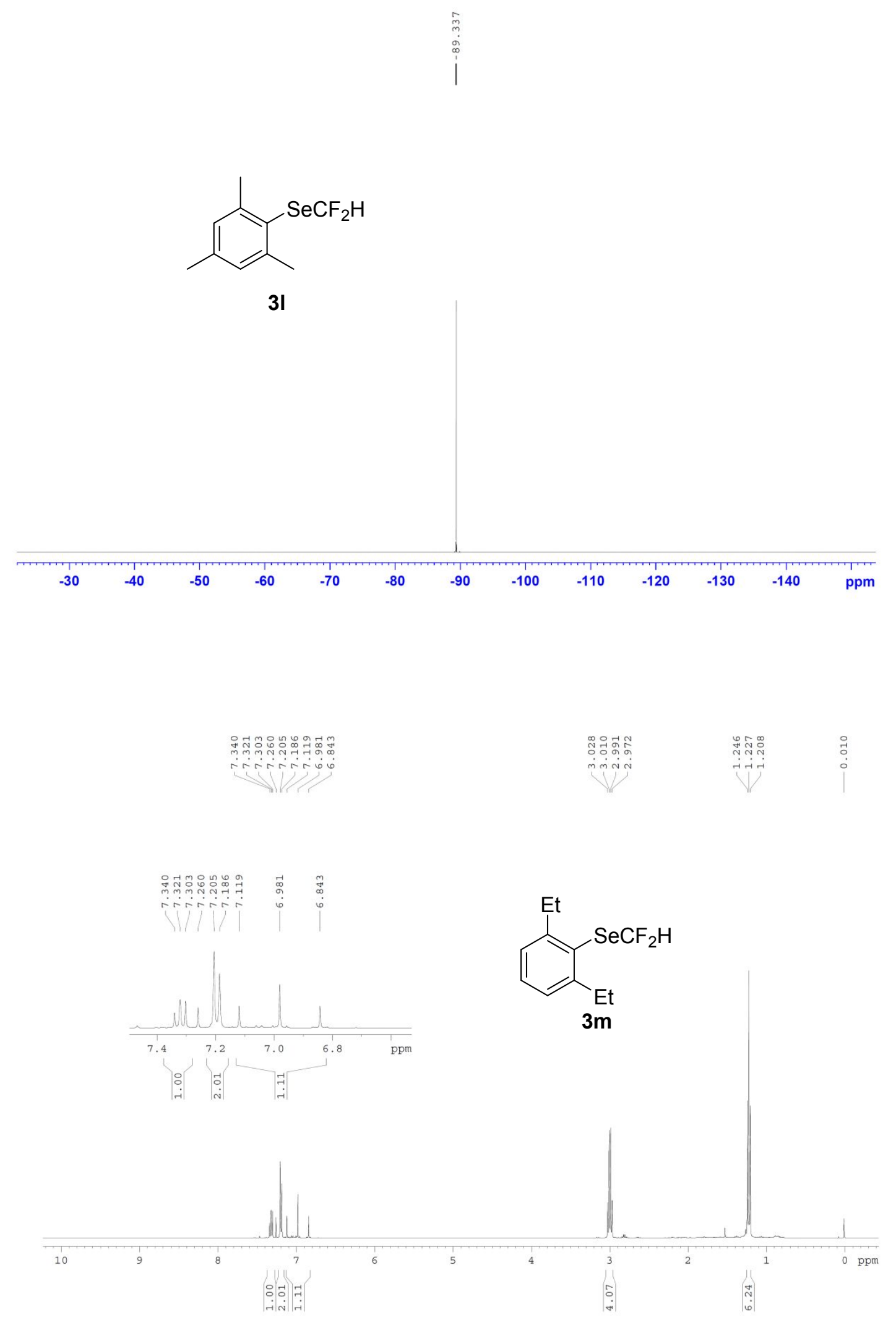



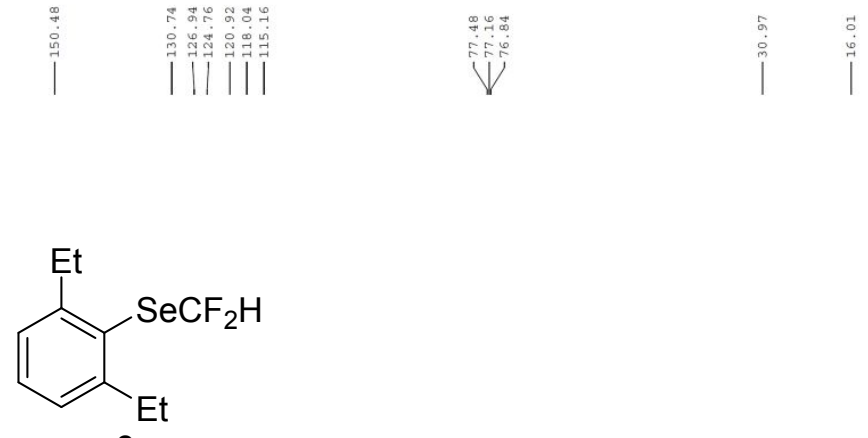

$3 \mathrm{~m}$
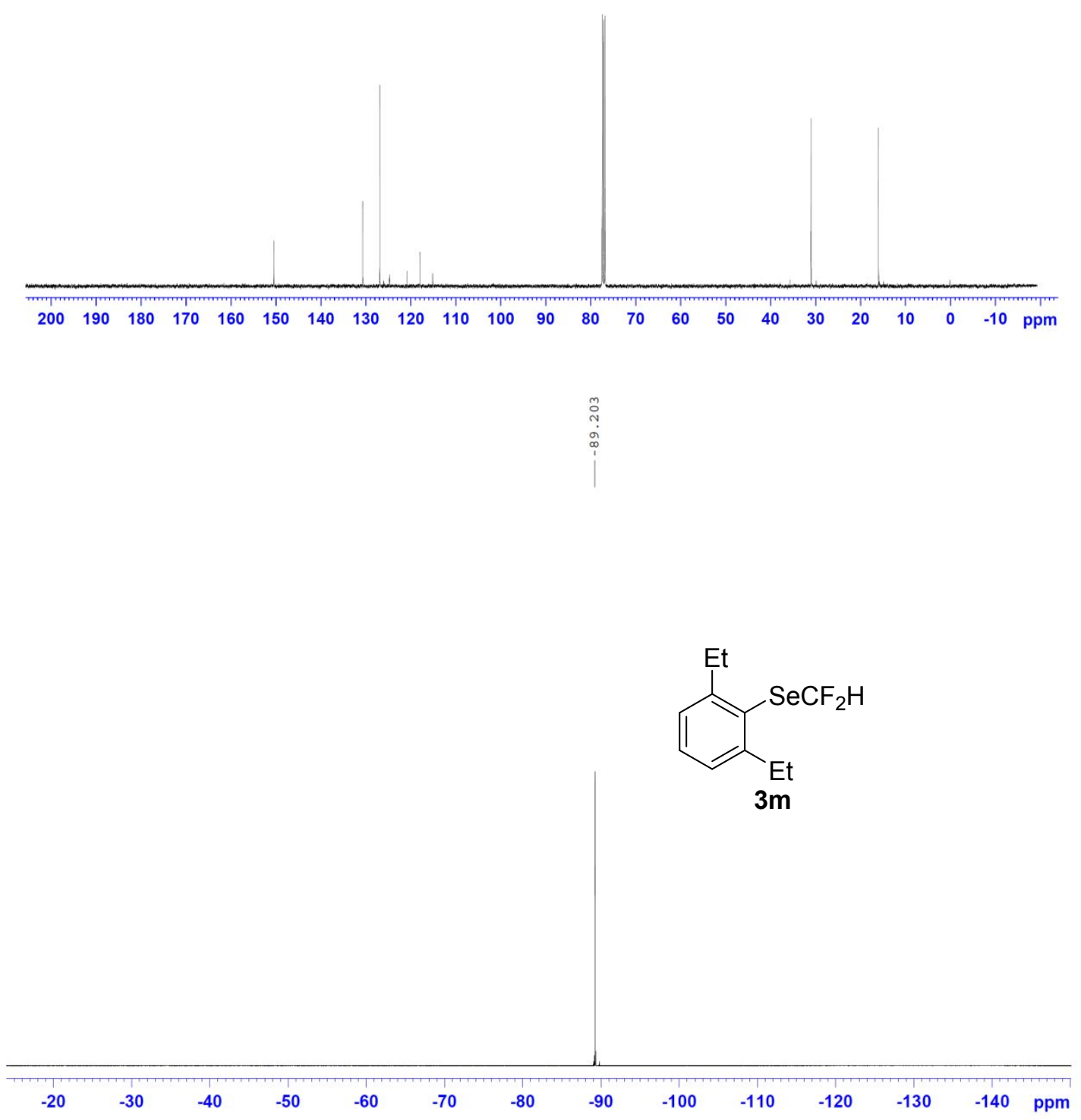


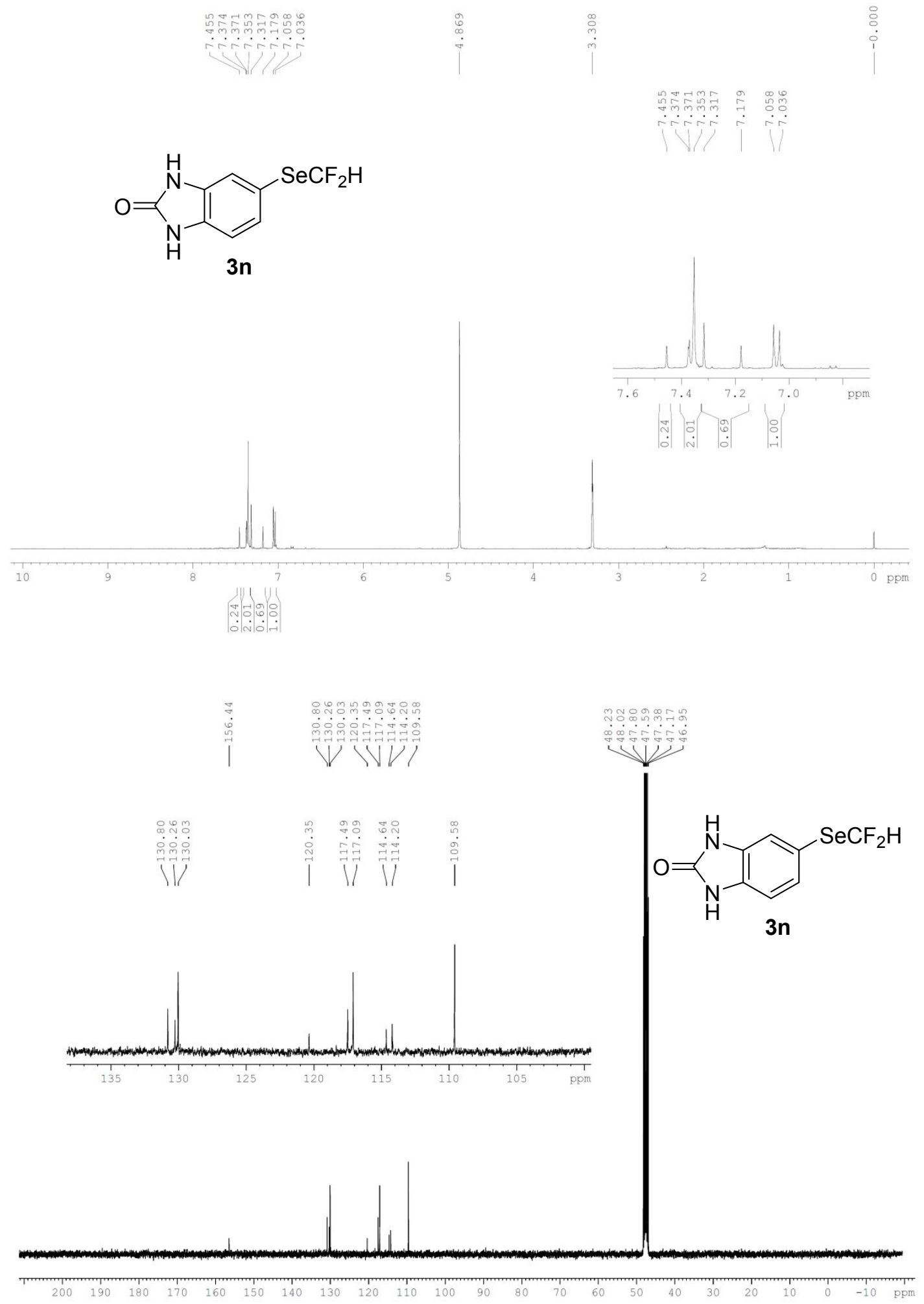



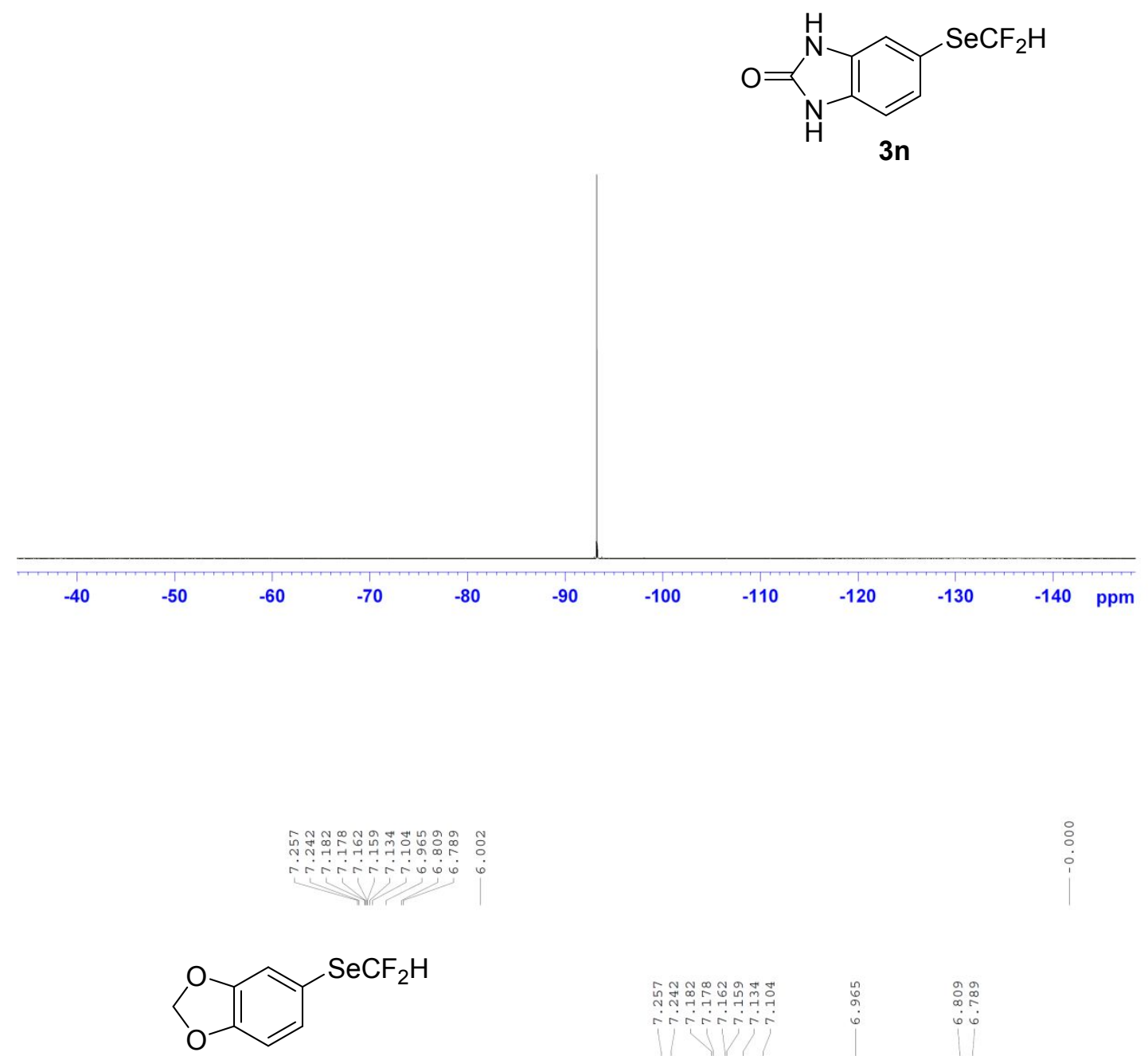

30

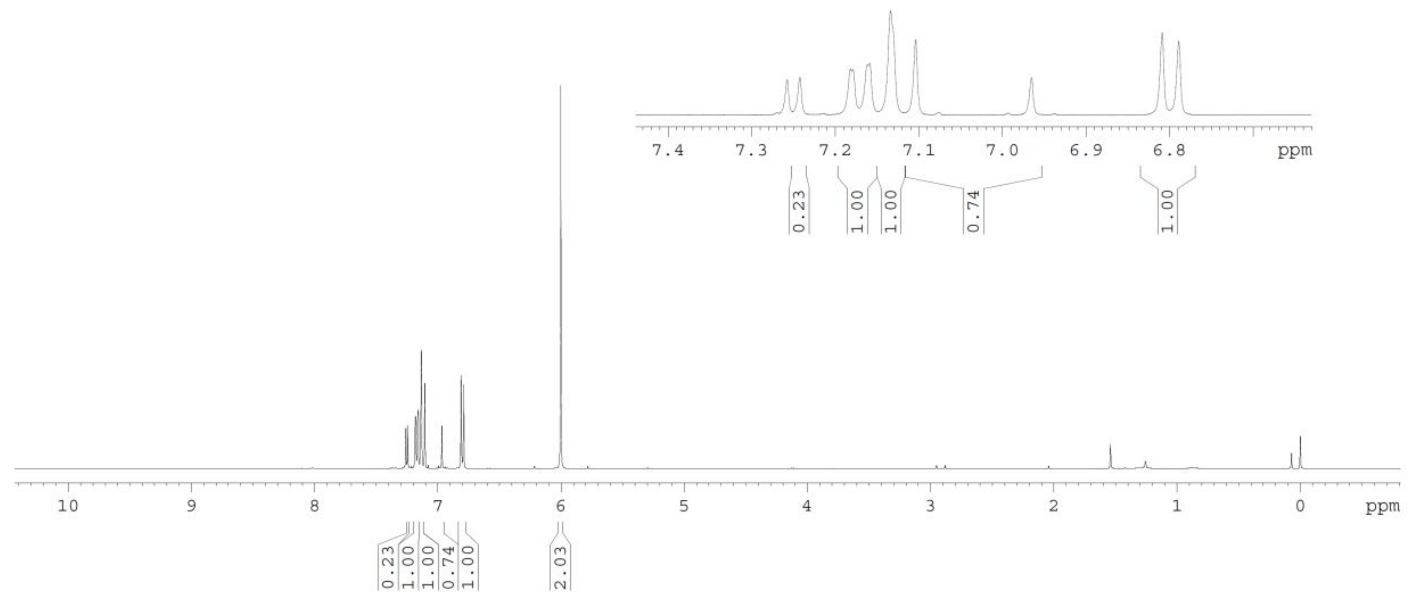




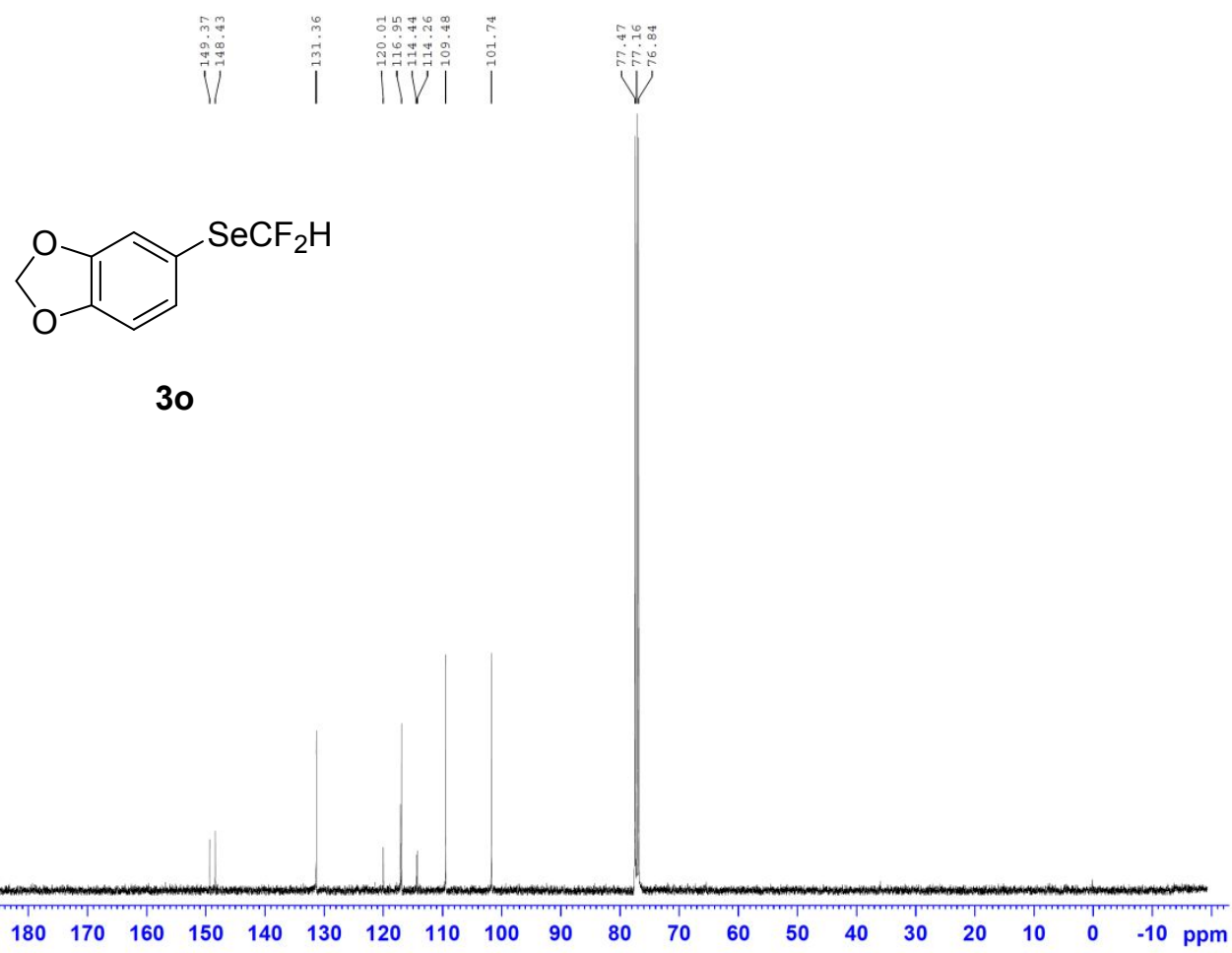<smiles>FC(F)(F)[Se]c1ccc2c(c1)OCO2</smiles>

30

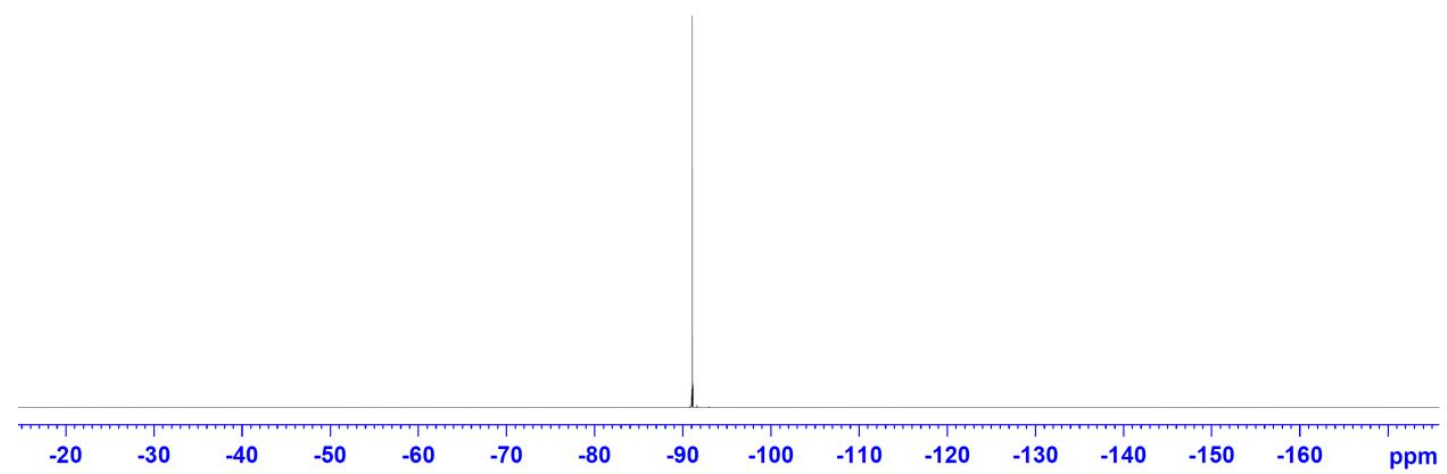


<smiles>O=C1NC(=O)c2cc(OC(F)(F)F)ccc21</smiles>
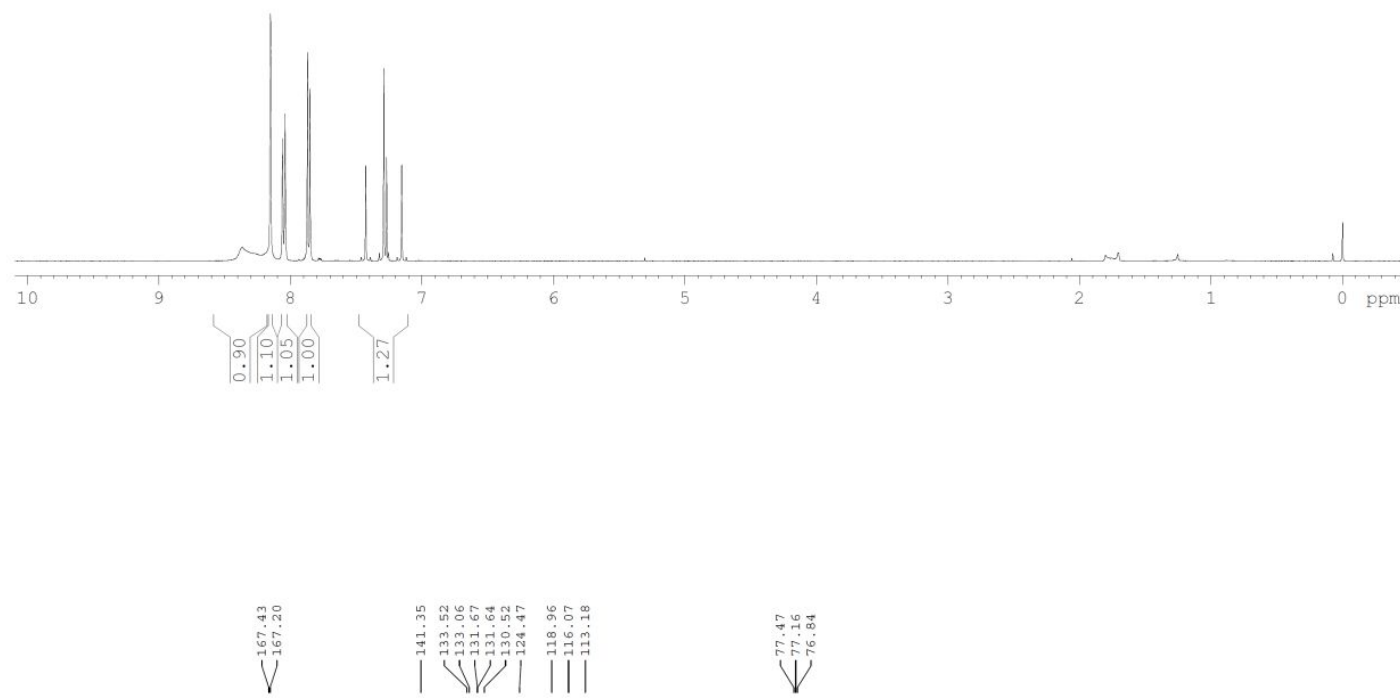<smiles>O=C1NC(=O)c2cc(OC(F)(F)F)ccc21</smiles> 
<smiles>O=C1NC(=O)c2cc([Se]C(F)(F)F)ccc21</smiles>
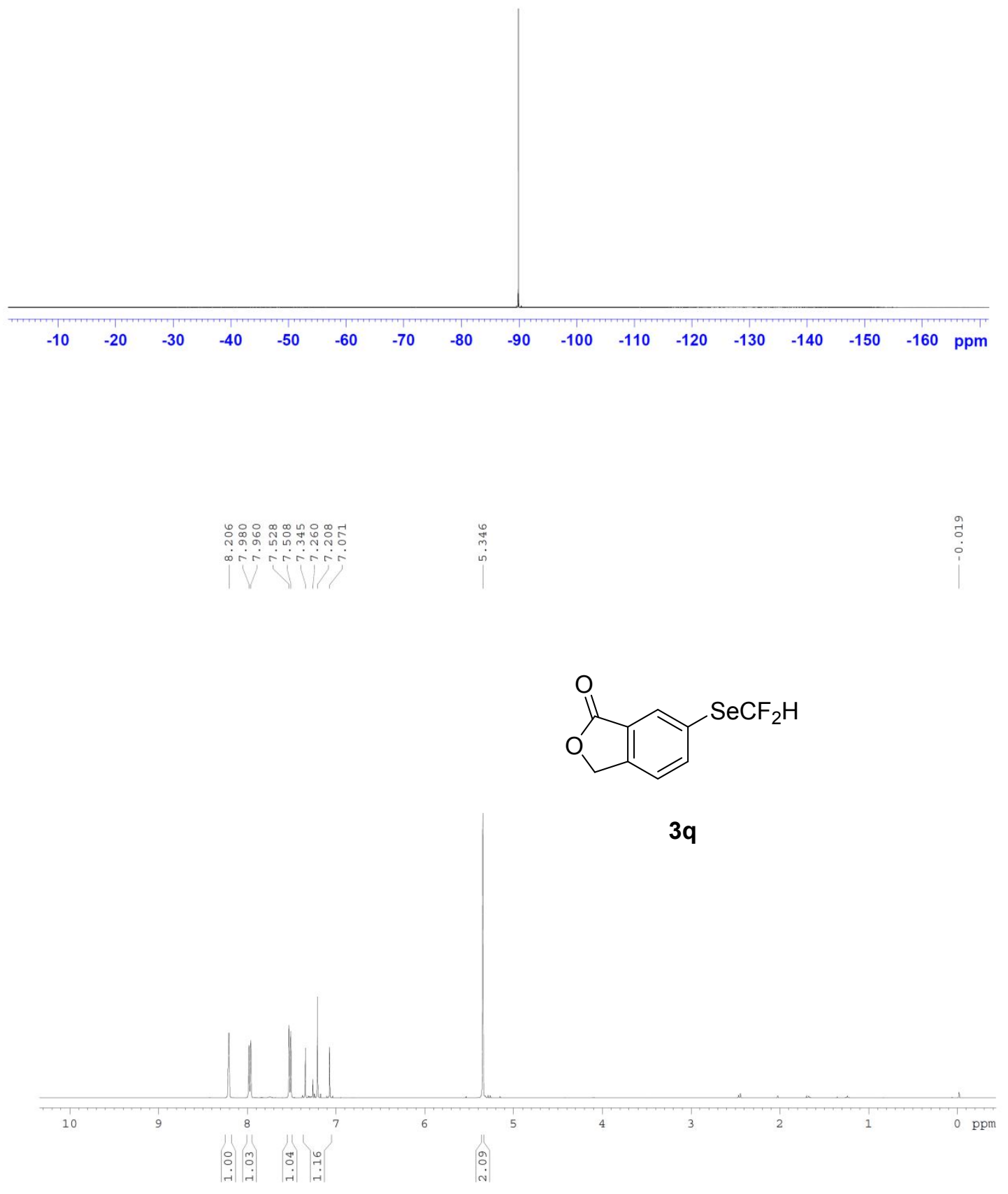


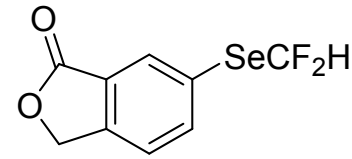

$3 q$

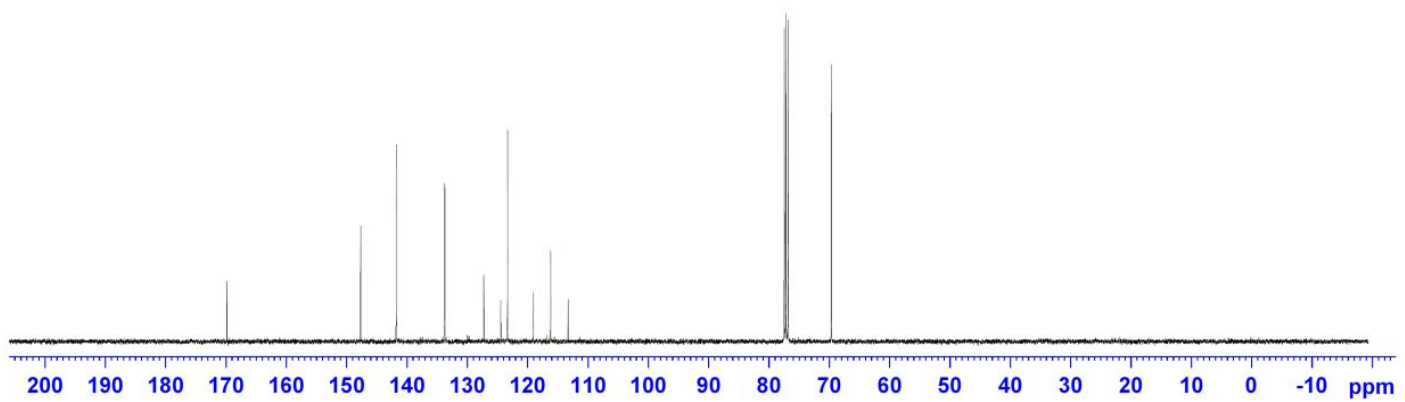<smiles>O=C1OCc2ccc([Se]C(F)F)cc21</smiles>

$3 q$

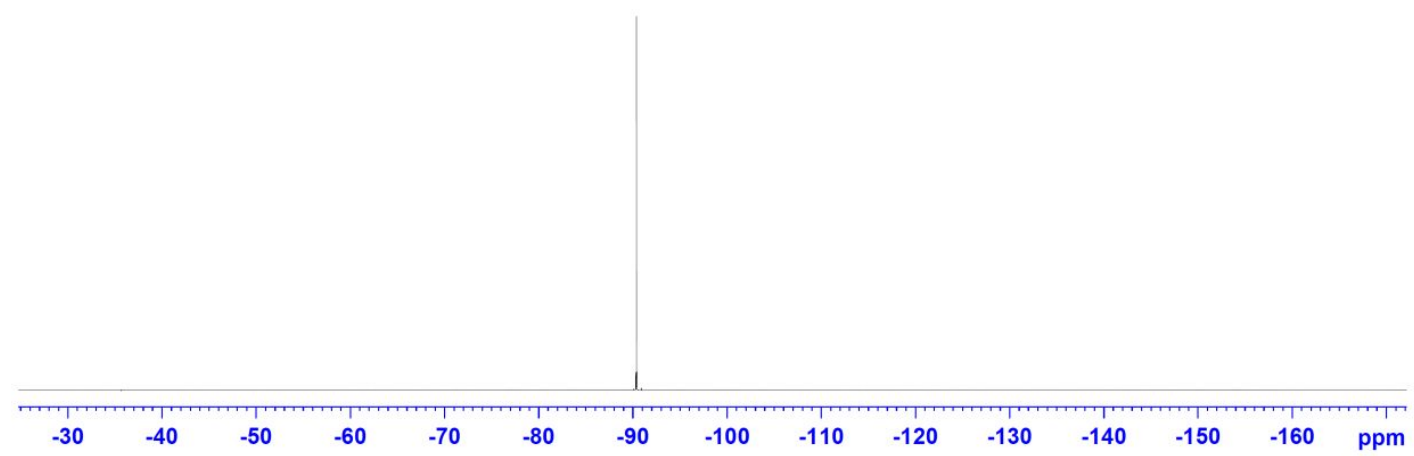




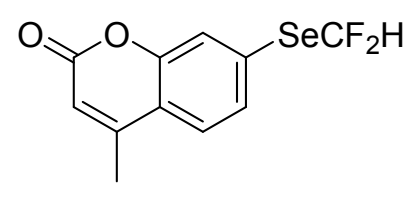

$3 r$
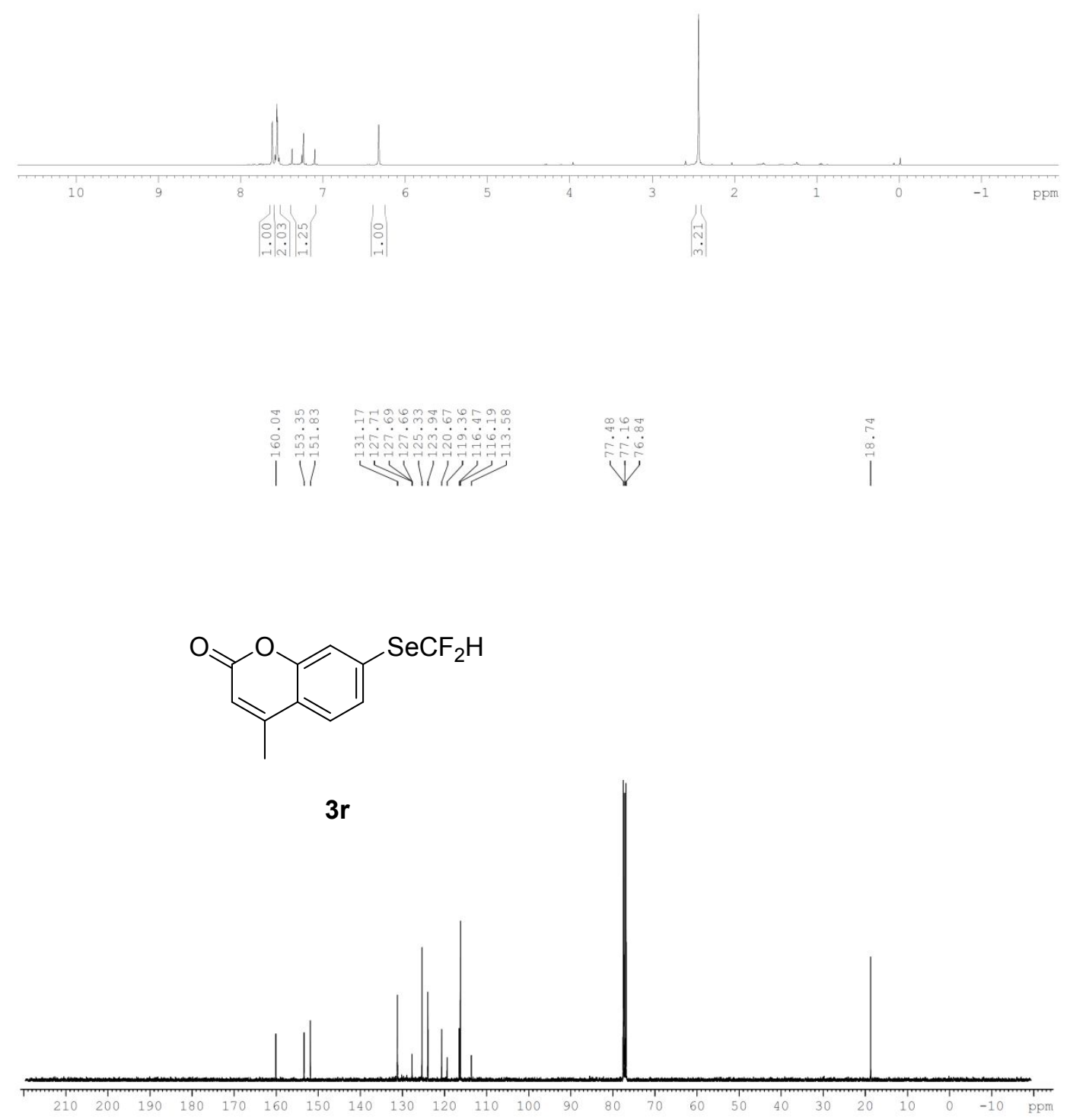


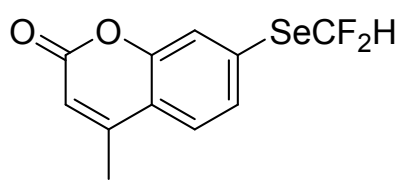

$3 r$

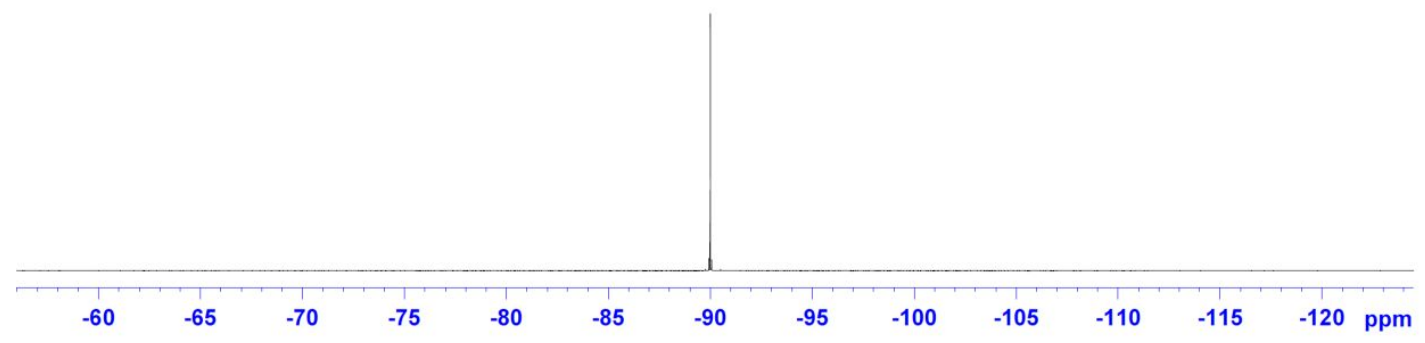

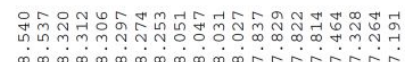

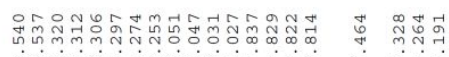

(l)

$3 s$
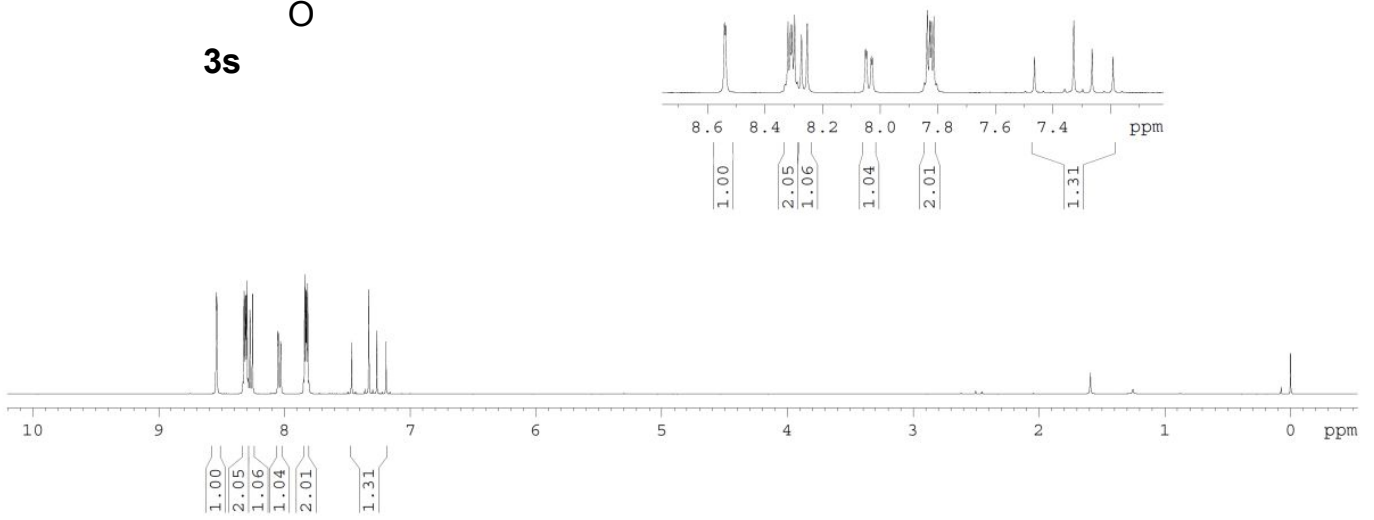

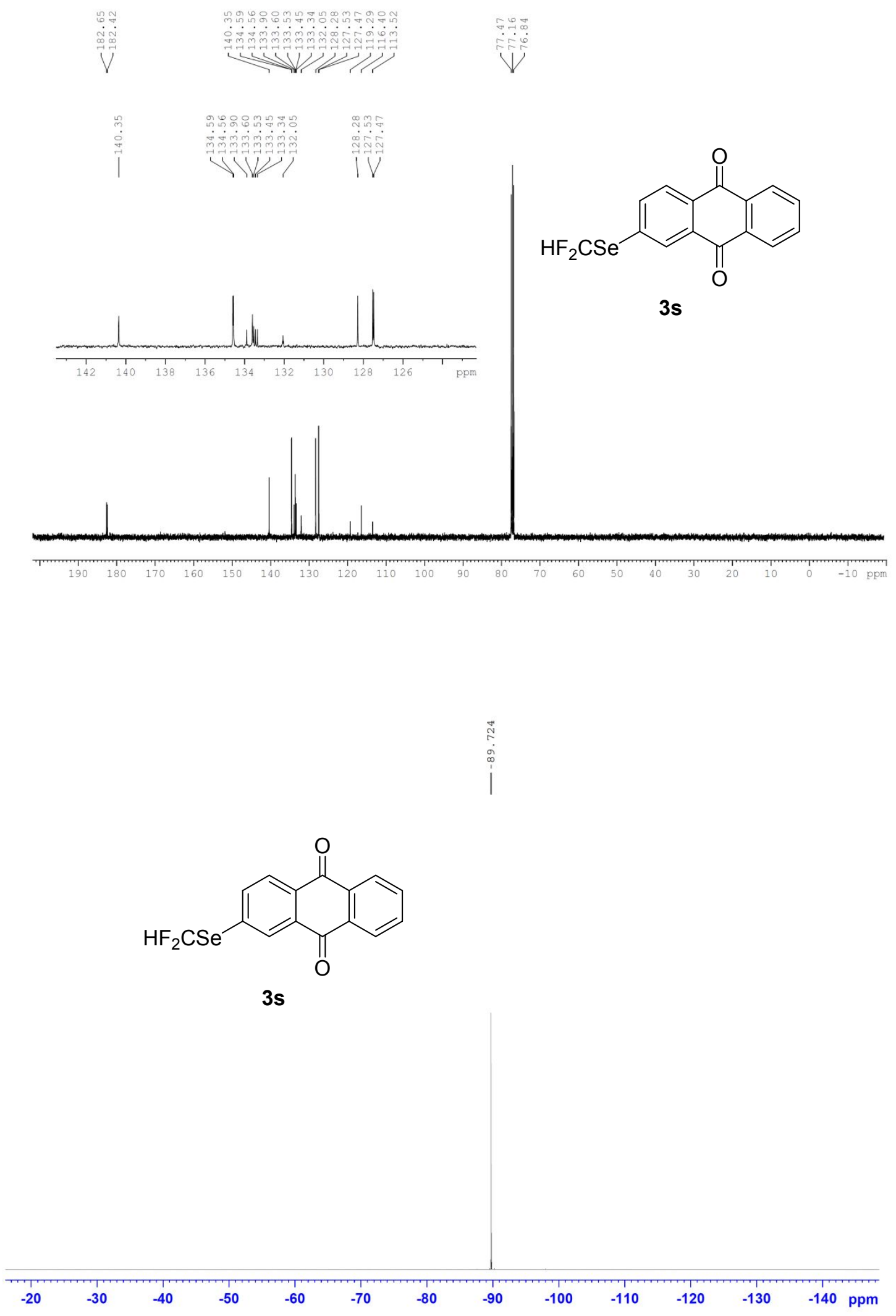


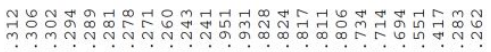

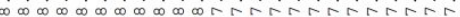

Vill

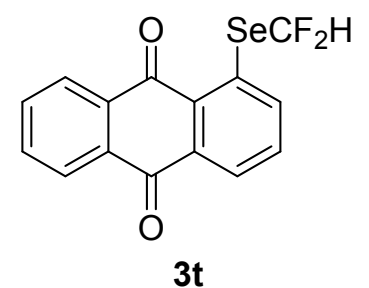
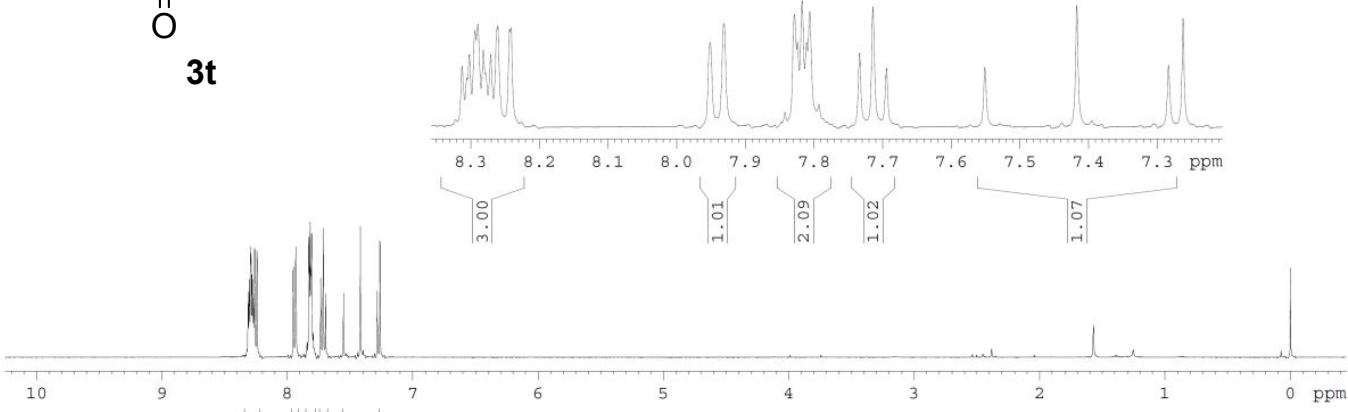

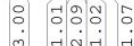

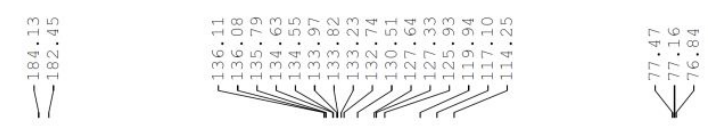

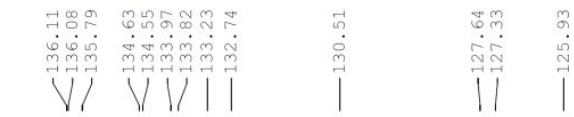
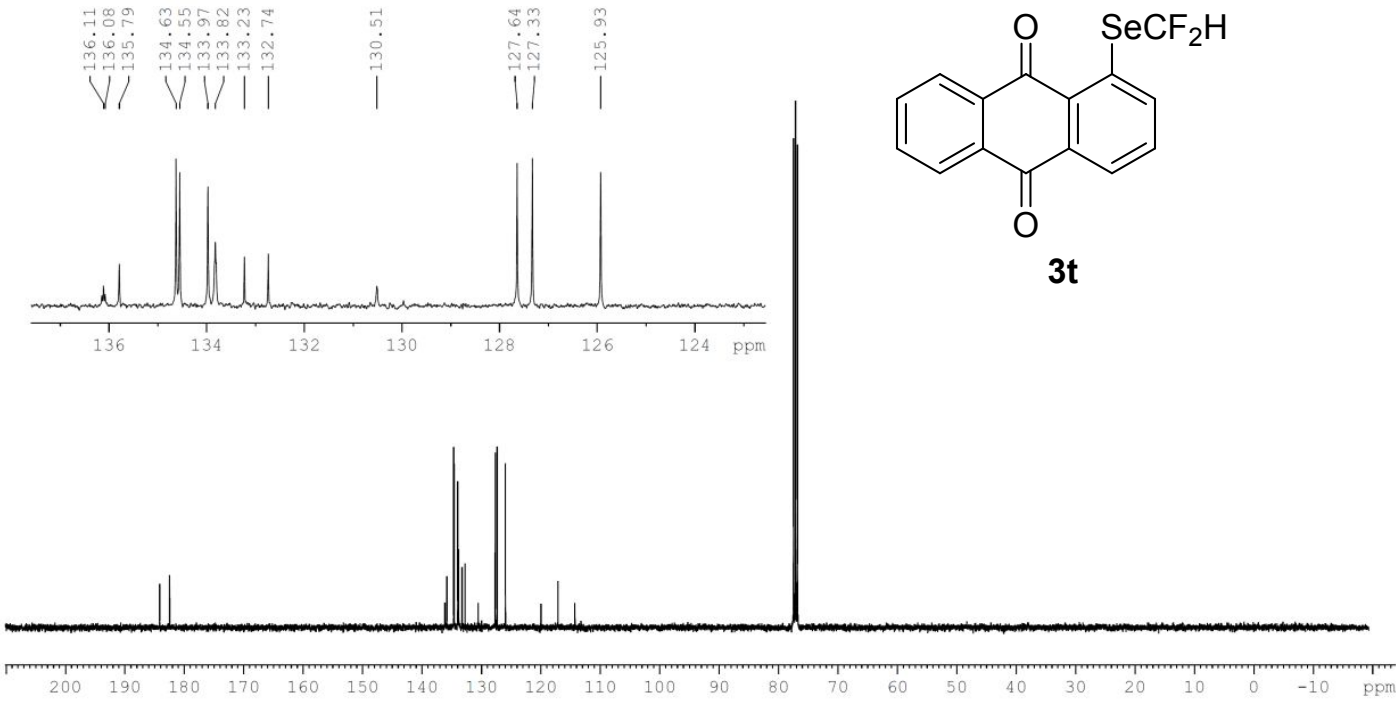


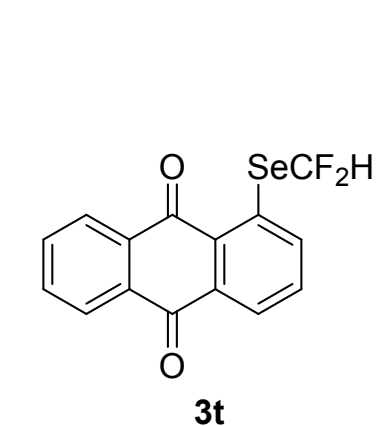

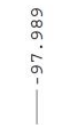

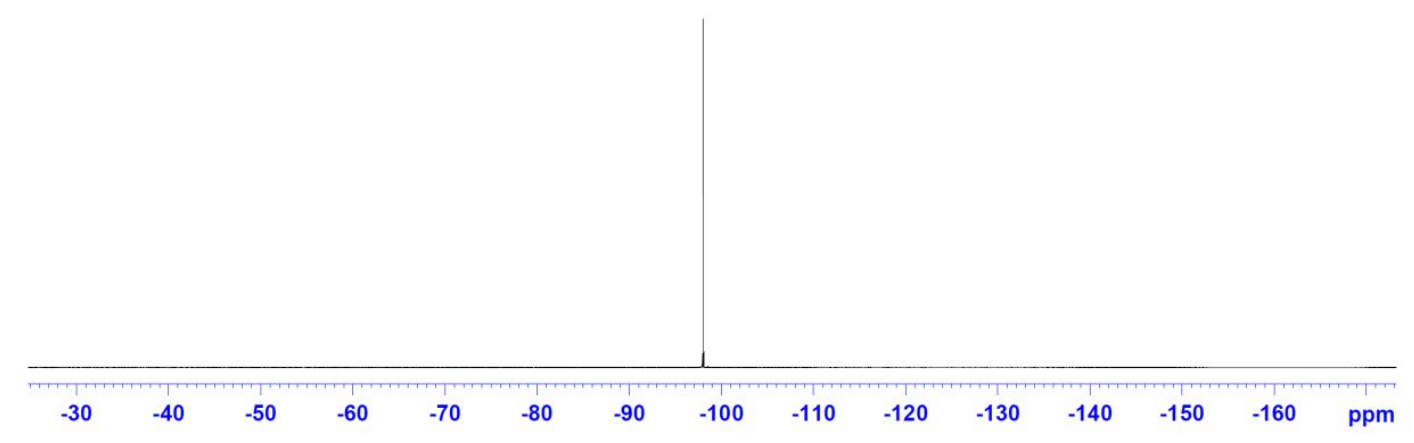

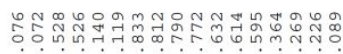

i

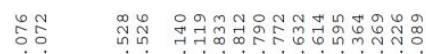

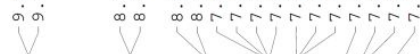

$3 u$
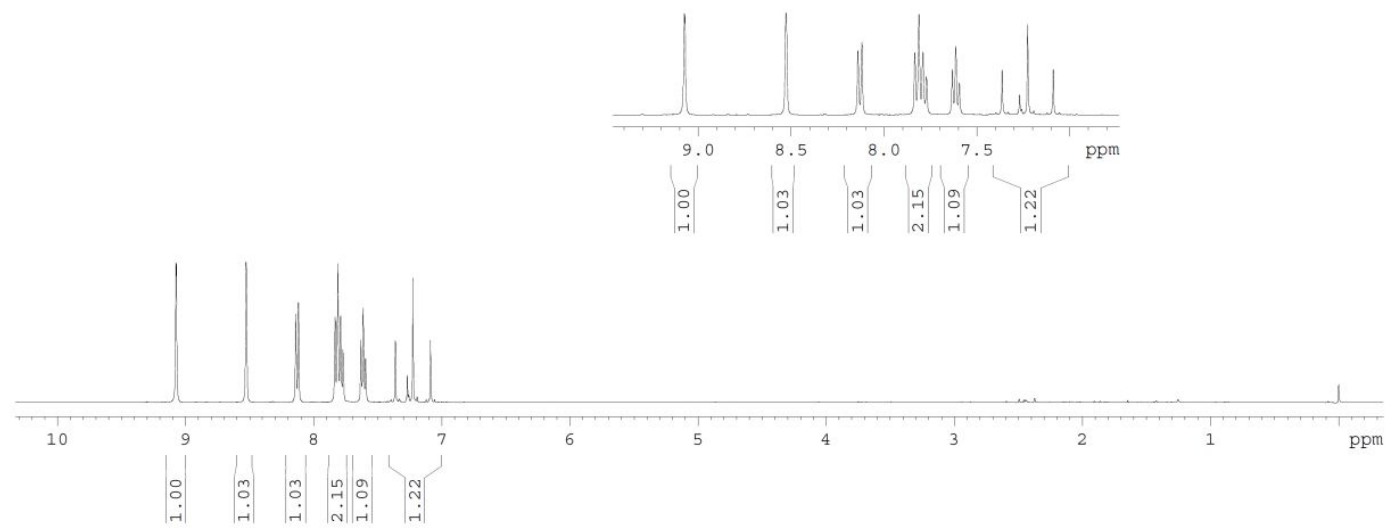

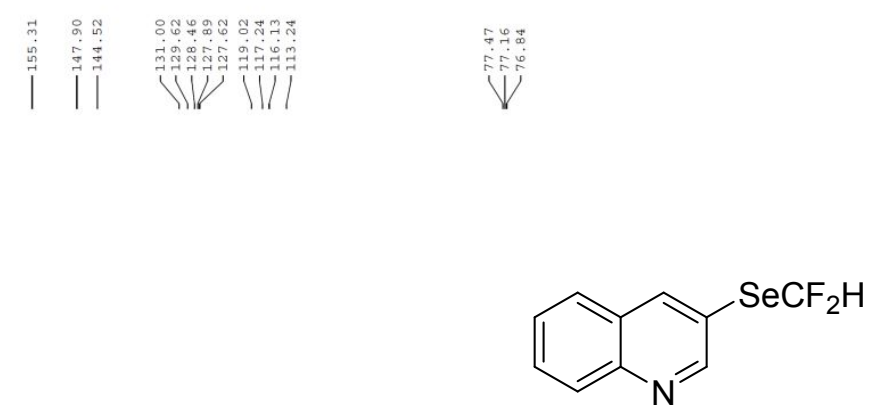

$3 u$

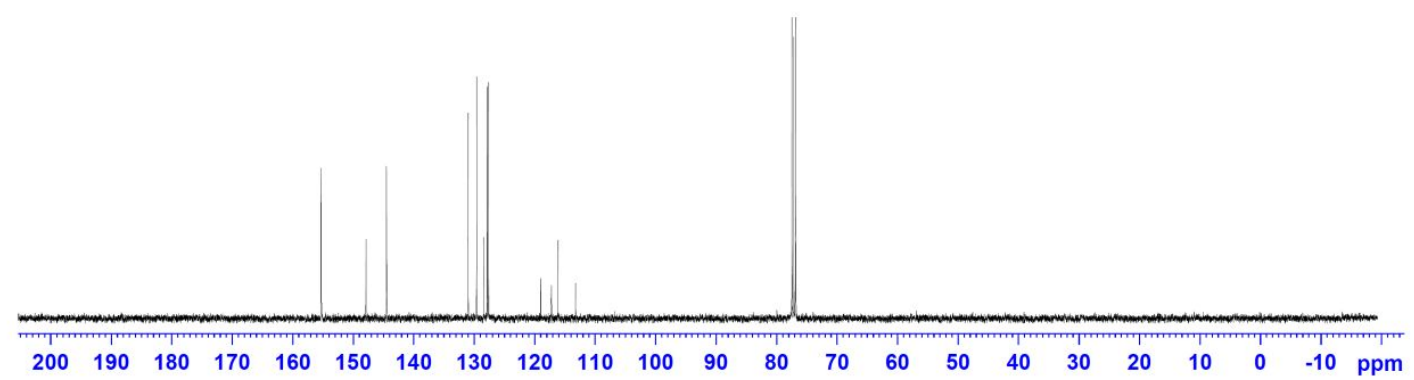<smiles>FC(F)(F)[Se]c1cnc2ccccc2c1</smiles>

$3 u$

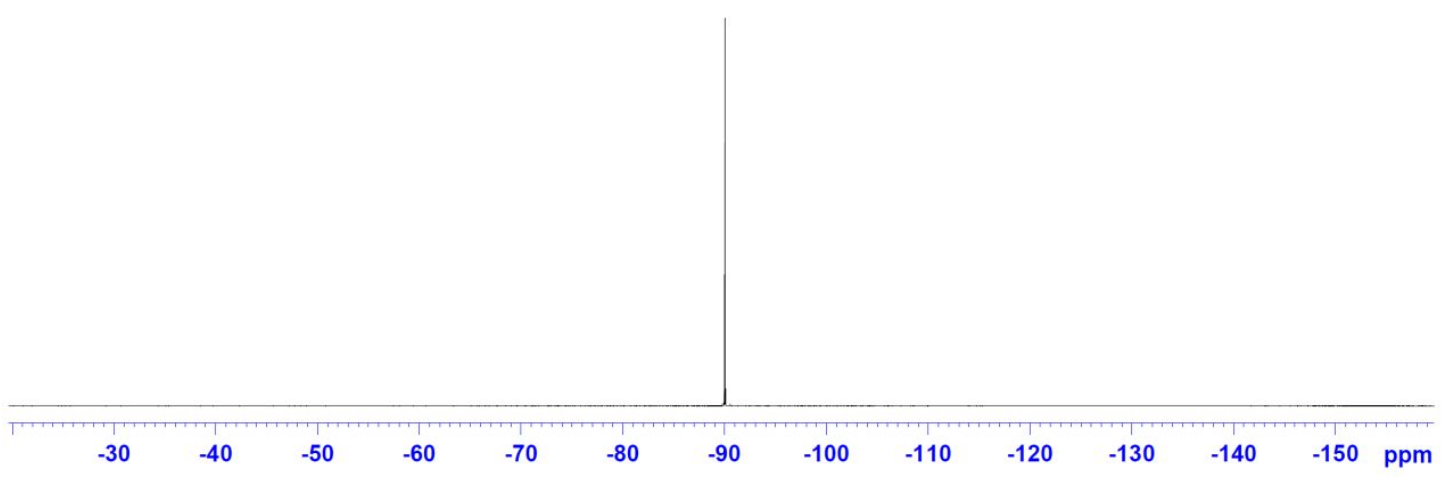




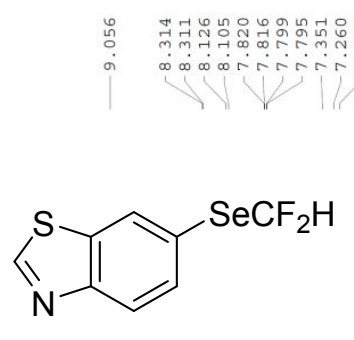

$3 v$
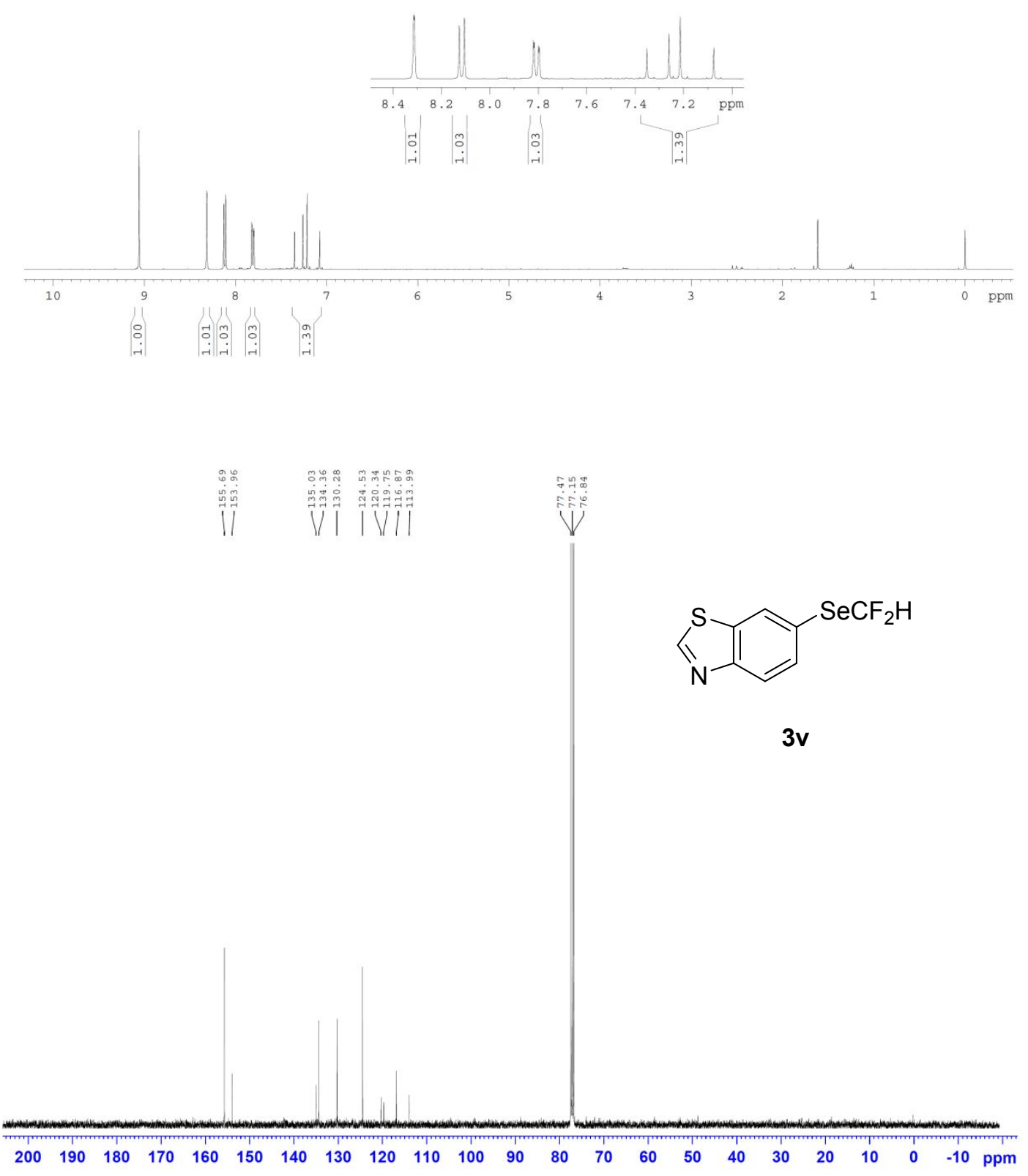


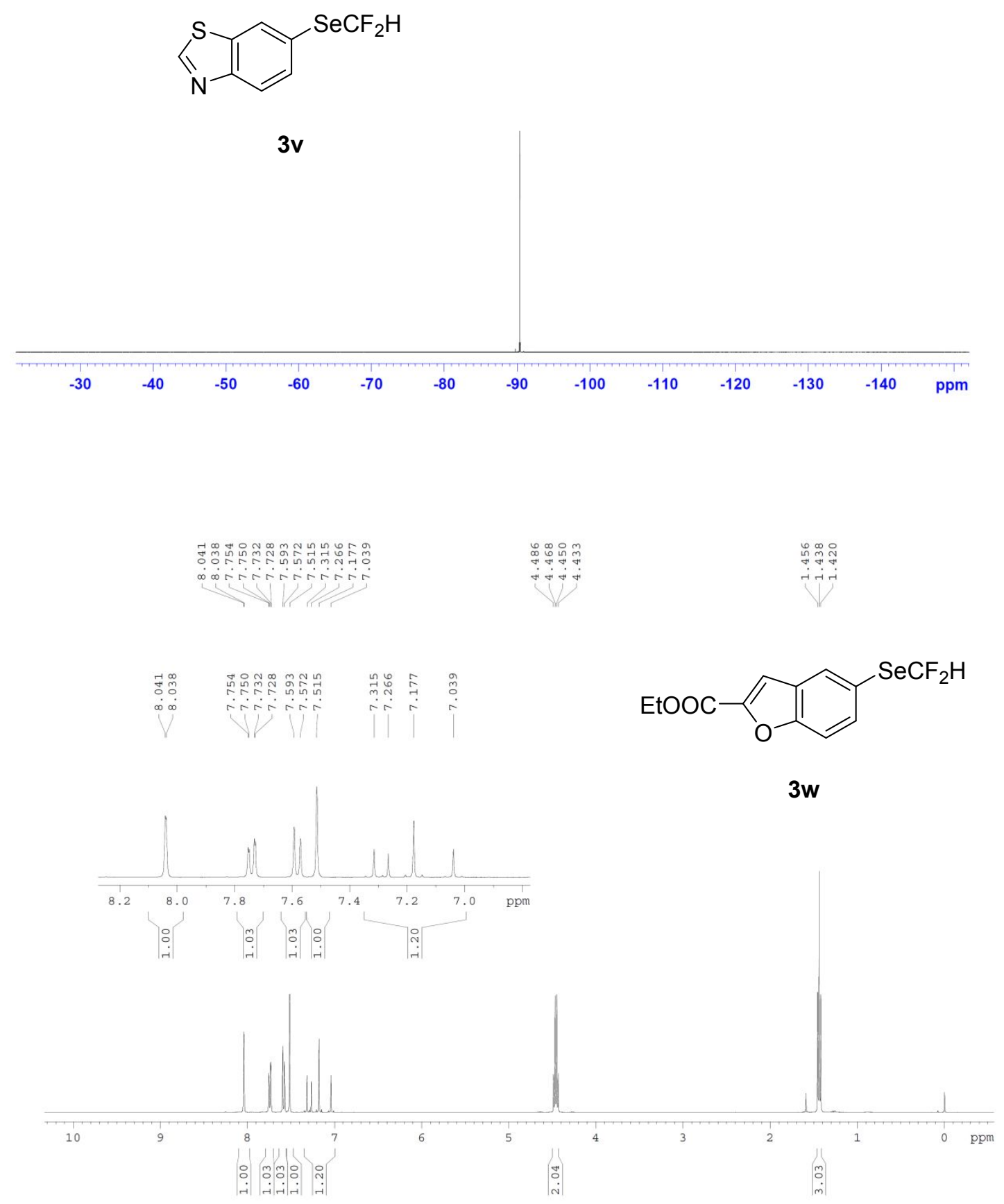




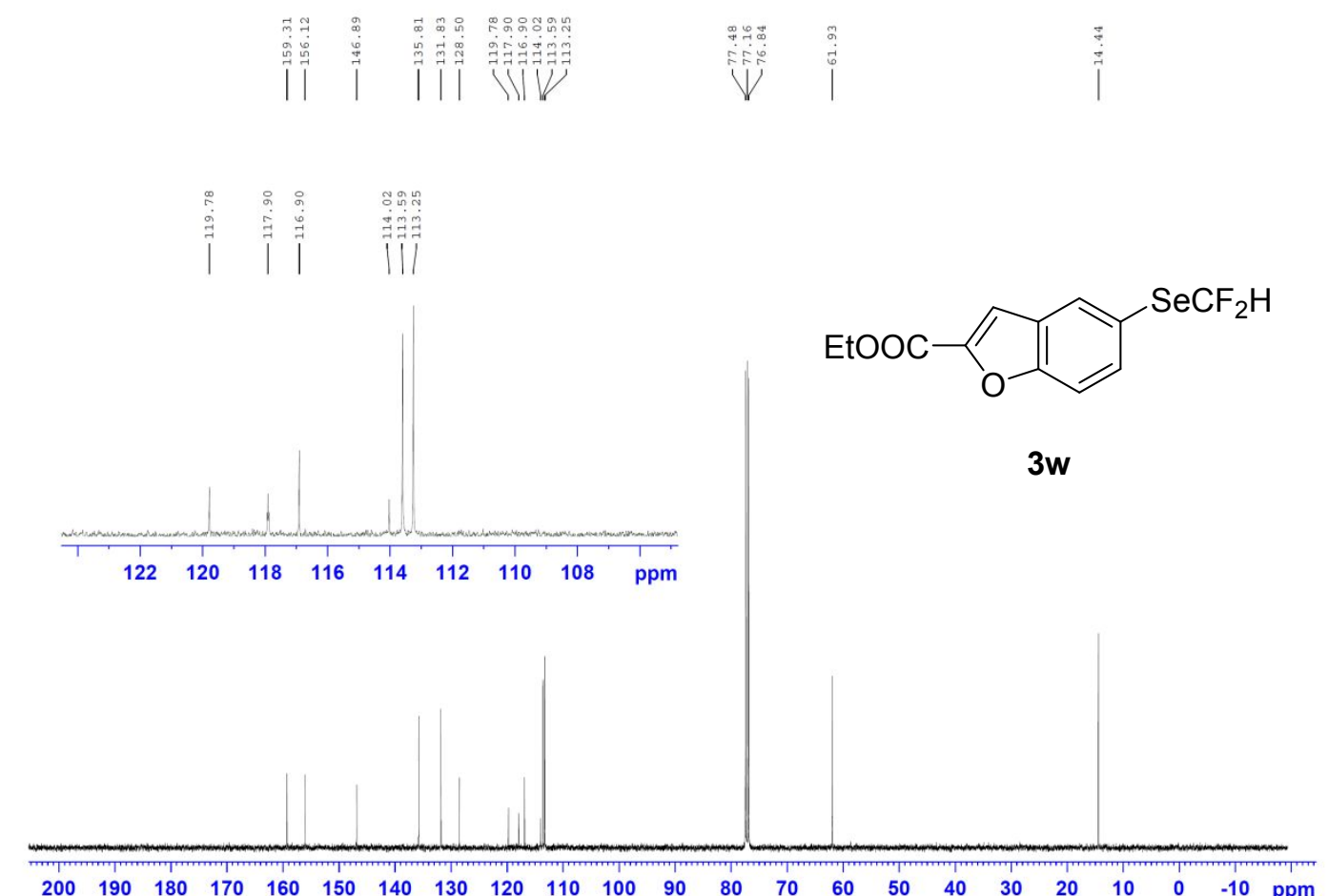

$\begin{array}{lllllllllllllllllllllll}200 & 190 & 180 & 170 & 160 & 150 & 140 & 130 & 120 & 110 & 100 & 90 & 80 & 70 & 60 & 50 & 40 & 30 & 20 & 10 & 0 & -10 & \mathrm{ppm}\end{array}$
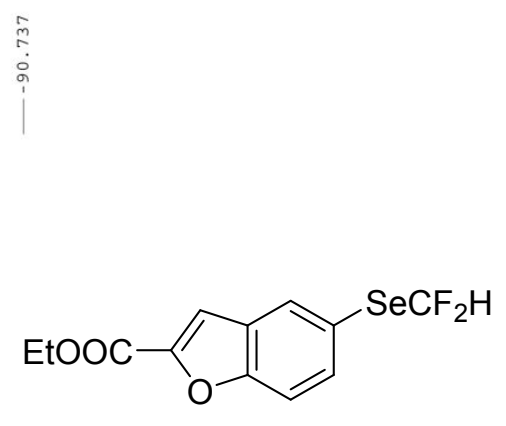

$3 w$

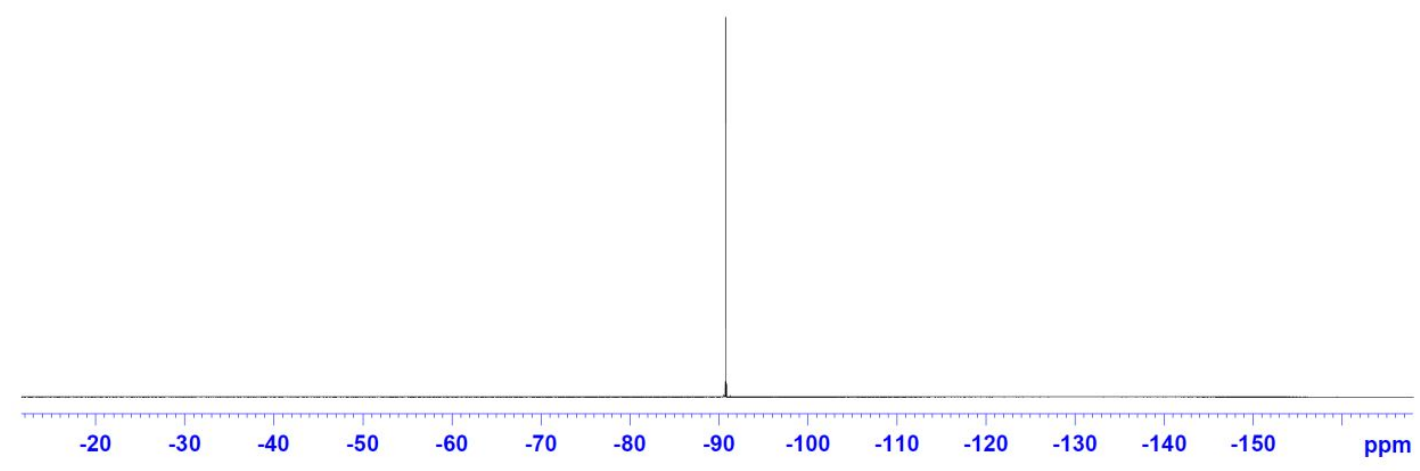




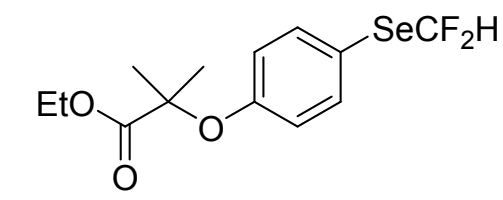

3aa

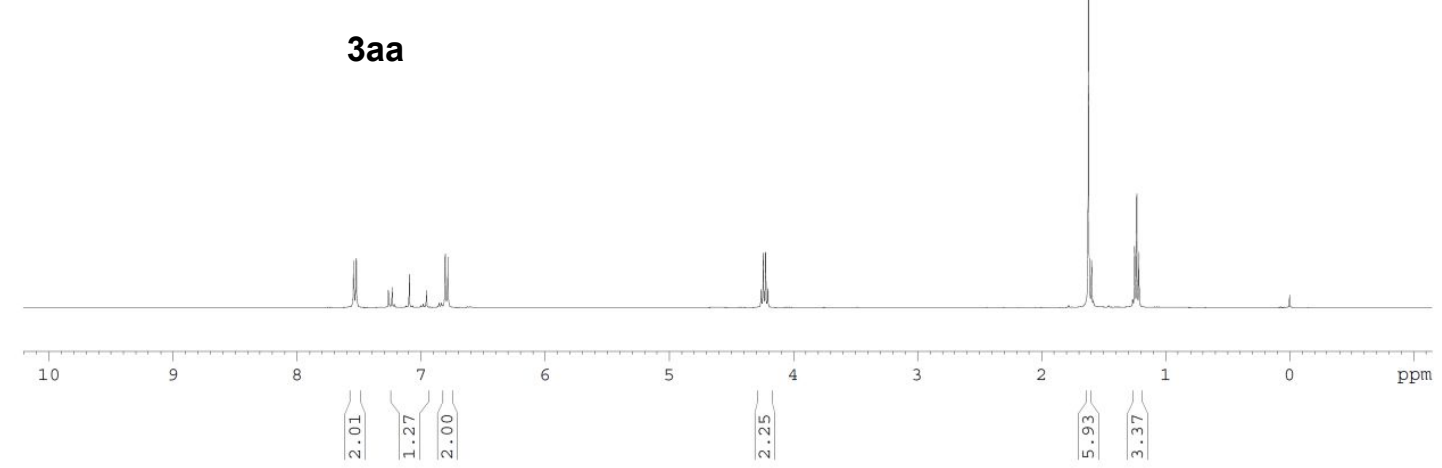

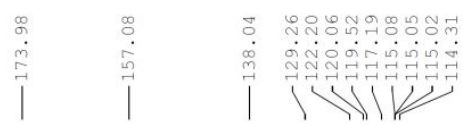
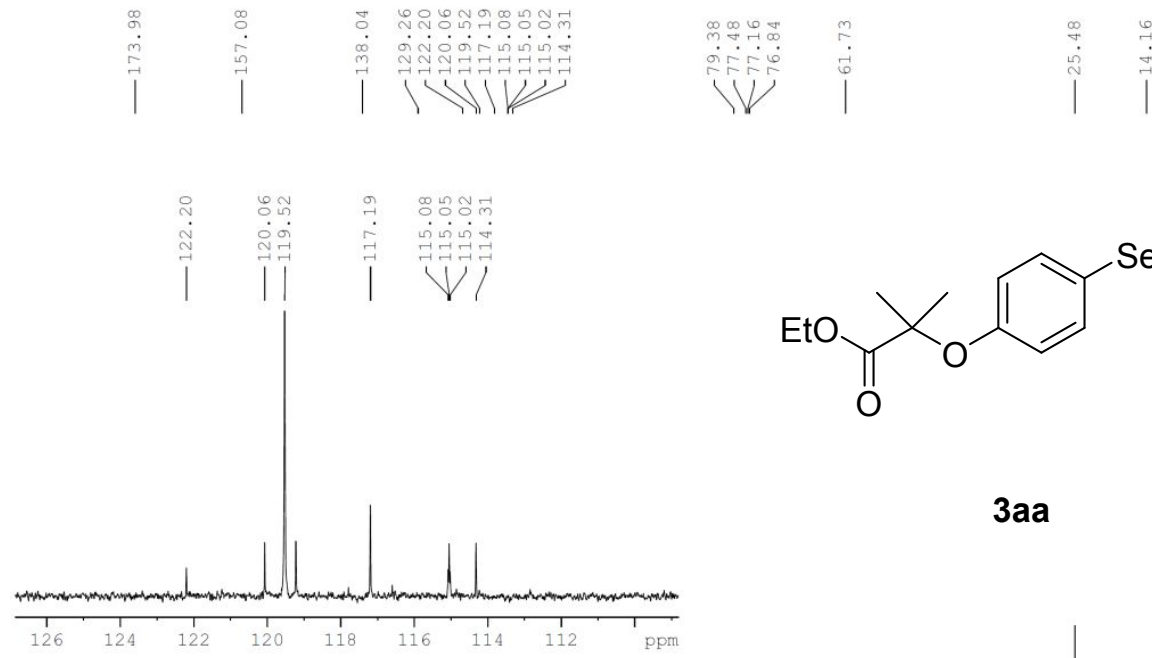<smiles>CCOC(=O)C(C)(C)Oc1ccc([Se]C(F)(F)F)cc1</smiles>

3aa

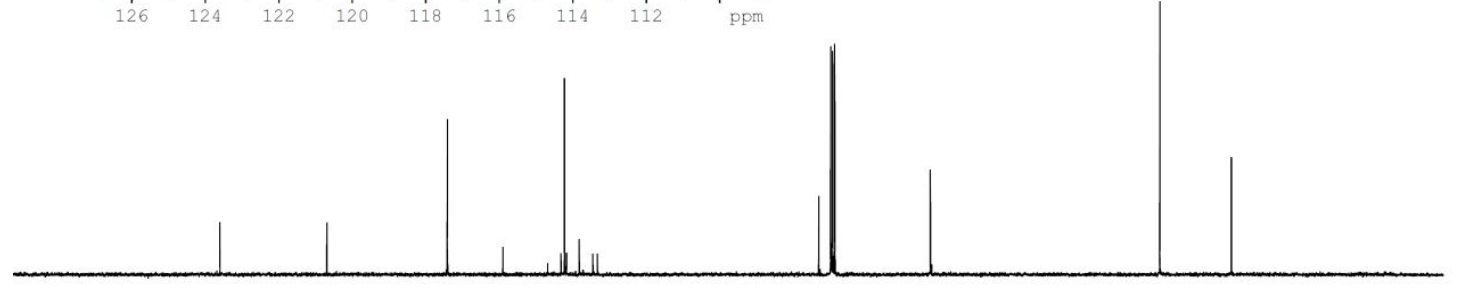

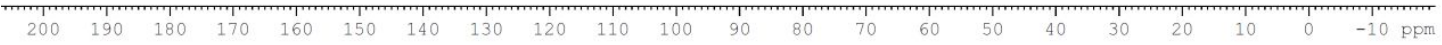



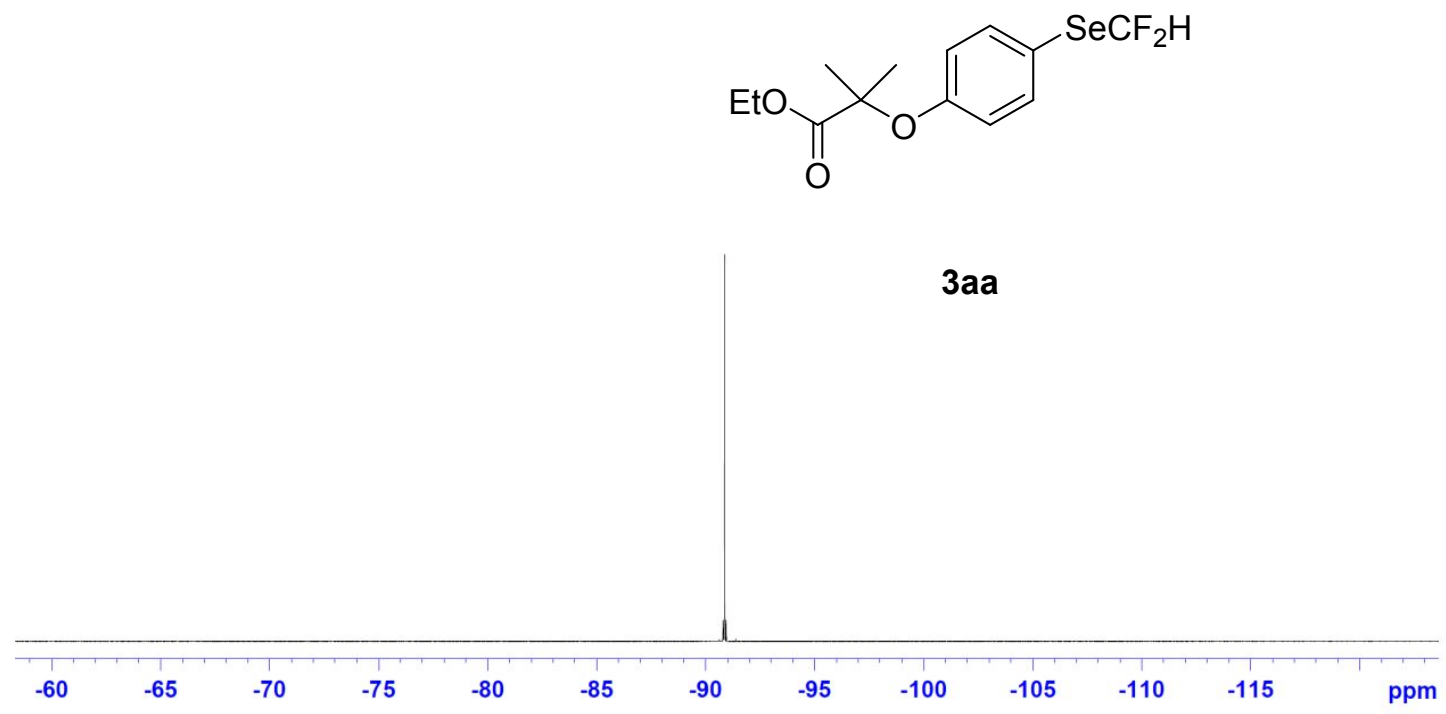

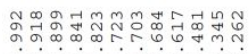

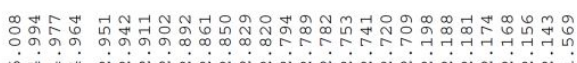

hathithat

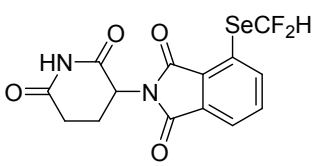

$3 a b$

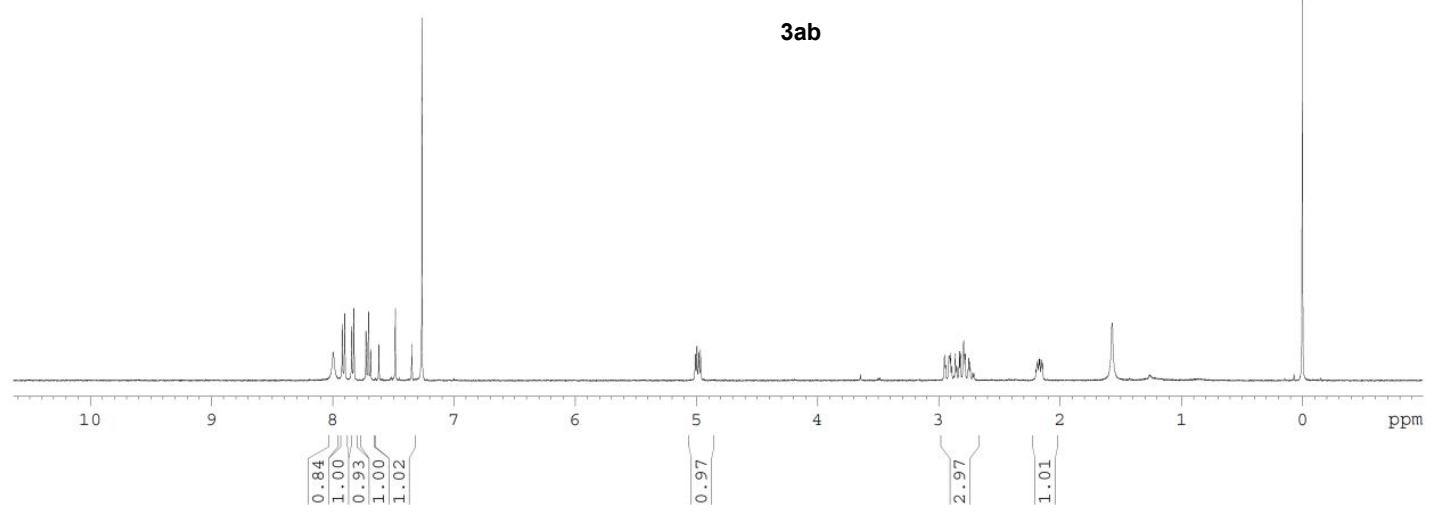




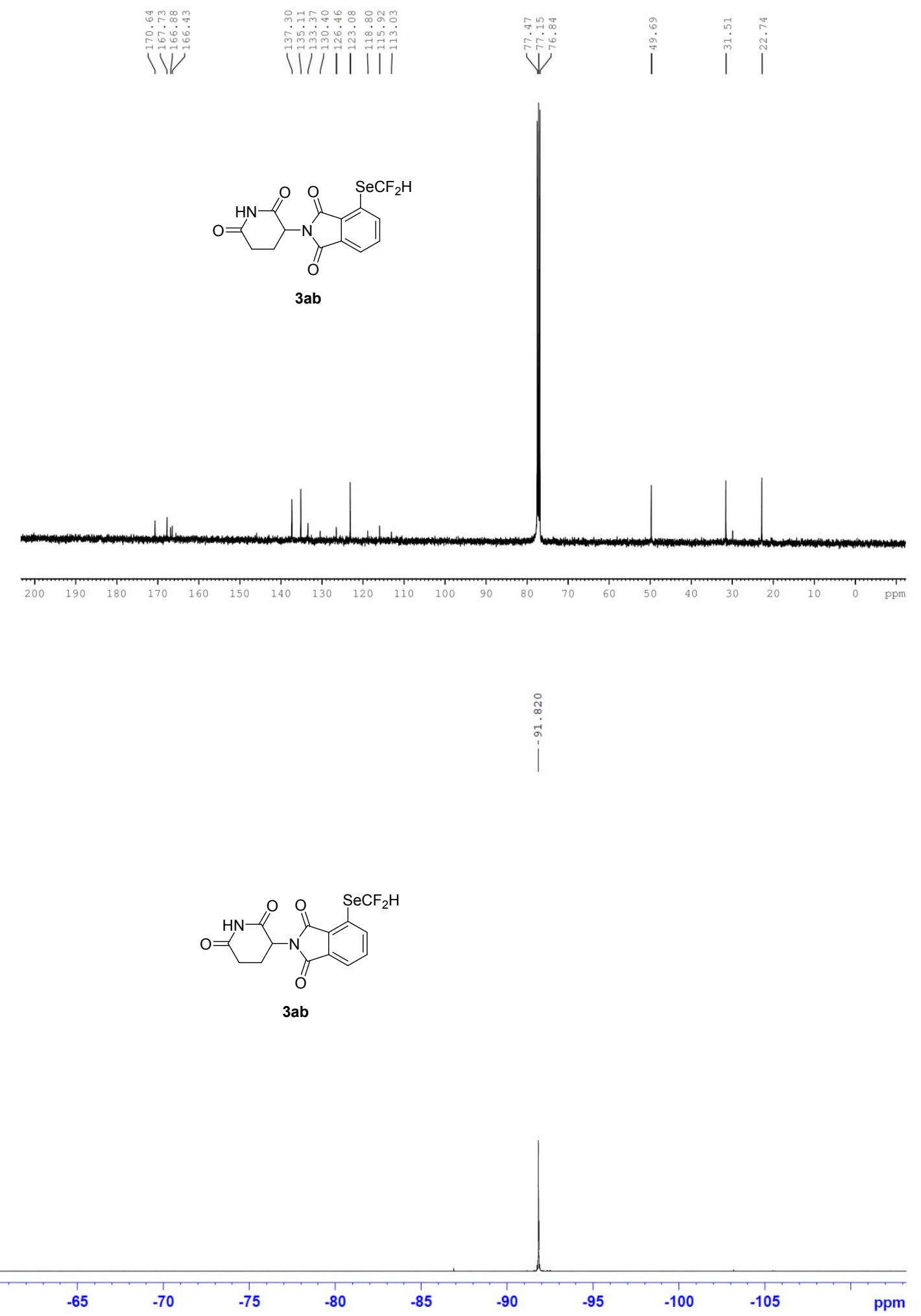



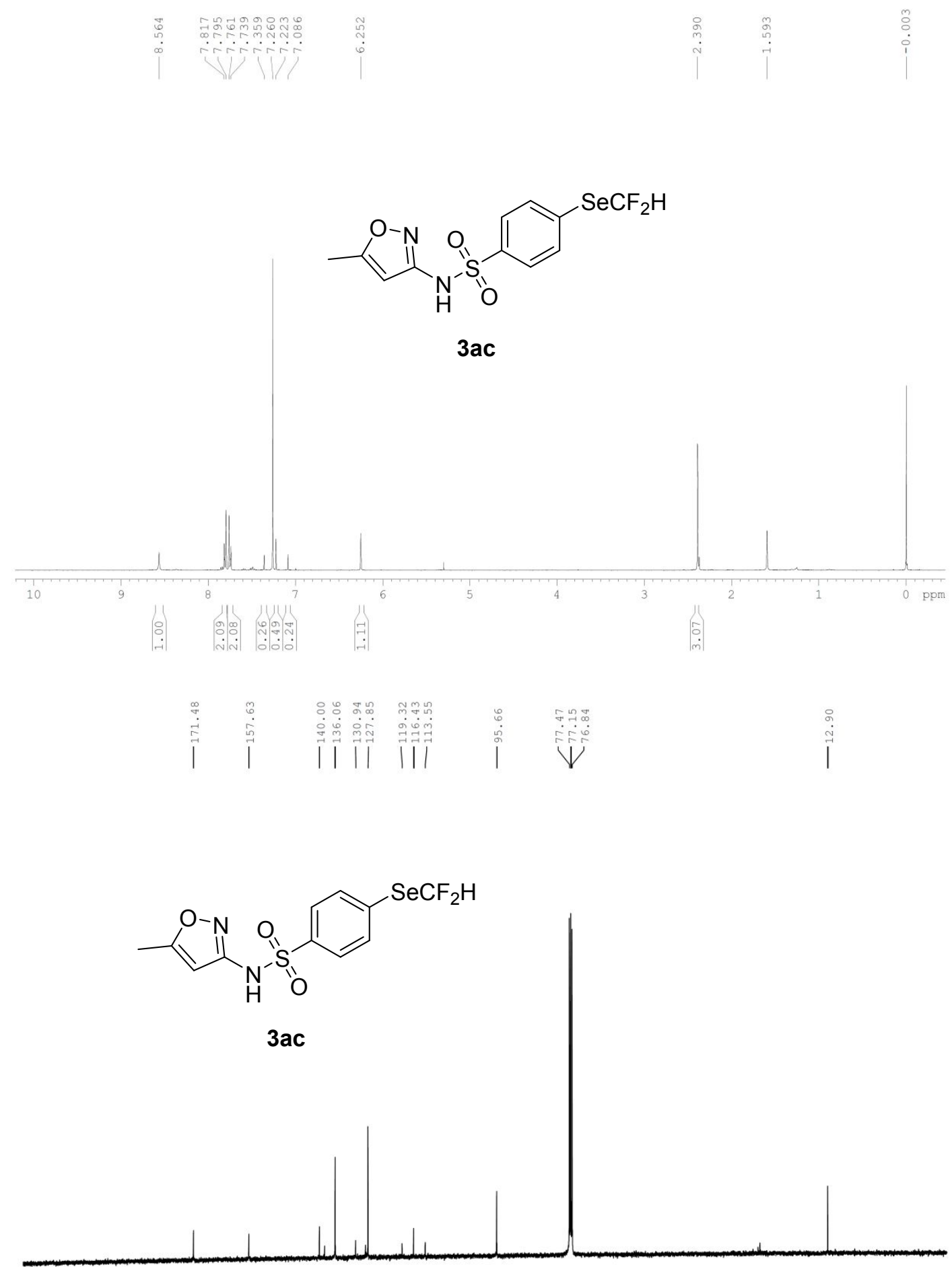


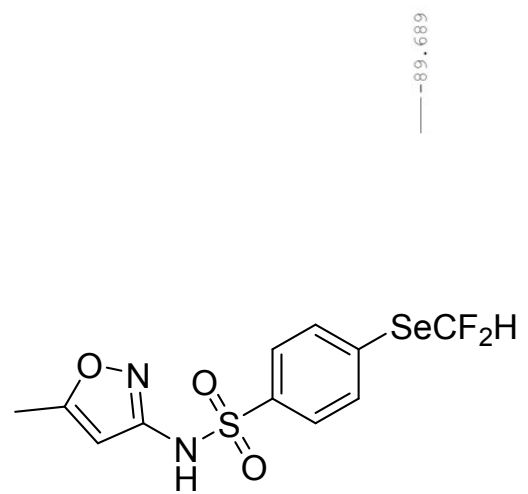

$3 a c$
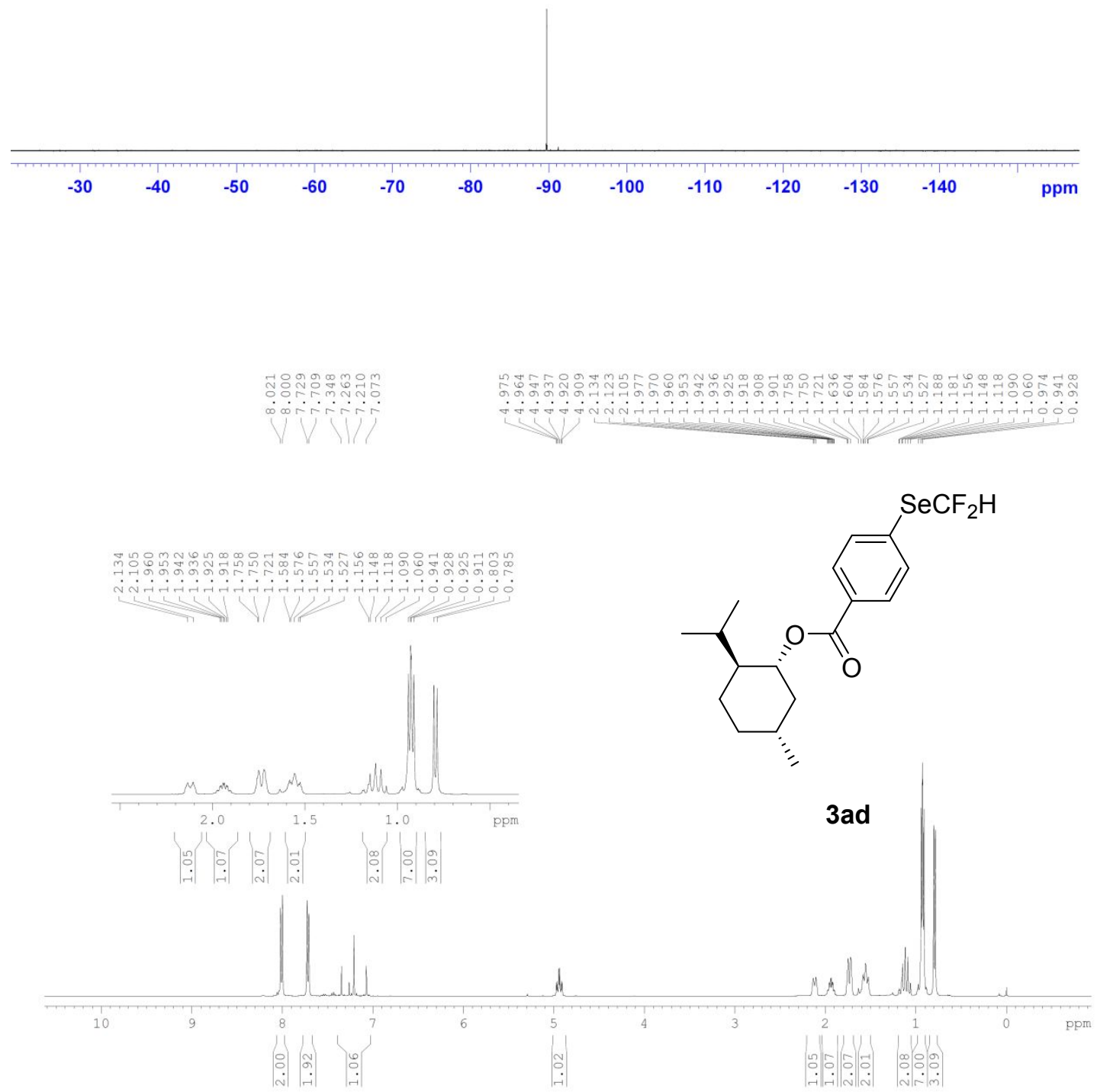


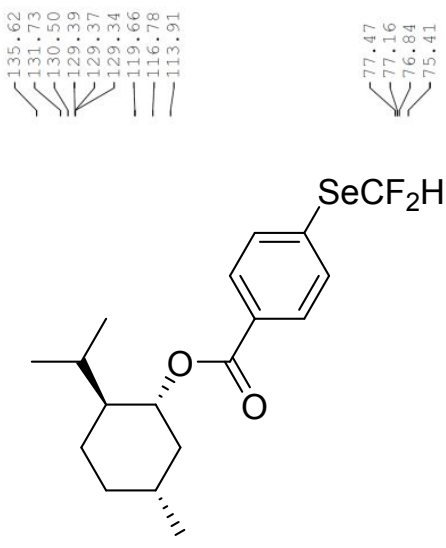

3ad
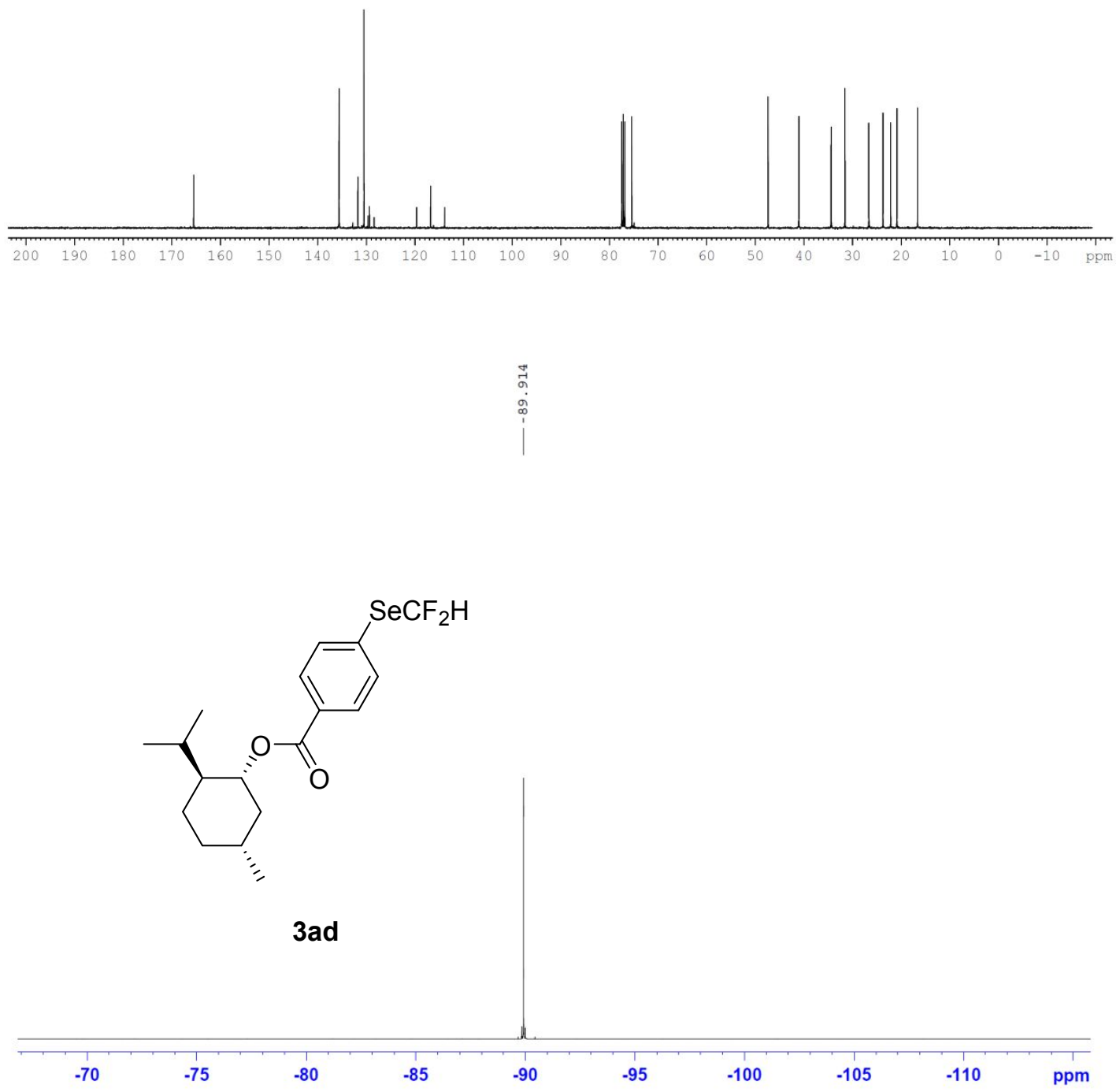